$L A--8870-P R$

DE82 007014
LA-8870-PR

Progress Report

UC-15

Issued: November 1981

\title{
Nuclear Safeguards
}

\section{Research and Development}

Program Status Report

October 1980-January 1981

\author{
Compiled by \\ C. N. Henry
}
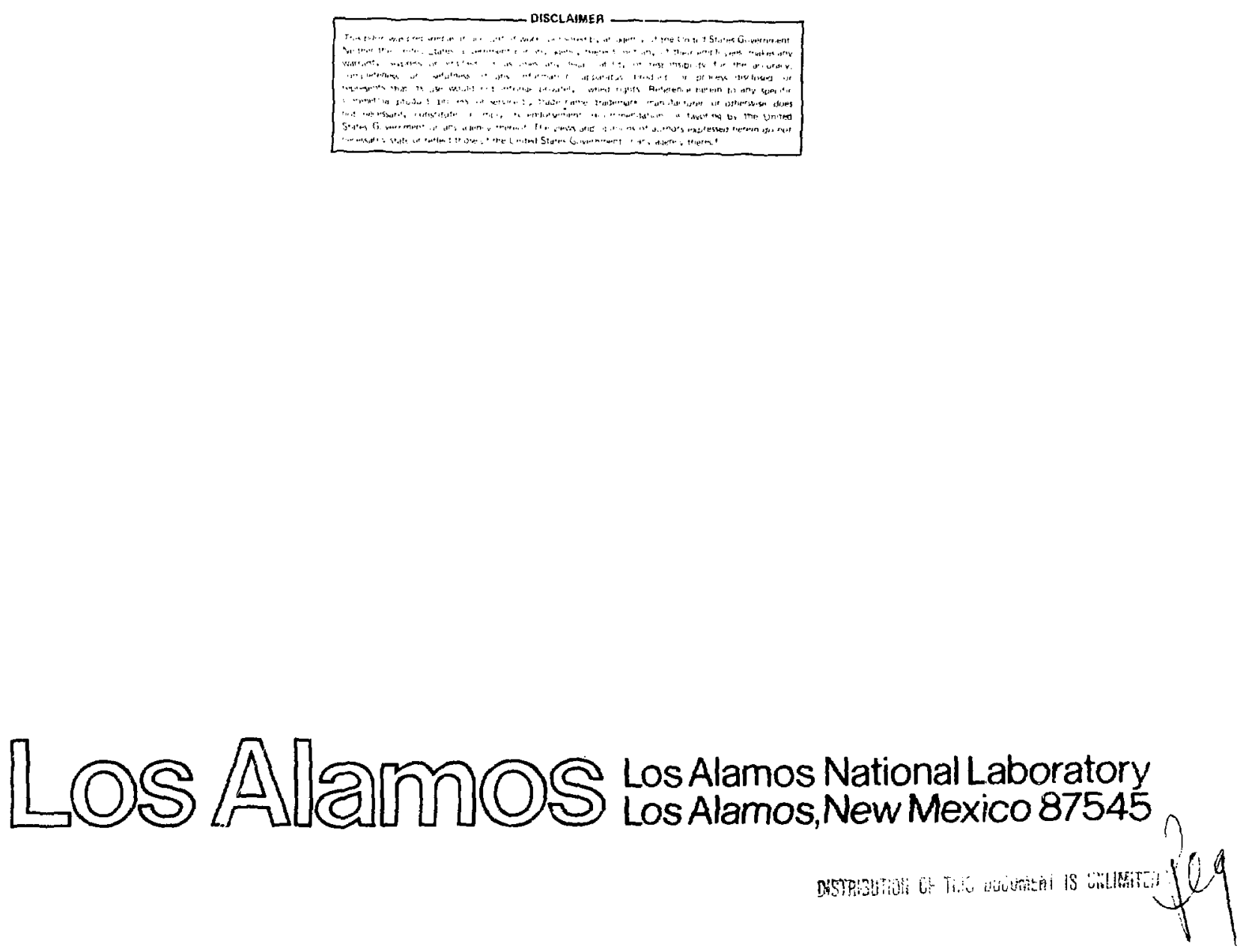


\section{CONTENTS}

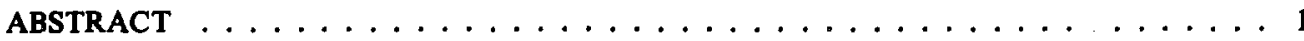

PART 1. SAFEGUARDS TECHNOLOGY $\ldots \ldots \ldots \ldots \ldots \ldots \ldots \ldots \ldots$

I. TEST AND EVALUATION PROGRAMS AT DEPARTMENT OF ENERGY

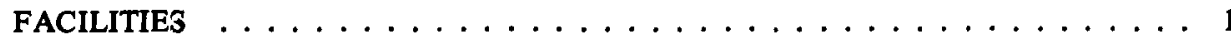

A. Test and Evaluauion of the In-Line Plutonium Solution Densitometer at the Savannah River Plant . . . . . . . . . . . . . . . . . . 1

B. Fluorinel and Storage Facility Dual-Californium-Source Storage and Transfer Casł . . . 2

C. Evaluation of In-Line Nondestructive Assay Systems . . . . . . . . . . . 3

D. Neutron Coincidence Counter for Plutonium Solutions $\ldots \ldots \ldots \ldots$

II. COMPONENT DEVELOPMENT FOR INTERNATIONAL SAFEGUARDS $\ldots \ldots$ Completion of the Gas-Phase $\mathrm{UF}_{6}$ Enrichment Monitor Prototype Evaluation

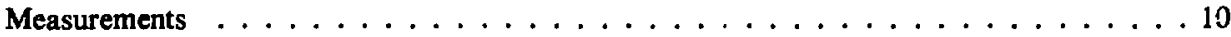

III. CURRENT DEVELOPMENTS $\ldots \ldots \ldots \ldots \ldots \ldots \ldots \ldots \ldots \ldots$

A. Plutonium Isotopic Composition Measurements on Mixed Oxides . . . . . . . 14

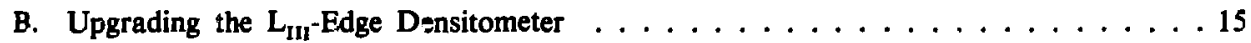

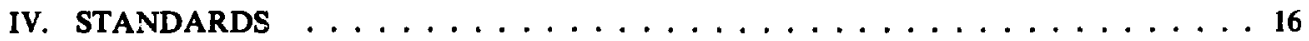

High-Temperature Gas-Cooled Reactor Fuels Intercomparison $\ldots \ldots \ldots$

PART 2. CONTAINMENT AND SURVEILLANCE TECHNIQUES $\ldots \ldots \ldots \ldots$

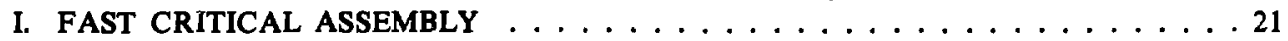

Neutron Monitoring of Plutonium Storage Vaults $\ldots \ldots \ldots \ldots$

II. AUTOMATED INVENTORY TEST AND EVALUATION $\ldots \ldots \ldots$

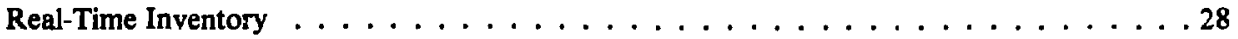

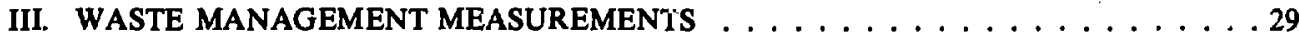

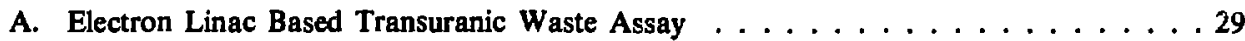

B. Differential Die-Away Pulsed Neutron Assay System $\ldots \ldots \ldots \ldots$

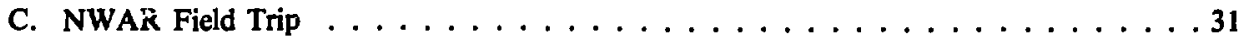

PART 3. SAFEGUARDS SYSTEMS AND TECHNOLOGY TRANSFER $\ldots \ldots \ldots \ldots$

I. SAF?GI IADS CONCEPT DEFINITION FOR FUEL CYCLE FACILITIES $\ldots \ldots 31$

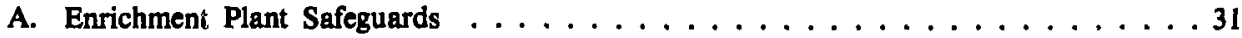

B. Los Alamos Plutonium Facility: Plutonium Metal-to-Oxide Conversion and

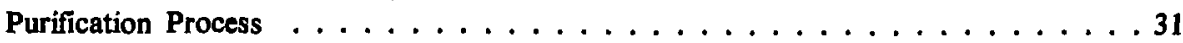

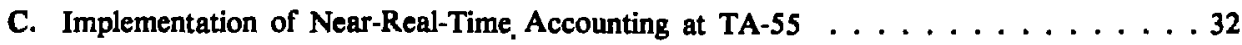

D. Advanced Materials Accounting System Demonstration at Allied-General Nuclear

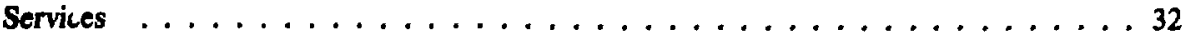


E. Design of Integrated Materials Control and Accounting and Physical Security
Safeguards $\ldots \ldots \ldots \ldots \ldots \ldots \ldots \ldots \ldots$
F. Safeguards Systems Design for the Fuels and Materials Examination Facility $\ldots \ldots \ldots 33$

II. SAFEGUARDS CONCEPTS FOR ALTERNATIVE FUEL CYCLE FACILITIES $\ldots 33$

A. Spent-Fuel Storage Facility Project $\ldots \ldots \ldots \ldots$

B. Consolidated Fuel Reprocessing Program-Hot Experimental Facility . . . . . . . . 34

C. Conceptual Design Study for the Liquid-Metal Fast Breeder Reactor . . . . . . . . . . 34

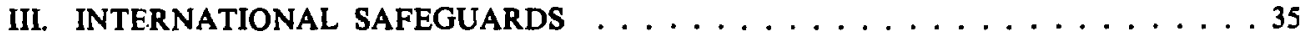

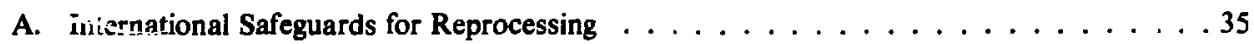

B. International Working Group-Reprocessing Plant Safeguards . . . . . . . . . . 35

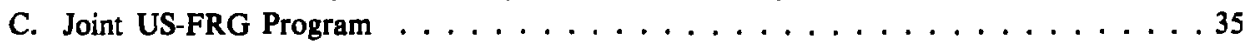

D. Advisory Group on Facility Design Considerations to Facilitate Safeguards . . . . . 36

E. Safeguards Cooperative Program with EURATOM, Ispra . . . . . . . . . . . 36

F. Assistance to Tokaj-mura in Near-Real-Time Accounting . . . . . . . . . 36

IV. DEVELOPMENT OF SAFEGUARDS TECHNOLOGY $\ldots \ldots \ldots \ldots$

A. In-Process Inventory in Solvent-Extraction Contactors . . . . . . . . . . 37

B. Away-from-Reactor Spent-Fuel Storage: Comparison of Measured and Predicted

Spent-Fuel Data . . . . . . . . . . . . . . . . . . 37

C. Development of Sequential Tests of Near-Real-Time Accounting Data . . . . . . . 38

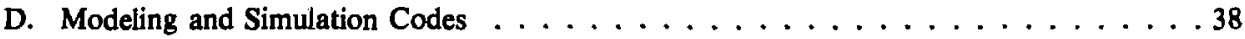

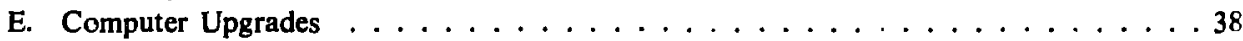

F. Systems Implementation . . . . . . . . . . . . . . . . . . . 39

V. TECHNICAL SUPPORT AND TECHNOLOGY TRANSFER $\ldots \ldots \ldots$

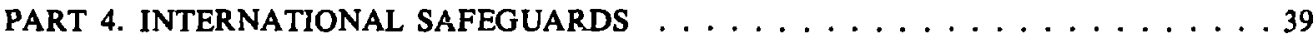

I. IAEA INSPECTOR INSTRUMENTATION DEVELOPMENT $\ldots \ldots \ldots$

A. High-Level Neutron Coincidence Counter Implementation: Assay of the Plutoniurn

Content of MOX Fuel Assemblies . . . . . . . . . . . . . . . . . 39

B. Neutron Coincidence Collar for the Assay of Unirradiated Fuel Assemblies . . . . . 41

II. SPENT-FUEL VERIFICATION TECHNIQUE DEVELOPMENT . . . . . . . . 43

A. Nondestructive Measurement of Spent-Fuel Assemblies at the GE-Morris Spent-Fuel

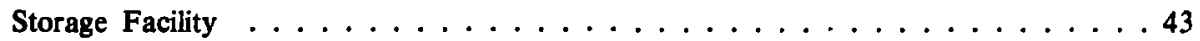

B. Calculation of Fission Product Inventories in Spent-Fuel Assemblies . . . . . . . . 46

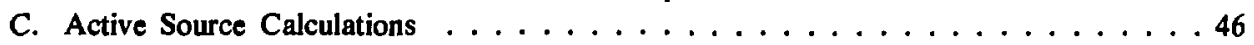

D. Active Neutron System for Spent-Fuel Measurements at AFR Storage Facilities:

Comparison of Design Calculations and Experiments . . . . . . . . . . . . . 54

E. Prompt and Delayed Neutron Yields as a Function of Exposure . . . . . . . . . 57

F. Cerenkov Spent-Fuel Instrumentation Upgrade . . . . . . . . . . . . 65

G. Field Test of the Cerenkov Technique for Spent Fuel . . . . . . . . . . . 65

III. INTERNATIONAL TRAINING AND TECHNOLOGY TRANSFER $\ldots \ldots 6$

Safeguards Technology Training Program ................66 
PART 5. ANALYTICAL CHEMISTRY METHODS FOR FISSIONABLE

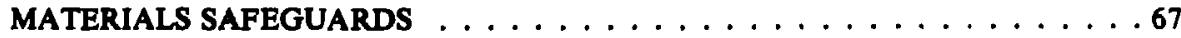

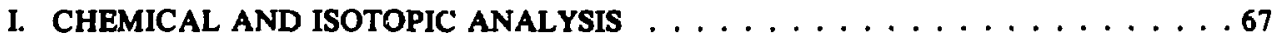

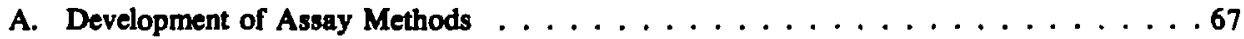

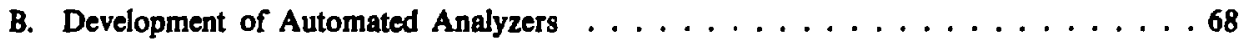

C. Evaluation of the Chemistry Preceding the Mass Spectrometric Ion-Exchange Bead

Technique .......................... 68

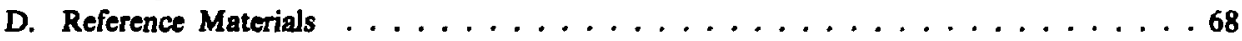

E. Plutonium Isotope Half-Life Measurements . . . . . . . . . . . . . . . 69

II. SUPPORT TO NONDESTRUCTIVE ASSAY $\ldots \ldots \ldots \ldots$

PART 6. COMPUTER AND OPERATIONAL SECURITY $\ldots \ldots \ldots \ldots \ldots$

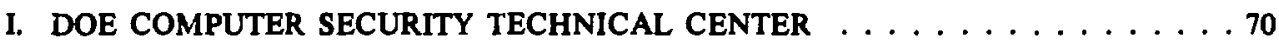

A. DOE Computer Security Technical Center Development . . . . . . . . . 70

B. Computer Network Key Notarization System . . . . . . . . . . . . . . 70

C. Standards Development for the Key Notarization System . . . . . . . . . . . 70

D. Kernelized Secure Operating System Testing and Implementation . . . . . . . . . 71

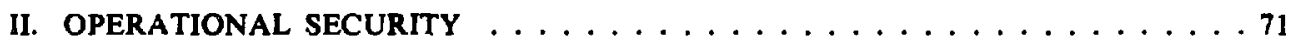

PART 7. NIICLEAR REGULATORY COMMISSION ACTIVITIES $\ldots \ldots \ldots \ldots \ldots$

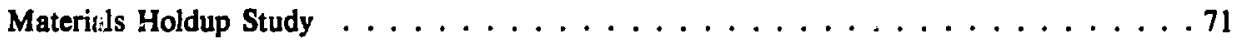

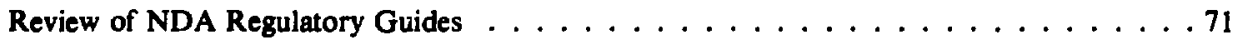

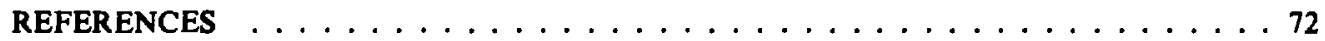




\title{
NUCLEAR SÁFEGUARDS \\ RESEARCH AND DEVELOPMENT
}

PROGRAM STATUS REPORT

October 1980-January 1981

C. N. Henry, Compiler

\begin{abstract}
This report presents thr: status of the Nuclear Safeguards Research and Development Program pursued by the Energy, Chemistry-Materials Science, and Operational Security/Safeguards Sivisions of the Los Alamos National Laboratory. Topics include nondestructive assay technology development and applications, international safeguards, perimeter safeguards and surveillance, concepts and subsystems development, and integrated safeguards systems. Also discussed are training courses, technology transfer, analytical chemistry methods for fissionable materials safeguards, the Department of Energy Computer Security Technical Center, and operational security.
\end{abstract}

\section{PART I}

\section{SAFEGUARDS TECHNOLOGY}

\section{TEST AND EVALUATION PROGRAMS AT DEPARTMENT OF ENERGY FACILITIES}

\begin{abstract}
A. Test and Evaluation of the In-Line Plutonium Solution Densitometer at the Savannah River Plant (H. A. Smith, T. Marks, S. S. Johnson, R. W. Slice, J. K. Sprinkle, L. R. Cowder, C. O. Shonrock, and D. L. Garci $)$
\end{abstract}

Off-line measurements with the $\mathrm{K}$-edge plutonium solution densitometer ${ }^{1}$ have continued. Concentrations of measured standards have been extended from the design range of 25 to $40 \mathrm{~g} \mathrm{Pu} / \ell$ to a range of 5 to $200 \mathrm{~g}$ $\mathrm{Pu} / \ell$. Figure 1 summarizes the instrument densitometry precisions achieved over this wider concentration range, and Fig. 2 compares the densitometer assay results with the corresponding chemical analyses. Figure 1 demonstrates that the densitometer can achieve betier than $0.5 \%$ statistical assay precision on plutonium concentrations ranging from 30 to $>100 \mathrm{~g} \mathrm{Pu} / t$. Figure 2 shows excellent agreement between the densitometer and chemical assays over the design range (and the range over which the calibration was established, as described in Ref. 2) and very good agreement beyond that range. The discrepancy at $200 \mathrm{~g} / \ell$ points out the limitation of 


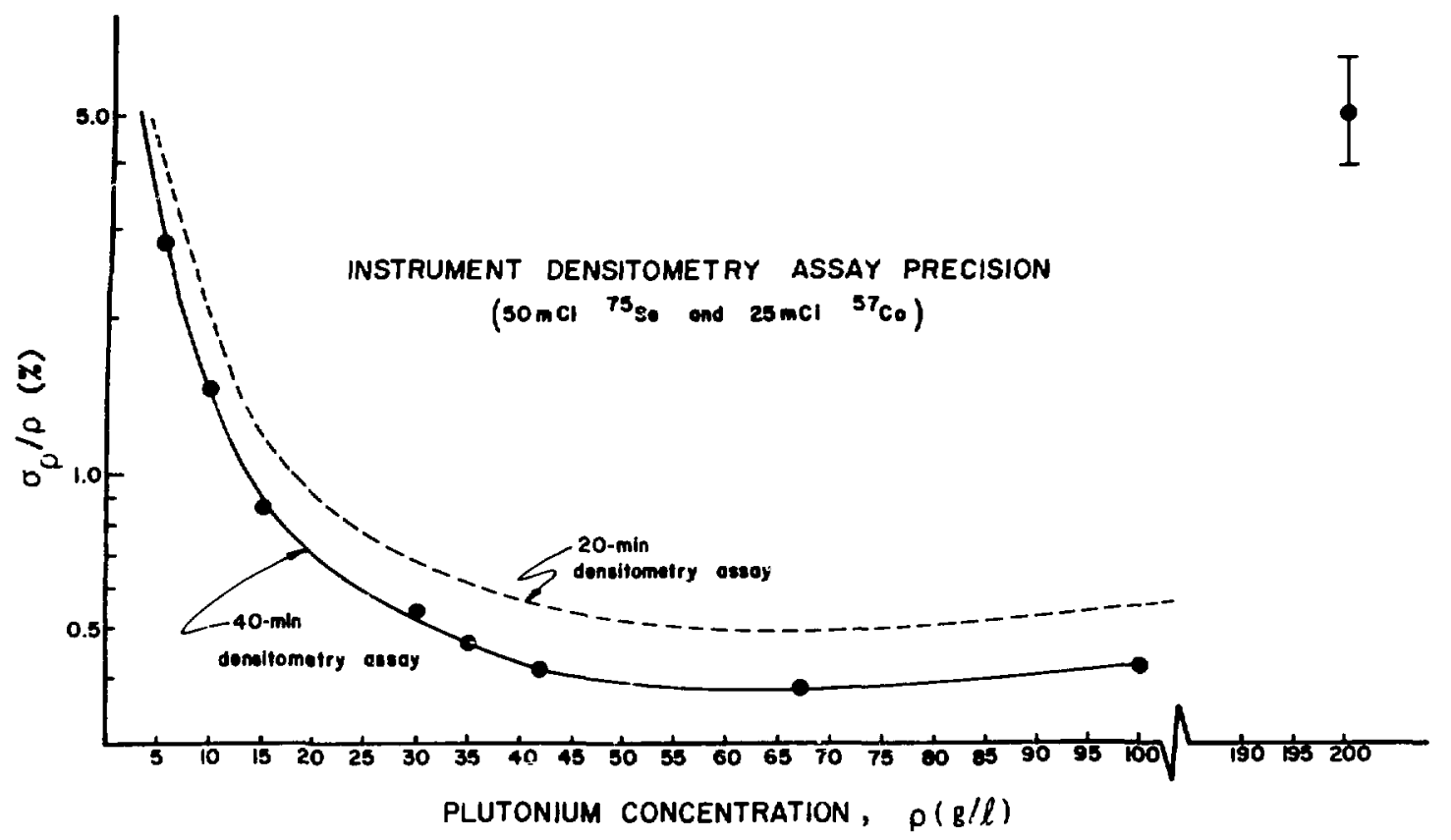

Fig. 1.

A summary of the densitometry assay precisions achieved by the Los Alamos K-edge plutonium solution densitometer under test and evaluation at SRP. The solid curve demonstrates that the instrument can readily provide statistical precisions of better than $0.5 \%$ over plutonium concentrations ranging from 30 to $>100 \mathrm{~g}$ $\mathrm{Pu} /\lfloor$. As selenium and cobalt transmission sources decay, the assay precision will deteriorate because of count rate degradation. The dotted curve shows the assay precision for half the counting time of the solid curve, which is a good measure of precision deterioration after the sources have decayed by approximately one half-life (that is, after 4 to 6 months).

this instrument design, specifically the cell thickness, at very high plutonium concentrations where statistical precision suffers (see Fig. 1) and where small-engle scattering effects in the sample solution begin to occur.

Furthermore, we have assayed mixed uranium/plutonium solutions for plutonium only to formulate the proper analysis software so as to eliminate uranium matrix effects on the plutonium assay. Software (based on Ref. 3) for this particular task has been written and is being tested on spectra recorded at Savannah River Plant (SRP) from mixed solutions with uranium/plutonium ratios ranging from 0 to 4 . Testing the $\mathrm{K}$-edge densitometer beyond its intended application in the JB line at SRP is providing useful performance data and may help in the ultimate instrument disposition after the formal test and evaluation.

Analysis of JB-line process solutions will begin soon. Large-volume stainless steel sampling vessels have been fabricated and tested at SRP and now are ready to transport process solutions from the process line to the off-line laboratory.

One further series of tests must be completed in the off-line phase of the test and evaluation; namely, tests of the solution plumbing hardware and the software that manages it. SRP is constructing the off-line version of this plumbing for our cold testing, and these tests should begin in February 1981. When test results satisfy the SRP separations staff, we will install the in-line plumbing and will begin in-line densitometer tests.

\section{B. Fluorinel and Storage Facility Dual-} Californium-Source Storage and Transfer Cask (G. W. Eccleston, M. L. Evans, K. E. Kroncke, S. E. Beach, C. O. Shonrock, and L. G. Speir)

A source transfer cask has been designed and fabricated to permit transfer of ${ }^{252} \mathrm{Cf}$ sources to and from the 


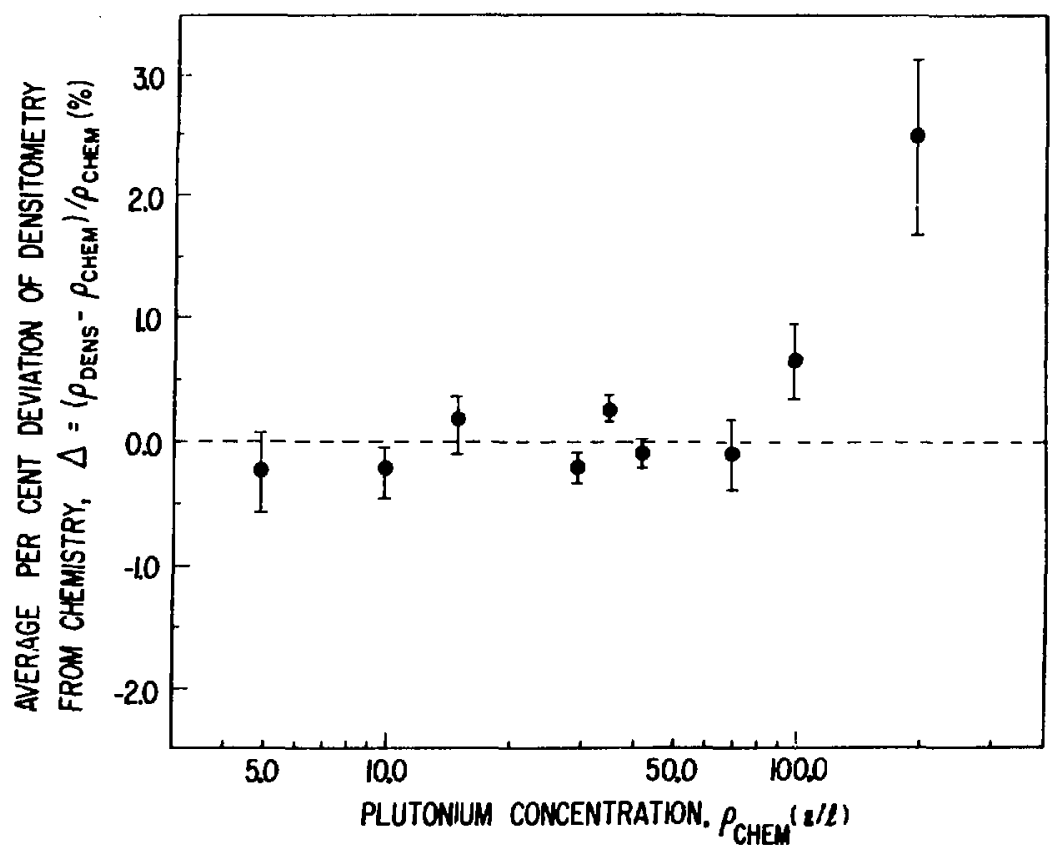

Fig. 2.

Comparison of K-edge densitometer assay results on secondary solution standands prepared at SRP with chemical assays of the same standards. Each data point represents the average of all askays run for the concentration given. The design range of plutonium concentrations for this instrument (and the range over which the calibration was established) is 25 to $40 \mathrm{~g} \mathrm{Pu} / l$. Assay measurements have been extended to 5 to 200 $\mathrm{g} \mathrm{Pu} / l$, and very good agreement between densitometry and chemistry over most of this concentration range has been found. At the highest phutonium concentration, the counting statistics suffer greatly, and small-angle scattering effects in the sample solution begin to occur, making it difficult to obtain good agreement between the two methods.

neutron interrogator at the Fluorinel and Storage Facility (FAST) and to satisfy Department of Transportation (DOT)-7A license requirements. The Type-A quartity limit for ${ }^{252} \mathrm{Cf}$ is $2 \mathrm{Ci}$, permitting up to a $3.7-\mathrm{mg}$ source to be shipped.

A special design feature of the cask is its dual source transfer mechanism. Californium sources to be shipped and stored in the cask will be attached to a Teleflex cable. The source transfer mechanism consists of two Teleflex gear boxes that enable a remote operator to crank the Teleflex cable through the gear box to load or unload a source. The cask design permits an operator to remove an old source from the FAST delayed neutron interrogator and to store it in the shield cask. The replacement source then can be transferred into the FAST instrument. Figure 3 shows the source attached to the Teleflex cable extending from the cask top.

Cask components are illustrated in Fig. 4. The central region containing the dual source storage and gear mechanism can be removed for repair and maintenance.
The cask's outer region consists of a braced steel sheet filled with water-extended polyester (WEP) to provide neutron and gamma shielding, and its outer edge is surrounded by $2.54 \mathrm{~cm}$ of lead. Shielding components of the central region are lead, lithiated-polyethylene, and polyethylene. Monte Carlo calculations using spheres with various material arrangements determined a combination of components suitable for the cask. Based on these calculations, the dose at the cask surface from 3.7 $\mathrm{mg}$ of ${ }^{252} \mathrm{Cf}$ source probably will be $<50 \mathrm{mR} / \mathrm{h}$.

C. Evaluation of In-Line Nondestructive Assay Systems (D. F. Bowersox, H. C. Muffly, C. L. Heinberg, R. Martinez, N. Ensslin, S. T. Hsue, S. S. Johnson, J. L. Parker, and T. E. Sampson)

1. Introduction. This report summarizes recent progress in the project to design, construct, and operate nondestructive assay systems for characterizing solids 


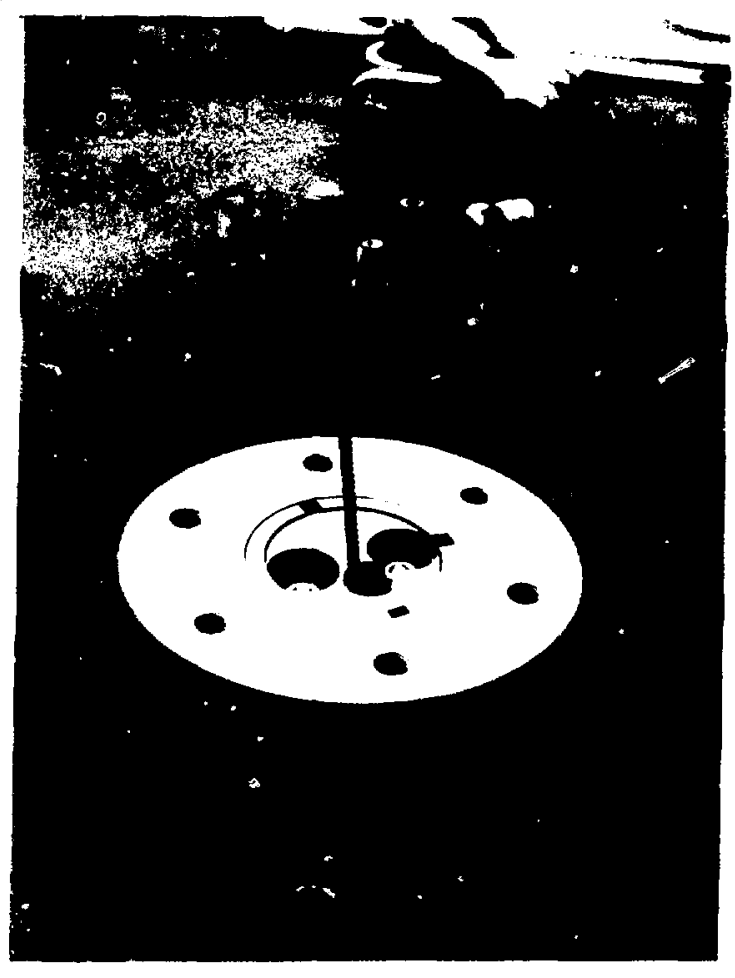

Fir. 3.

Dummy source attached to Teleflex cable extending from cask top.

and liquids containing plutonium. Successful characterization could lead to timely in-line and at-line automated analysis of nuclear materials.

Most instruments have been described in previous reports. ${ }^{4-11}$ These descriptions include properties to be measured, interfering species, accepted measurement limitations, and estimations of precision and accuracy of assay in our applications. Mass spectrometry and chemical analysis were performed by Los Alamos National Laboratory Group CMB-1 under the direction of G. R. Waterbury.

2. Experiment. The experimental gamma and neutron counters are designed for assays of trays, bottles, and cans of plutonium materials in-line or at-line. Kilogram quantities of oxide or metal plutonium in sealed cans are counted, then are transferred to the Plutonium Facility (PF)-4 counting room for calorimetry. In $24 \mathrm{~h}$, isotopic distribution and two values of the total plutonium mass are obtained. Samples from these ingots are used to determine isotopic distribution by mass spectrometry. By combining total wcight with chemical assay of small samples, the plutonium mass of selected ingots is determined. The nondestructive assay data then are compared with data obtained by more conventional analyses.

Preliminary studies of a gamma-spectra method for determining concentrations of 10 to $200 \mathrm{mg} \mathrm{Pu} / \ell$ in the range of $600<\mathrm{Am} / \mathrm{Pu}<150000$ are continuing. Precision and sensitivity range from 0.5 to $3.0 \%$, but can be improved. A standard operating procedure for assay of solutions in this concentration range has been written and approved, ${ }^{12}$ and experiments in PF-4 probably will be started next quarter.

A counter for neutron coincidence counting in solutions has been installed, and a solution loop has been constructed and tested. Preliminary system approval has been given, and the operating procedure for the initial experiments has been submitted for approval. ${ }^{13}$

3. Results and Conclusions. Twenty-four ingots of plutonium, $1680 \mathrm{~g}<$ mass of ingot $<3838 \mathrm{~g}$, were received in sealed cans, assayed, sampled, and purified. The nondestructive assay consisted of a gamma analysis for isotopic distribution, neutron coincidence count, and calorimetry for determining plutonium mass and for weighing the entire can. The ingot was removed, weighed, and sampled for assay by mass spectrometry and chemical assay.

Isotopic distributions are given in Table I (gamma spectrometry) and Table II (mass spectrometry). Estimated precisions of the gamma spectrometry assays are given in Table III. The precision of ${ }^{238} \mathrm{Pu}$ estimates is twice as accurate as that determined in recent replicate runs. Estimated precision increases with counting time and with increasing concentration. Ratios of results from gamma-to-mass spectrometry are shown in Table IV. The agreement for ${ }^{239} \mathrm{Pu}$ and ${ }^{241} \mathrm{Pu}$ is excellent. The ratio for ${ }^{260} \mathrm{Pu}$ indicates a positive bias in the gamma results of $1.8 \%$, which agrees with earlier standards work. ${ }^{14}$ This bias probably can be eliminated by slight adjustments in the calibration constants used in calculating the isotopic ratios.

At very low ${ }^{238} \mathrm{Pu}$ ratios, as in this material, sample and filament contamination with environmental ${ }^{238} U$ for mass spectroscopy analysis is a problem; therefore, alpha spectrometric assays now are requested for most of our samples. The ${ }^{242} \mathrm{Pu}$ concentrations are too low to contribute to the calorimeter/gamma determination of plutonium mass $(<0.01 \%)$. In the gamma method, the ${ }^{242} \mathrm{Pu}$ fraction is determined by isotopic correlation techniques. At these low concentrations the ${ }^{242} \mathrm{Pu}$ would not affect significantly the mass determinations. 

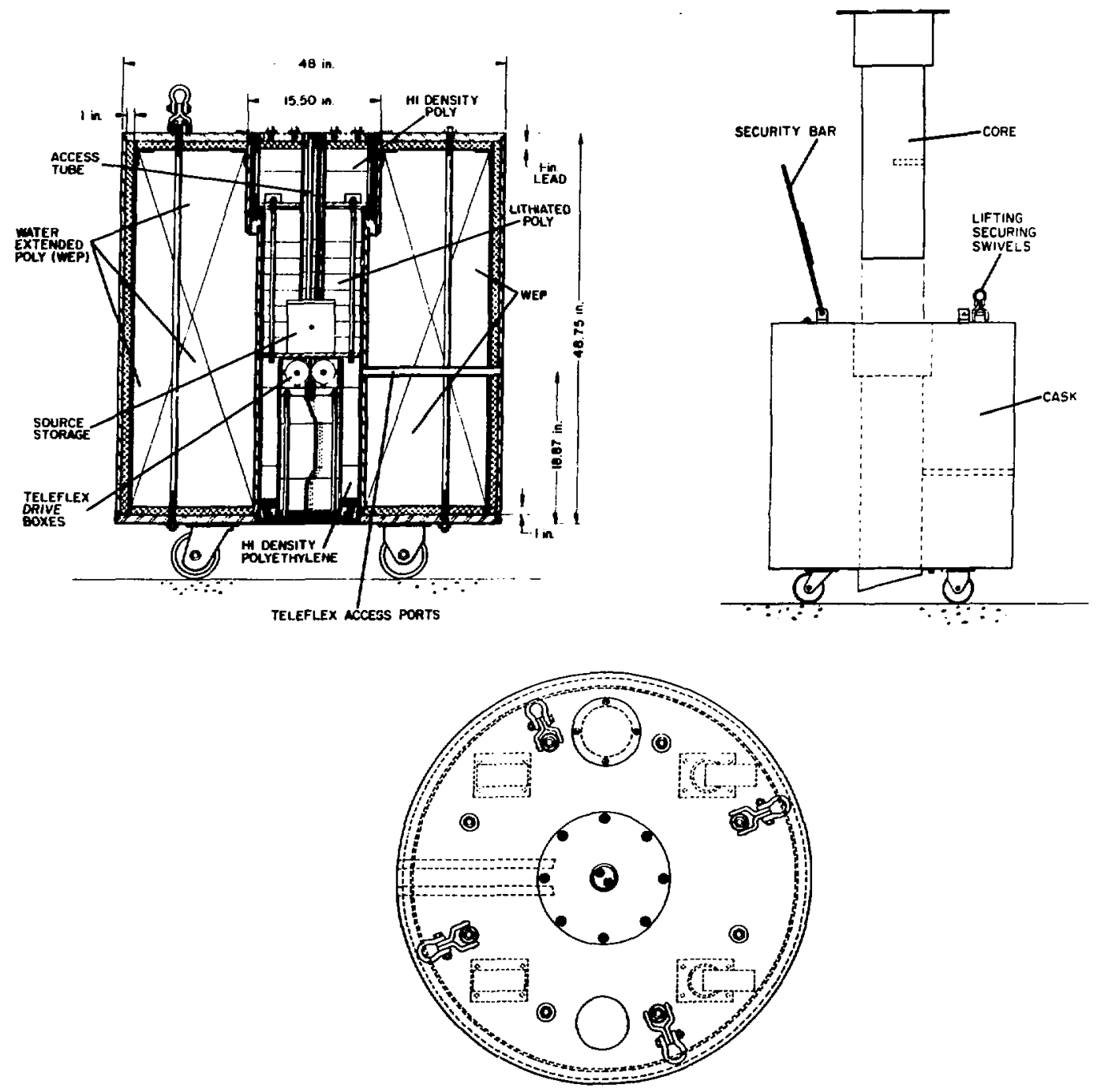

Fig. 4.

Major cask components.

Differences in ${ }^{241} \mathrm{Am}$ values between chemical analysis and gamma measurements may be due to nonuniform distribution in the ingot. Results of ${ }^{241} \mathrm{Am}$ assay (by radioanalytical techniques) of samples from the bottom (S2) and the top (S1) of selected ingots are compared in Table $\mathrm{V}$. The differences ranged from -4.7 to $26 \%$. On the other hand, determinations of americium by gamma and mass spectrometry in blended oxide were in excelient agreement. $^{14}$

Calorimetry results for this series of ingots are tabulated in Table VI. Mass spectrographic values are about $1 \%$ lower than values obtained by gamma spectrometry/calorimetry. Both methods yield results slightly less than the shipper's value. For the range of isotopic concentrations in these ingots, the percentage of power contributed by the isotopes is: ${ }^{238} \mathrm{Pu}, 2.5 \% ;{ }^{239} \mathrm{Pu}, 75 \%$; ${ }^{240} \mathrm{Pu}, 17$ to $18 \% ;{ }^{241} \mathrm{Pu}, 0.4 \% ;{ }^{242} \mathrm{Pu},<0.01 \%$; and $\mathrm{Am}$, 5 to $6 \%$. Thus, the uncertainty in the calorimetry measurement can be -alculated at $\pm 1 \%$ from the estimated precisions of the isctopic data from the gamma measurements. The remaining $0.3 \%$ could be caused by a variety of factors; for example, inhomogeneity of 
TABLE I

\section{ASSAY OF EXCM SERIES BY GAMMA SPECTROMETRY ISOTOPIC ABUNDANCE}

\begin{tabular}{|c|c|c|c|c|c|c|}
\hline \multirow{2}{*}{$\frac{\text { Ingot }}{\text { EXCM }}$} & \multicolumn{5}{|c|}{$\% \mathrm{Pu}$} & \multirow{2}{*}{$\frac{\mathrm{ppm}}{{ }^{241} \mathrm{Am}}$} \\
\hline & 238 & 239 & 240 & 241 & 242 & \\
\hline 017 & 0.009589 & 94.02 & 5.694 & 0.2556 & 0.01818 & 1166 \\
\hline 025 & 0.009083 & 93.63 & 6.115 & 0.2302 & 0.01766 & 1573 \\
\hline 026 & 0.01264 & 93.77 & 5.992 & 0.2755 & 0.02040 & 1044 \\
\hline 009 & 0.01260 & 93.36 & 6.335 & 0.2672 & 0.02136 & 1176 \\
\hline 015 & 0.01046 & 93.68 & 6.038 & 0.2509 & 0.01899 & 1115 \\
\hline 022 & 0.00131 & 94.01 & 5.722 & 0.2396 & 0.01707 & 1472 \\
\hline $02 \mathrm{i}$ & 0.01189 & 93.56 & 6.147 & 0.2651 & 0.02048 & 727 \\
\hline 034 & 0.01204 & 93.73 & 5.975 & 0.2627 & 0.01965 & 719 \\
\hline 012 & 0.01268 & 94.08 & 5.641 & $0.2471^{\circ}$ & 0.01732 & 1401 \\
\hline 037 & 0.01255 & 93.98 & 5.740 & 0.2509 & 0.01794 & 679 \\
\hline 023 & 0.00899 & 94.08 & 5.653 & 0.2433 & 0.01709 & 1409 \\
\hline 027 & 0.01230 & 93.68 & 6.061 & 0.2303 & 0.01750 & 1589 \\
\hline 030 & 0.01022 & 93.64 & 6.091 & 0.2537 & 0.01935 & 1328 \\
\hline 031 & 0.01079 & 94.34 & 5.401 & 0.2328 & 0.01554 & 1714 \\
\hline 032 & 0.008317 & 94.07 & 5.665 & 0.2396 & 0.01688 & 1761 \\
\hline$n 33$ & 0.01133 & 94.18 & 5.558 & 0.2320 & 0.01599 & 1602 \\
\hline 035 & 0.01065 & 93.77 & 5.954 & 0.2488 & 0.01853 & 734 \\
\hline 038 & 0.01027 & 93.82 & 5.914 & 0.2385 & 0.01763 & 1342 \\
\hline 039 & 0.008599 & 93.89 & 5.816 & 0.2630 & 0.01909 & 772 \\
\hline 040 & 0.01117 & 93.59 & 6.115 & 0.2632 & 0.02021 & 797 \\
\hline 041 & 0.01336 & 93.59 & 6.115 & 0.2580 & 0.01981 & 1159 \\
\hline 042 & 0.01225 & 93.78 & 5.927 & 0.2655 & 0.01968 & 905 \\
\hline 043 & 0.01953 & 94.00 & 5.714 & 0.2566 & 0.01825 & 1334 \\
\hline 044 & 0.01099 & 93.78 & 5.913 & 9.2572 & 0.01908 & 1300 \\
\hline
\end{tabular}

americium in the ingot. The reasons for a standard deviation of $1.7 \%$ for the mass spectrometric-based results are not known.

The neutron coincidence counting method is much faster than calorimetry, but instrument calibration is not as straightforward. The count is affected by sample geometry, impurities, ingot size, and sample position during counting. Neutron count precision is limited by the precision of the ${ }^{240} \mathrm{Pu}$ measurement that, in this series, is estimated at $3.7 \%$. Accuracy of the results also is limited because no standard of similar size, shape, and composition was available for calibration. Of $\mathbf{2 6}$ assays, 7 were obviously outliers that could be caused by impurities such as fluoride or magnesium. We were unaivle to redo these counts or to keep these ingots for more coincidence counts, gamma spectra, and analytical data. The remaining 19 assays, based on neutron coincidence counting/gamma spectrometry, were 0.988 
TABLE II

\section{ASSAY OF EXCM SERIES OF MASS SPECTROMETRY} ISOTOPIC ABUNDANCES

\begin{tabular}{|c|c|c|c|c|c|c|}
\hline Ingot & & & \% Pu & & & ppm \\
\hline EXCM & 238 & 239 & 240 & 241 & 242 & ${ }^{241} \mathrm{Am}$ \\
\hline 017 & 0.019 & 93.91 & 5.78 & 0.257 & 0.029 & 1050 \\
\hline 025 & 0.014 & 94.12 & 5.61 & 0.233 & 0.023 & 1420 \\
\hline 026 & 0.023 & 93.86 & 5.80 & 0.274 & 0.044 & 840 \\
\hline 009 & 0.027 & 93.87 & 5.81 & 0.260 & 0.030 & 1030 \\
\hline 015 & 0.014 & 93.95 & 5.75 & 0.253 & 0.028 & 1080 \\
\hline 022 & 0.022 & 94.05 & 5.66 & 0.239 & 0.026 & 1240 \\
\hline 021 & 0.016 & 93.86 & 5.83 & 0.266 & 0.031 & 664 \\
\hline 034 & 0.016 & 93.87 & 5.82 & 0.262 & 0.031 & 657 \\
\hline 012 & 0.019 & 94.01 & 5.70 & 0.248 & 0.028 & 1020 \\
\hline 037 & 0.023 & 93.46 & 6.17 & 0.304 & 0.046 & 507 \\
\hline 023 & 0.029 & 94.03 & 5.66 & 0.243 & 0.027 & 1090 \\
\hline 027 & 0.024 & 93.28 & 6.36 & 0.286 & 0.056 & 1400 \\
\hline 030 & 0.014 & 93.93 & 5.77 & 0.255 & 0.028 & 1050 \\
\hline 031 & 0.016 & 94.10 & 5.62 & 0.234 & 0.024 & 1340 \\
\hline 032 & 0.033 & 94.04 & 5.67 & 0.238 & 0.025 & 1160 \\
\hline 033 & 0.018 & 94.11 & 5.61 & 0.232 & 0.024 & 1370 \\
\hline 035 & 0.013 & 94.00 & 5.71 & 0.250 & 0.028 & 978 \\
\hline 038 & 0.021 & 94.06 & 5.66 & 0.237 & 0.025 & 1280 \\
\hline 039 & 0.016 & 93.85 & 5.84 & 0.266 & 0.032 & 664 \\
\hline 040 & 0.018 & 93.87 & 5.81 & 0.264 & 0.032 & 682 \\
\hline 041 & 0.023 & 93.89 & 5.80 & 9.258 & 0.030 & 1020 \\
\hline 042 & 0.017 & 93.84 & 5.84 & 0.266 & 0.032 & 659 \\
\hline 043 & 0.016 & 93.92 & 5.78 & 0.256 & 0.029 & 978 \\
\hline 044 & 0.017 & 93.91 & 5.79 & 0.257 & 0.028 & 974 \\
\hline
\end{tabular}

\pm 0.033 of the shipper's value. This result is in good agreement with those values obtained by gamma spectrometry/calorimetry. The method will need more study and development, but it does look promising, particularly for repetitive samples.

The gamma spectrometry/calorimetry, mass spectrometry/calorimetry, and gamma spectrometry/neutron counting programs are continuing with evaluation of many ingots and buttons. Results are similar to those reported, but data collection is not complete. These data can be used to rapidly verify isotopic distribution, determine plutonium mass, and resolve shipper/receiver differences. The gamma spectrometry/calorimetry technique appaars ready for application in routine assay situations. The present gamma system then could be used for additional test and evaluation programs. 
TABLE III

ESTIMATED PRECISIONS OF GAMMA SPECTROMETRIC EXCM SERIES ASSAY (Rel \%)

\begin{tabular}{|c|c|c|c|c|c|c|}
\hline EXCM & 238 & 239 & 240 & 241 & 242 & ${ }^{241} \mathrm{Am}$ \\
\hline 017 & 11.3 & 0.2 & 3.6 & 0.4 & 0.5 & 1.8 \\
\hline 025 & 13.1 & 0.3 & 3.9 & 0.4 & 0.4 & 1.5 \\
\hline 026 & 5.6 & 0.1 & 2.2 & 0.2 & 0.5 & 1.3 \\
\hline 009 & 9.5 & 0.2 & 3.6 & 0.4 & 0.5 & 1.9 \\
\hline 015 & 11.5 & 0.2 & 3.9 & 0.4 & 0.5 & 2.1 \\
\hline 022 & 11.4 & 0.2 & 4.0 & 0.4 & 0.4 & 1.6 \\
\hline 021 & 10.2 & 0.2 & 3.8 & 0.4 & 0.5 & 3.2 \\
\hline 034 & 5.6 & 0.1 & 2.1 & 0.2 & 0.4 & 1.8 \\
\hline 012 & 14.2 & 0.4 & 6.0 & 0.6 & 0.4 & 25 \\
\hline 037 & 9.5 & 0.2 & 4.1 & 0.4 & 0.4 & 3.4 \\
\hline 023 & 17.9 & 0.3 & 5.5 & 0.6 & 0.4 & 2.2 \\
\hline 027 & 9.8 & 0.3 & 4.0 & 0.4 & 0.4 & 1.5 \\
\hline 030 & 17.2 & 0.4 & 5.6 & 0.6 & 0.5 & 2.6 \\
\hline 031 & 10.5 & 0.2 & 4.0 & 0.4 & 0.4 & 1.3 \\
\hline 032 & 19.3 & 0.3 & 5.4 & 0.6 & 0.4 & 1.8 \\
\hline 033 & 11.5 & 0.3 & 4.5 & 0.5 & 0.4 & 1.6 \\
\hline 035 & 6.5 & 0.1 & 2.3 & 0.2 & 0.5 & 1.8 \\
\hline 038 & 19.6 & 0.4 & 6.7 & 0.7 & 0.4 & 2.9 \\
\hline 039 & 18.2 & 0.3 & 5.0 & 0.6 & 0.5 & 4.0 \\
\hline 040 & 10.3 & 0.2 & 3.6 & 0.4 & 0.5 & 2.8 \\
\hline 041 & 12.0 & 9.3 & 4.9 & 0.6 & 0.5 & 2.7 \\
\hline 042 & 9.1 & 0.2 & 4.0 & 0.4 & 0.5 & 2.4 \\
\hline 043 & 15.2 & 0.3 & 5.3 & 0.6 & 0.5 & 2.3 \\
\hline 044 & 11.3 & 0.3 & 4.0 & 0.4 & 0.5 & 1.8 \\
\hline
\end{tabular}

D. Neutron Coincidence Counter for Plutonium Solutions (N. Ensslin, E. L. Adams, R. L. Brewer, M. L. Evans, G. Walton, R. B. Walton, and D. F. Bowersox)

This section describes the design, installation, and initial checkout of a neutron coincidence counter developed specifically for the assay of plutonium solutions. In principle, the spentaneous fission of the even plutonium isotopes can be detected as readily in solutions as in metals or oxides. However, preliminary measurements with existing counters showed that the moderating effects of the solution can bias the assay. ${ }^{15}$
For this reason the Solution Neutron Coincidence Counter (SNCC) in Fig. 5 was designed to provide an optimum response for plutonium solutions in the range 10 to $300 \mathrm{~g} / l$. Twenty-six ${ }^{3} \mathrm{He}$ tubes in two rings ere tightly spaced around a $1-\ell$ solution bottle to achieve high counting efficiency. The $50-\mathrm{cm}$ active length tubes are the same length as the bottle to confine the sensitive volume to the bottle and to minimize the overall size of the detector. Including the $10-\mathrm{cm}$-thick polyethylene shield and the 1-cm-thick steel shell, the detector has a $48-\mathrm{cm}$ diam and is $82 \mathrm{~cm}$ long.

Because the solution bottle has an interior diameter of $5.2 \mathrm{~cm}$, the solution itself provides about $2.6 \mathrm{~cm}$ of moderator thickness. Thus, no large amount of polyethylene is required between the inner $0.4-\mathrm{mm}$ cadmium liner and the ${ }^{3} \mathrm{HIc}$ tubes. A series of laboratory measurements with the SNCC showed that $1.1 \mathrm{~cm}$ of polyethylene up to the first ring of tubes was nearly optimum. With this thickness, the absolute efficiency is $33 \%$ and the die-away time is $38 \mu \mathrm{s}$ at the center. Figure 6 illustrates the axial efficiency profile. The normal efficiency profile (dashed curve) was enhariced by removing the last $10 \mathrm{~cm}$ of the inner cadmium liner from each end (solid curve). A flat efficiency profile is not needed for homogeneous solutions, but a high overall efficiency is useful for the assay of $1-$ to $10-\mathrm{g} / \ell$ solutions. For solutions from 10 to $300 \mathrm{~g} / \ell$, the full cadmium iner probably will be needed to minimize self-multiplication effects. At $2 \mathrm{~g} / \ell$, the expected assay precision is $2 \%$, with $2 \%$ self-multiplication. For solutions near $100 \mathrm{~g} / \ell$, the expected assay precision is $0.5 \%$, with $20 \%$ seli-multiplication. Laboratory measurements showed that the $10-\mathrm{cm}$ polyeihylene shield reduced the total neutron background in the counter by a factor of 5 to 10 . Thus, self-multiplication corrections based on the ratio of coincident-to-total neutrons should be possible where needed.

Figure 7 shows installation of the SNCC above the experimental solutions glovebox in Room 209 of the Los Alamos Plutonium Processing Far:ity (TA-55). The blue steel container is mounted directly on the concrete wall. The polyethylene parts of the counter and the ${ }^{3} \mathrm{He}$ tubes can be removed without disturbing the steel containeit or the inner solution bottle. The bottle consists of 2.8-mm-thick stainless steel with a $0.8-\mathrm{mm}$ secondary steel container. The steel tubing between the solution bottle and the glovebox has a flexible Tygon tubing secondary containment. The primary containment system was leak-tested and radiographed before installation. The secondary containment system can be vented back 
TABLE IV

RATIOS OF RESULTS OF GAMMA-TO-MASS SPECTROMETRY FOR THE EXCM SERIES

\begin{tabular}{|c|c|c|c|c|c|c|}
\hline EXCM & 238 & 239 & 240 & 241 & 242 & ${ }^{241} \mathrm{Am}$ \\
\hline 017 & .505 & $' .001$ & .985 & .995 & .627 & 1.111 \\
\hline 025 & .649 & .995 & 1.090 & .988 & .768 & 1.108 \\
\hline 026 & .550 & 1.001 & 1.033 & 1.006 & .464 & 1.243 \\
\hline 009 & .467 & .995 & 1.090 & 1.028 & .712 & 1.142 \\
\hline 015 & .747 & .997 & 1.050 & .992 & .678 & 1.032 \\
\hline 022 & .469 & 1.000 & 1.011 & 1.003 & .656 & 1.187 \\
\hline 021 & .743 & 9?? & 1.054 & .997 & .661 & 1.095 \\
\hline 034 & .753 & .959 & 1.027 & 1.003 & .634 & 1.094 \\
\hline 012 & .667 & 1.001 & .990 & .996 & .619 & 1.374 \\
\hline 037 & .550 & 1.006 & .930 & $.825^{\prime}$ & $.390^{n}$ & 1.339 \\
\hline 023 & .310 & 1.000 & 999 & 1.001 & .633 & 1.293 \\
\hline 027 & .513 & 1.004 & .953 & $.805^{a}$ & $.313^{2}$ & 1.135 \\
\hline 030 & .730 & .997 & 1.054 & .995 & .691 & 1.265 \\
\hline 031 & .719 & 1.003 & .961 & .995 & .648 & 1.279 \\
\hline 032 & .252 & 1.000 & .999 & 1.007 & .675 & 1.518 \\
\hline 033 & .629 & 1.001 & .991 & 1.000 & .666 & 1.169 \\
\hline 035 & .819 & .998 & 1.043 & .995 & .662 & .751 \\
\hline 038 & .489 & .997 & 1.045 & 1.006 & .705 & 1.048 \\
\hline 039 & .537 & 1.000 & .996 & .989 & .597 & 1.162 \\
\hline 040 & .621 & .997 & 1.053 & .997 & .632 & 1.169 \\
\hline 041 & .581 & 997 & 1.054 & 1.000 & .660 & 1.136 \\
\hline 042 & .721 & .999 & 1.015 & .998 & .615 & 1.373 \\
\hline 043 & .658 & 1.001 & .989 & 1.002 & .629 & 1.364 \\
\hline 044 & .647 & .999 & 1.021 & 1.001 & .681 & 1.335 \\
\hline $\mathbf{x}$ & .597 & .999 & 1.018 & 1.000 & .651 & 1.197 \\
\hline$\sigma$ & \pm .140 & \pm .003 & \pm .041 & \pm .008 & \pm .057 & \pm 0.155 \\
\hline
\end{tabular}

"These values excluded from average; both the mass spectrometry values were high.

into the glovebox if a leak in the primay system should occur. At the base of the SNCC, a small hole is provided for inserting a californium normalization srurce. The preamplifier junction box is mounted on top of the
SNCC, and the shift register electronics package is mounted beneath the glovebox (lower right corner of Fig. 7). 
TABLE V

\section{DIFFERENCE IN Am VALUE BY SAMPLE LOCATION}

\begin{tabular}{|c|c|c|c|}
\hline \multirow[t]{2}{*}{ Ingot } & \multicolumn{3}{|c|}{ Am, ppm } \\
\hline & S2 & S1 & $\begin{array}{c}\Delta \mathbf{S}^{\prime} \mathbf{S} 2 \\
\text { (\%) }\end{array}$ \\
\hline 1 & 1150 & 1270 & 10.4 \\
\hline 2 & 1140 & 1140 & 0.0 \\
\hline 3 & 1160 & 1270 & 9.5 \\
\hline 4 & 1150 & 1350 & 17.4 \\
\hline 5 & 1150 & 1270 & 10.4 \\
\hline 6 & 1080 & 1200 & 11.1 \\
\hline 7 & 945 & 1190 & 25.9 \\
\hline 8 & 720 & 741 & 2.9 \\
\hline 9 & 1220 & 1290 & 5.7 \\
\hline 10 & 660 & 686 & 3.8 \\
\hline 11 & 993 & 1170 & 15.1 \\
\hline 12 & 1030 & 984 & -4.7 \\
\hline
\end{tabular}

The transfer system for moving plutonium solution into the counter is diagrammed in Fig. 8. Using the plant's overhead conveyer system, hot solutions will be moved into the glovebox in $2-\ell$ bottles. Within the glovebox, soluticins will be transferred with the plant's "wet vacuum." A vacuum transfer system was recommended by the Los Alamos Plutonium Chemistry and Metallurgy Group (CMB-11) to minimize plutonium solution loss if a leak should orcur in tubing outside the glovebox. Solution is drawn by vacuum into the SNCC from Tank 2 and then returned by gravity to Tanks 2 and 1 . Tank 3 isolates the vacuum line from the solution tanks. All features of the solution transfer system have been tested with cold solutions.

Initial hot experiments will be conducted with 2- to $10-\mathrm{g} / \ell$ plutonium nitrate solutions. If these experiments are successful, the plutonium concentration will be increased in steps up to $300 \mathrm{~g} / \ell$. These measurements will determine assay precision, accuracy, and reproducibility. Of particular interest will be the self-multiplication of neutrons from spontanecus fission and $(a, n)$ reactions. The assay of solutions by neutron coincidence counting should benefit from a uniform matrix and a fixed-sample geometry. However, self-muitiplication effects may be large because of the moderating properties of the solution. Where possible, experimental results from the SNCC will be compared with Monte Carlo calculations.

\section{COMPONENT DEVELOPMENT FOR INTERNATIONAL SAFEGUARDS}

\section{Completion of the Gas-Phase UF $_{6}$ Enrichment Monitor Prototype Evaluation Meusurements (R. B. Strittmatter)}

A measurement program to evaluate performance of the laboratory prototype of the gas-phase $\mathrm{UF}_{6}$ enrichment monitor has been completcd. The measurements were designed to determine the accuracy of the measurement technique nver the range of important variables encountered during operation of the enrichment monitor. The viuiabies investigated were uranium enrichment, $\mathrm{UF}_{6}$ gas pressure, and gamma-ray backgrounds. Also included in the program was a measurement of the intermediate and short-term precision of the assay results. During this reporting period performance over a range of uranium enrichments was tested, the effect of ${ }^{238} U$ daughter-product buildup on the assay result was monitored, and measurements of the assay precision were conducted. Instrument response over a range of $\mathrm{UF}_{6}$ pressures for a single enrichment has been reported previously. ${ }^{16}$ Also completed in this reporting period were a measurement of uranium plating on a section of pipe from the Oak Ridge Gaseous Diffusion Plant (ORGDP) feed station and the report, "Conceptual Design for the Field Test and Evaluation of the Gas-Phase UF 6 Enrichment Meter." 17

Accuracy of the enrichment measurements was studied using four samples of $\mathrm{UF}_{6}$ with ${ }^{235} \mathrm{U}$ enrichments ranging from 0.71 to $5.4 \mathrm{wt} \%$. The $\mathrm{UF}_{6}$ samples were obtained from ORGDP, which also provided ${ }^{235} U$ enrichment data from mass spectroscopy analysis. The samples were introduced into the enrichment monitor by vaporization transfer after vacuum evacuation of the system. The relative enrichment was measured for each sample at nominal pressures of $100,200,400,600,700$, and 800 torr. The method for determining enrichment from data obtained by the enrichment monitor is described in Ref. 17. Three 1-h measurements were performed at each pressure, and an average relative enrichment for 
TABLE VI

\section{CALORIMETRY RESULTS FOR THE EXCM SERIES}

\begin{tabular}{|c|c|c|c|c|c|}
\hline Ingot & $\begin{array}{c}\text { MS' } \\
(\mathrm{g})\end{array}$ & $\begin{array}{c}\mathbf{G S}^{\mathbf{b}} \\
(\mathbf{g}) \\
\end{array}$ & $\begin{array}{l}\mathbf{S V} \mathbf{c} \\
(\mathrm{g}) \\
\end{array}$ & ${ }^{\mathbf{R}} \mathbf{M} \mathbf{S}^{\mathbf{d}}$ & ${ }^{x} \mathbf{G S}^{e}$ \\
\hline 026 & 3185.3 & 3263 & 3263 & 0.976 & 0.986 \\
\hline 022 & 2580.5 & 2617 & 2646 & 0.975 & 0.989 \\
\hline 021 & 2901.9 & 2901 & 2924 & 0.993 & 0.992 \\
\hline 015 & 3359.6 & 3361 & 3396 & 0.989 & 0.990 \\
\hline 037 & 1572.8 & 1612 & 1681 & 0.936 & 0.959 \\
\hline 012 & 2726.5 & 2720 & 2782 & 0.980 & 0.978 \\
\hline 027 & 3200.3 & 3275 & 3363 & 0.952 & 0.974 \\
\hline 023 & 2914.3 & 3121 & 3045 & 0.957 & 1.024 \\
\hline 030 & 3326.2 & 3290 & 3357 & 0.991 & 0.980 \\
\hline 031 & 3557.7 & 3554 & 3615 & 0.984 & 0.983 \\
\hline 034 & 2193.2 & 2199 & 2258 & 0.971 & 0.974 \\
\hline 032 & 3435.7 & 3533 & 3636 & 0.945 & 0.972 \\
\hline 033 & 3556.6 & 3576 & 3629 & 0.980 & 0.985 \\
\hline 035 & 3063.3 & 3098 & 3158 & 0.970 & 0.981 \\
\hline 038 & 3464.6 & 3521 & 3576 & 0.969 & 0.985 \\
\hline 039 & 3564.1 & 3609 & 3598 & 0.991 & 1.003 \\
\hline 040 & 3620.3 & 3634 & 3665 & 0.998 & 0.992 \\
\hline 041 & 3588.5 & 3620 & 3696 & 0.971 & 0.979 \\
\hline 042 & 3554.0 & 3544 & 3596 & 0.988 & 0.986 \\
\hline 043 & 3621.0 & 3610 & 3667 & 0.988 & 0.984 \\
\hline 044 & 3785.3 & 3768 & 3838 & 0.986 & 0.982 \\
\hline$\overline{\mathbf{x}}$ & & & & 0.975 & 0.985 \\
\hline$\sigma$ & & & & $(1.7 \%)$ & (1.3\%) \\
\hline
\end{tabular}

"GPu, based on assay by mass spectrometry.

${ }^{\mathrm{G}} \mathrm{GPu}$, based on assay by gamma spectrometry.

'GPu, based on shipper's value.

'Ratio of MS value to shipper's value.

'Ratio of GS value to shipper's value.

each sample was computed using the results obtained at $400,600,700$, and 800 torr. This $\mathrm{UF}_{6}$ pressure range is expected at the ORDGP Paducah product feed station where the field test and evaluation of the enrichment monitor will be conducted. ${ }^{17}$
After al! measurements were completed for each sample, the $U F_{6}$ was cryopumped into a waste cylinder and a sample was drawn for mass spectroscopy analysis at Los Alamos. The natural $\mathrm{UF}_{6}$ sample was used as a standard to calibrate the enrichment monitor, and the 


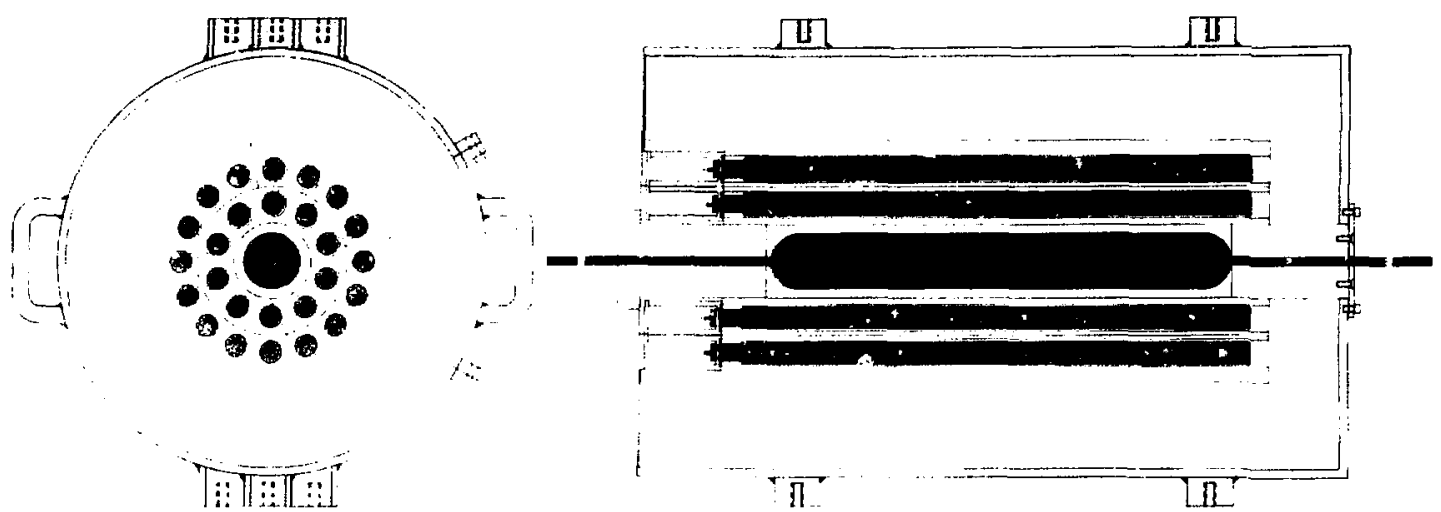

Fig. 5.

Top and side views of SNCC.

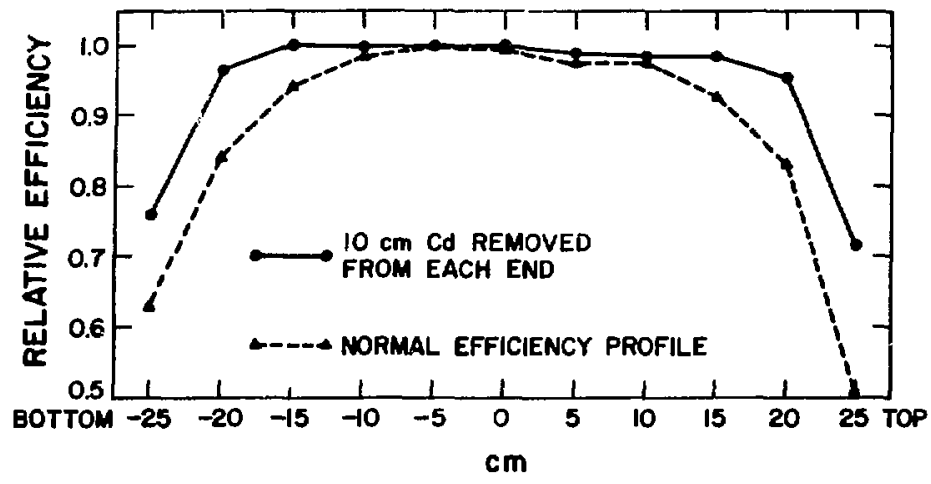

Fig. 6.

SNCC axial efficiency profile. The solid curve was obtained by removing the last $10 \mathrm{~cm}$ of the inner cadmium liner from each end of the cavity.

average of the Los Alamos and ORDGP mass spectroscopy results was used for the tag value of this standard. Using $0.7105 \%$ for the calibration standard, enrichments for the other three samples were computed from the enrichment monitor data. Table VII presents the ${ }^{235} U$ enrichment results of the mass spectroscopy analysis by ORDGP and Los Alamos and the assay obtained using the enrichment monitor. Assignment of the 1- $\sigma$ error bars to the enrichment monitor values is based on a measured short-term precision.

The effect of ${ }^{238} U$ datiditer-product buildup on the enrichment measurement was investigated by filling the enrichment monitor with $1 \%$ enrichment $\mathrm{UF}_{6}$ at 700 torr and measuring the enrichment over a 40 -day period. The daughter-product concent-ation at the beginning of the measurement was equivalent to the equilibrium concentration at approximately 100 torr. During the 40-day period the count rate used to determine the background under the 186-keV peak increased by $75 \%$. After 40 days the daughter-product concentration reached $68 \%$ of the equilibrium concentration, assuming a zero concentration as the initial condition. The background count rate and the measured enrichment normalized to the average value are presented as a function of time in Fig. 9. The standard deviation of the eight 3-h assays over the 40-day period is $0.21 \%$. This value compsres favorably with the expected precision for each 3-h measurement of $0.23 \%$ based on the measured short-term precision. 


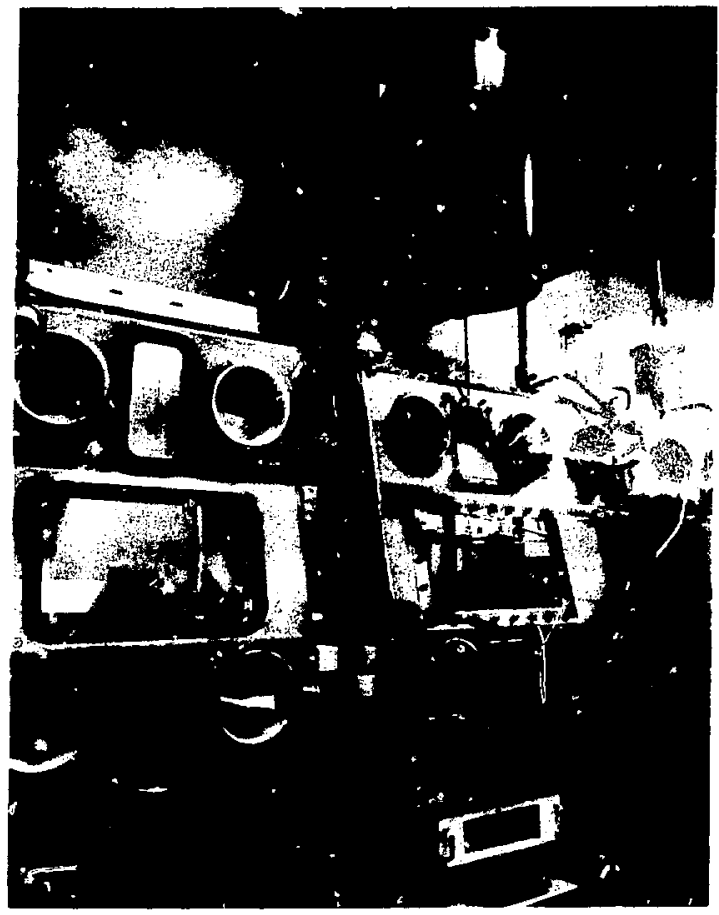

Fig. 7.

Location of the SNCC above the experimental soiutions glovebox in the Los Alamos Plutonium Processing Facility.

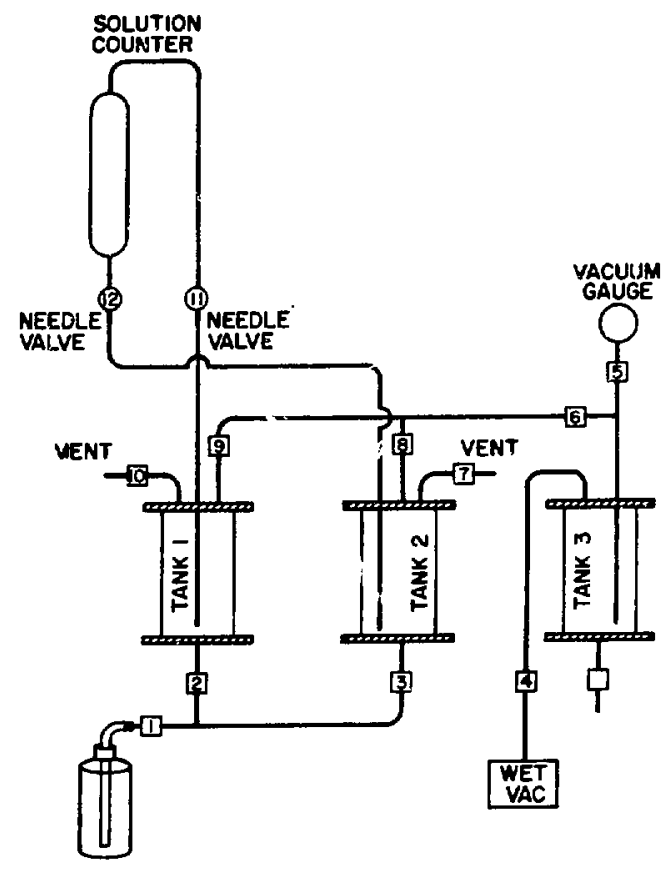

Fig. 8.

Solution transfer system for the SNCC. The tubing above needie valves 11 and 12 is outside the glovebox and is doubly contained.

TABLE VII

${ }^{235}$ U ENRICHMENT RESULTS

Mass Spectroscopy

\begin{tabular}{clcc}
\multicolumn{3}{c}{ Mass Spectroscopy } & Enrichment Monitor \\
\hline & & & \\
Sample & \multicolumn{2}{c}{${ }^{235} \mathrm{U}$ wt\% } & \\
ID & ORGDP & Los Alamos & ${ }^{239} \mathrm{U}$ wt\% $( \pm 1$ o) \\
R1 & 5.360 & 5.419 & $5.320 \pm 0.008$ \\
R2 & 0.711 & 0.710 & $0.7105 \pm 0.001^{2}$ \\
R3 & 3.000 & 3.009 & $2.995 \pm 0.005$ \\
R4 & 1.002 & 1.007 & $1.011 \pm 0.002$ \\
\end{tabular}

Enrichment Monitor

Value used for calibration of enrichment monitor. 


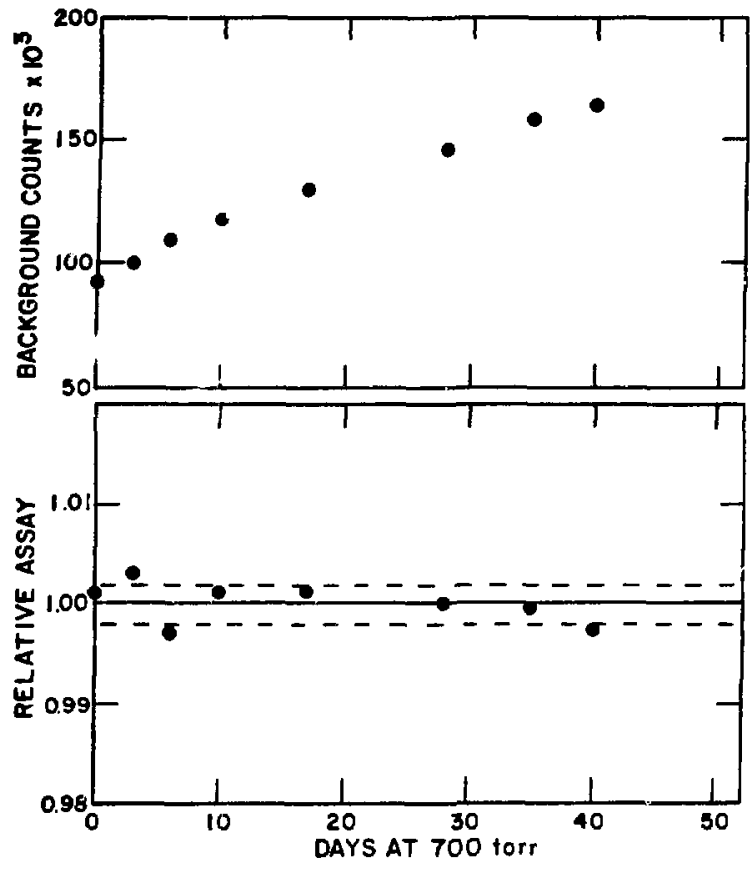

The short-term precision for a 1-h measurement was determined by making a series of 26 consecutive 1-h measurements of $1.0 \%$ enriched $\mathrm{UF}_{6}$ at a pressure of 700 torr and by calculating the standard deviation. The measured standard deviation was $0.39 \%$ for a 1 -h measurement, and the precision determined from counting statistics for each peak and their associated backgrounds was $0.36 \%$.

To study the expected amount of uranium plating in the measurement chamber under normal process conditions, a section of pipe used in the ORGDP normal feed line was obtained. The amount of uranium plating in the pipe was determined by measuring the count rate of
Fig. 9.

Results of the gas-phase $\mathrm{UF}_{6}$ enrichment moritor assays of $1.0 \%$ enriched $\mathrm{UF}_{6}$ at a pressure of $700 \mathrm{~d}$ torr during a 40-day buildup of ${ }^{23 !} U$ daughter-product concentration. (Top) Background counts used to determine the background under the 186-keV peak for a 1-h measurement. (Bottom) Measured enrichments normalizet to the average vahue. Each data point is the average of three 1-h measurements. The dashed lines represent the precision $( \pm \sigma)$ for a 3-h measurement.

\section{CURRENT DEVELOPMENTS}

\section{A. Plutonium Isotopic Composition Measurements on Mixed Oxides (T. E. Sampson)}

The plutonium isotopic measurement techniques described in Refs. 14 and 18 have been extended to mixed uranium-plutonium oxides (MOX) with proof-of-principle measurements on samples with ${ }^{233} \mathrm{U} / \mathrm{Pu}$ ratios up to 3.0
186-keV gamma rays with a high-resolution germanium detector placed in the center of the $15.2-\mathrm{cm}$-diam, 25.4-cm-long pipe. This measurement indicates that the uranium plated on the measurement chamber will be 0.5 to $2.0 \%$ of the uranium in the gas-phase measurement for an operating pressure of 840 torr. The lower limit of $0.5 \%$ would occur if the amount of plating were proportional to the operating $\mathrm{UF}_{6}$ pressure between 840 and 4000 torr. If this assumption is not correct, the ratio could increase to $2 \%$. The effect of a quantity of plating in this range can be corrected by periodic background measurements.
The presence of ${ }^{233} U$ in MOX complicates the plutonium isotopic composition measurements because ${ }^{233} \mathrm{U}$ gamma rays at $163.35,202.12$, and $205.31 \mathrm{keV}$ interfere with the plutonium gamma rays at 164.6 and $208.0 \mathrm{keV}$. These two plutonium gamma rays measure the ${ }^{2010} \mathrm{Pu} /{ }^{241} \mathrm{Pu}$ ratio at $160.2 / 164.6 \mathrm{keV}$ and the ${ }^{239} \mathrm{Pu} /{ }^{241} \mathrm{Pu}$ ratio at $203.5 / 208.0 \mathrm{keV}$. The simple region 
of interest peak integration method requires that background regions not fall in the area of possible peak interferences. Careful selection of the background regions allows measuring the ${ }^{240} \mathrm{Pu} /{ }^{241} \mathrm{Pu}$ and ${ }^{239} \mathrm{Pu} /{ }^{241} \mathrm{Pu}$ ratios on MOX in the presence of ${ }^{235} \mathrm{Pu}$ up to ${ }^{235} \mathrm{U} / \mathrm{Pu}$ ratios of 0.3 for the ${ }^{239} \mathrm{Pu} /{ }^{241} \mathrm{Pu}$ ratio and 3.0 for the ${ }^{240} \mathrm{Pu} /{ }^{24} \mathrm{Pu}$ ratio.

The results of proof-of-principle measurements are shown in Fig. 10. Seven MOX samples with ${ }^{23 s} \mathrm{U} / \mathrm{Pu}$ ratios ranging from 0.0 to 2.85 were measured. The ${ }^{240} \mathrm{Pu}$ content ranged from 10 to $18 \%$ and the ${ }^{241} \mathrm{Pu}$ varied from 1 to $3 \%$.

Five samples were used to calibrate the three adjustable constants in the ${ }^{240} \mathrm{Pu} /{ }^{241} \mathrm{Pu}$ ratio expression to remove bias caused by the specific peak area integration and relative efficiency determination methods. An adjustment of $<1 \%$ was made in the multiplicative constant for the ${ }^{239} \mathrm{Pu} /{ }^{241} \mathrm{Pu}$ ratio. These slight adjustments are part of the normal process to reduce bias in the plutonium isotopic ratio measurements.

In Fig. 10 , the ${ }^{240} \mathrm{Pu} /{ }^{241} \mathrm{Pu}$ ratio measurements are bias free for all data taken. The ${ }^{239} \mathrm{Pu} /{ }^{241} \mathrm{Pu}$ ratio is bias free up to a ${ }^{235} \mathrm{U} / \mathrm{Pu}$ ratio of about 0.3 . The large statistical errors on the ${ }^{240} \mathrm{Pu} /{ }^{241} \mathrm{Pu}$ ratio arise from the very small amount of plutonium in the samples (three samples had $<0.3 \mathrm{~g} \mathrm{Pu}$ ). More realistically sized samples may not produce results as good as those displayed here because of resolution broadening arising from the higher count rates involved.

MOX with natural uranium/plutonium ratios of 3 or 4 to 1 will give a ${ }^{235} \mathrm{U} / \mathrm{Pu}$ ratio from 0.02 to 0.03 , well within this technique's applicable range.

B. Upgrading the $\mathrm{L}_{\mathrm{III}}$-Edge Densitometer (S. S. Johnson, D. C. Langner, P. A. Russo, and J. K. Sprinkle, Jr.)

Preparations for further test and evaluation of the $L_{\text {III }}$-edge densitometer (Ref. 19 and Ref. 20, pp. 9-11) at the New Brunswick Laboratory (NBL) included an upgrade of the densitometer hardware and software. The computer-based multichannel analyzer was changea to a Canberra Series 80 system to improve its reliability. The signal-processing electronics were upgraded to improve resolution of the spectrometer. Finally, the computer software was modularized and rewritten in FORTRAN to allow for more flexibility in the densitometer's operation and for easier implementation of future software modifications.

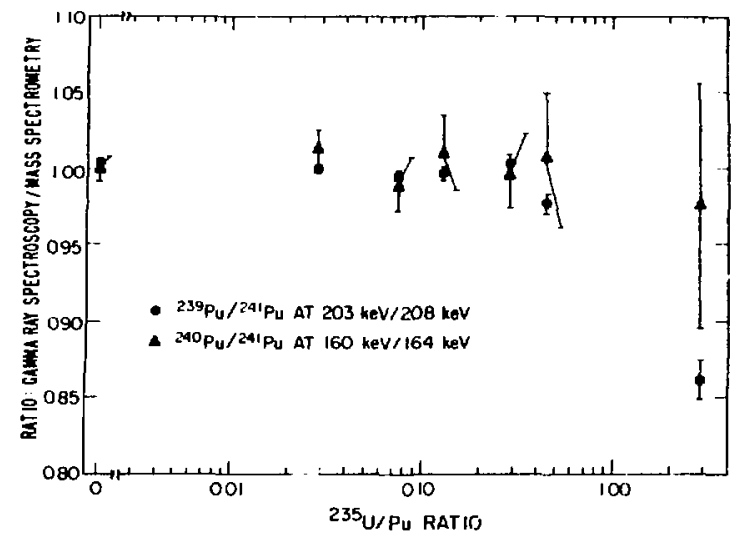

Fig. 10.

Plutonium isotopic ratio measurements in the presence of interferences from ${ }^{235} \mathrm{U}$ in MOX.

After the hardware and software changes were accomplished, a reanalysis of data acquired at Savannah River Laboratory (SRL) on a set of reference samples prepared at Los Alamos ${ }^{21}$ indicated that a linear calibration could be obtained for uranium concentrations of 20 to $90 \mathrm{~g} / \ell$ (see Fig. 11). Consequently, two sets of reference solutions were prepared. One set consisted of seven uranium solutions in eight removable glass spectroscopic cells. The second set used removable stainless steel cells identical to the fixed position flow-through cell. These nine stainless steel cells contained two uranium, two plutonium, and five mixed reference solutions. Table VIII lists the reference concentrations of the three sets of solutions. Figure 12 shows the measured calibration factor for samples in the glass cells, and Fig. 13 shows the same results for the single special nuclear material (SNM) component assays of the metal cells. The glass cells are $15 \%$ thinner than the metal cells; consequently, their average calibration parameter is smaller.

Figures 14 and 15 show the calibration results for uranium and plutonium (respectively) in the mixed reference solutions. Two types of analysis, "fit" and "no fit," refer to the technique used for obtaining photon transmission values above and below the absorption edge. The fit analysis is expected to be less sensitive to matrix effects. Each data point is the average of three statistically precise results. Note that the calibration is independent of the uranium/plutonium ratio for the plutonium fit results and for both the fit and no-fit uranium data and that large matrix effects appear for the plutonium no-fit case. 


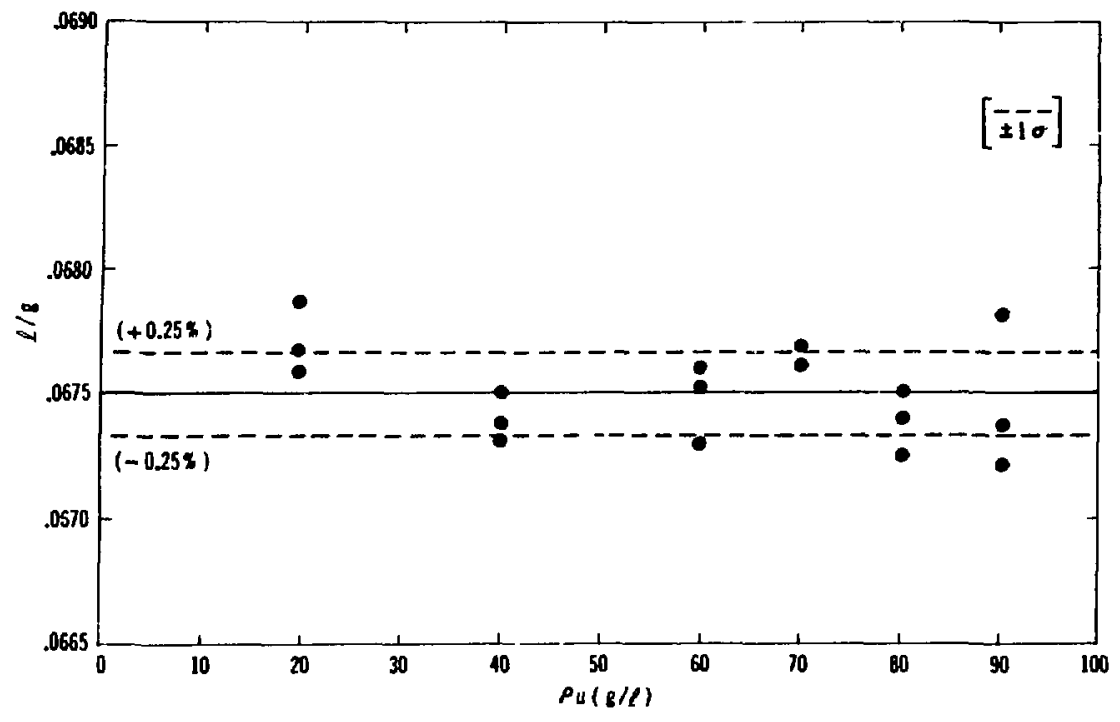

Fig. 11.

Uranium calibration factor plotted vs uranium concentration. Each data point is derived from the result of one 1000-s assay. Data were obtained at SRL and analyzed at Los Alamos, and reference samples were prepared at Los Alamos. The flow-through sample cell was used for all measurements. Precision is indicated by the dashed lines.

Figures 16 and 17 demonstrate the assay precisions obtained for single SNM-bearing solutions and for plutonium in multiple SNM solutions. The curves indicate the values obtained at SRL, and the upper points correspond to the values obtained at Los Alamos in September 1980. The corrections, which lowered the points, take into account the different count rates used at Los Alamos and at SRL. In the uranium case, for mixed solutions the precisions are slightly higher than those obtained for the single SNM case. All these measured precisions agree with the values calculated from counting statistics.

Figures 12 and 13 display results inconsistent with a linear calibration. Figures 16 and 17 indicate that these variations do not result from poor measurement precision. However, small variations in cell-to-cell thick- nesses, cell positioning in the densitometer, chemical analysis, and the densitometer's analysis technique may possibly cause these inconsistencies.

The first two causes can be eliminated by a single fixed-geometry flow-through cell. The last two can be evaluated by carefully comparing the densitometer and chemical assays for many samples, using various data analysis techniques. The test and evaluation plan that has been negotiated with NBL is designed to perform such a comparison using a flow-through cell. Current plans include studies of the material-handling characteristics of the system, such as sampling and flushing of the cell contents, and precision and accuracy studies as functions of the concentration of both SNM and matrix components.

\section{STANDARDS}

High-Temperature Gas-Cooled Reactor Fuels Intercomparison (J. L. Parker and M. M. Meier)

In February $1979 \mathrm{NBL}$ invited the Los Alamos National Laboratory to participate in an investigation and evaluation of nondestructive assay of the ${ }^{235} U$ content of fabricated fuel rods for high-temperature gas-cooled reactors. As a result, Los Alamos undertook an extensive set of measurements including both delayed-neutron and passive gamma-ray nondestructive 
TABLE VIII

\section{REFERENCE CONCENTRATIONS FOR SOLUTION STANDARDS}

\begin{tabular}{|c|c|c|c|}
\hline & Nurnber & $\mathrm{U} \mathrm{g} / \ell$ & Pu g/t \\
\hline \multirow[t]{6}{*}{ SRL } & 1 & 19.96 & - \\
\hline & 2 & 40.06 & - \\
\hline & 3 & 60.01 & - \\
\hline & 4 & 70.06 & - \\
\hline & 5 & 79.99 & - \\
\hline & 6 & 89.93 & - \\
\hline \multirow[t]{8}{*}{ Glass cells" } & 1 & 13.94 & - \\
\hline & 2 & 22.87 & - \\
\hline & 3 & 43.40 & - \\
\hline & 4 & 65.78 & - \\
\hline & 5 & 65.78 & - \\
\hline & 6 & 75.33 & - \\
\hline & 7 & 87.23 & - \\
\hline & 8 & 98.85 & - \\
\hline \multirow[t]{9}{*}{$\begin{array}{l}\text { Removable cells } \\
\text { (stainless steel) }\end{array}$} & 1 & - & 4.18 \\
\hline & 2 & - & 17.99 \\
\hline & 3 & 32.49 & - \\
\hline & 4 & 69.80 & - \\
\hline & 5 & 10.59 & 2.83 \\
\hline & 6 & 12.86 & 5.48 \\
\hline & 7 & 44.31 & 11.31 \\
\hline & 8 & 22.55 & 6.22 \\
\hline & 9 & 49.97 & 5.57 \\
\hline
\end{tabular}

"NOTE: Numbers 1 to 4 and 5 to 8 represent two matched sets of cells. Normalization was evaluated with samples 4 and 5.

assay procedures. Data acquisition was complete early in 1980 , but data analysis continued throughout the year. During the reporting period, analysis of the Los Alamos data was completed and results were reported to NBL.
A report concisely outlining the measurement methods used, summarizing the results, and giving tentative conclusions from the work has been written and soon will appear as a Los Alamos informal report. Several other reports in preparation detail the intercomparison effort and work arising from it. 


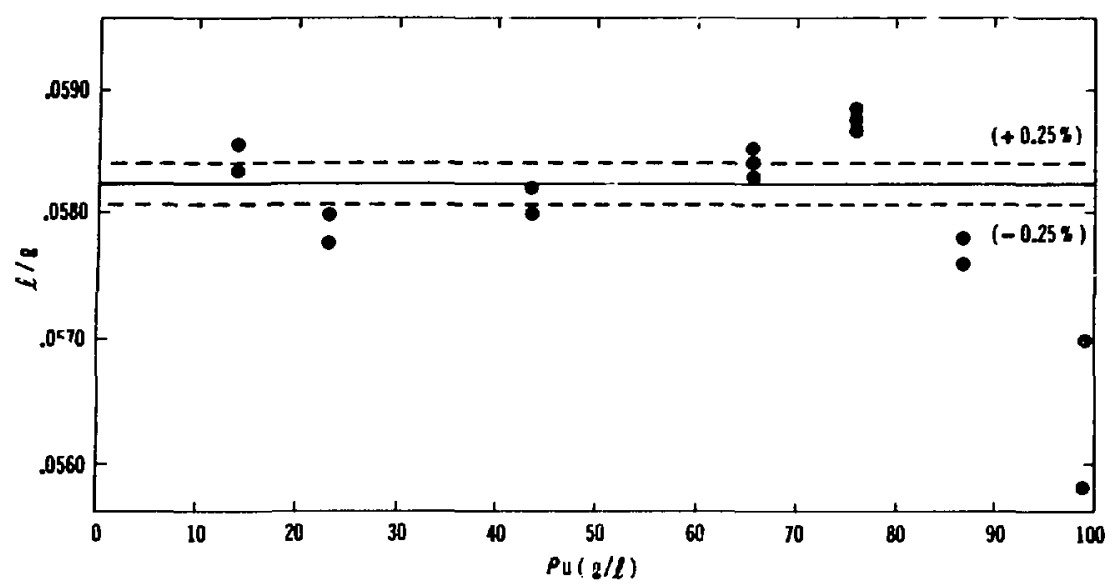

Fig. 12.

Uranium calibration factor plotted vs uranium concentration. Each data point is derived from the average result of 6 to 201000 -s assays. Reference samples were prepared at Los Alamos, and data were obtained at Los Alamos using the 1 -cm-thick glass cells. The dashed lines indicate $0.25 \%$ limits for comparison with Fig. 26.

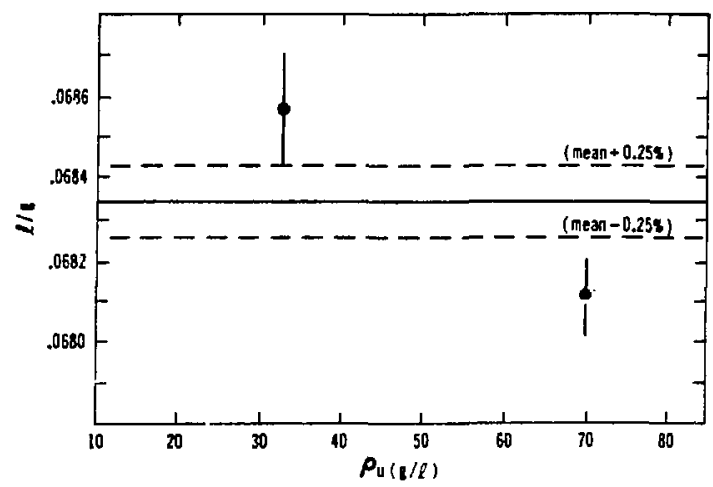

Fig. 13.

Uranium (upper) and plutonium (lower) calibration factor plotted vs uranium and plutonium concentration respectively. Each data point is derived from the average result of three statistically precise assays. The error bar $(1 \mathrm{\sigma})$ is a measure of the precision in the three results. Reference samples were prepared at Los Alamos, and data were obtained at Los Alamos using removable, stainless steel cells. The dashed lines indicate $0.25 \%$ limits for comparison with Fig. 26. 


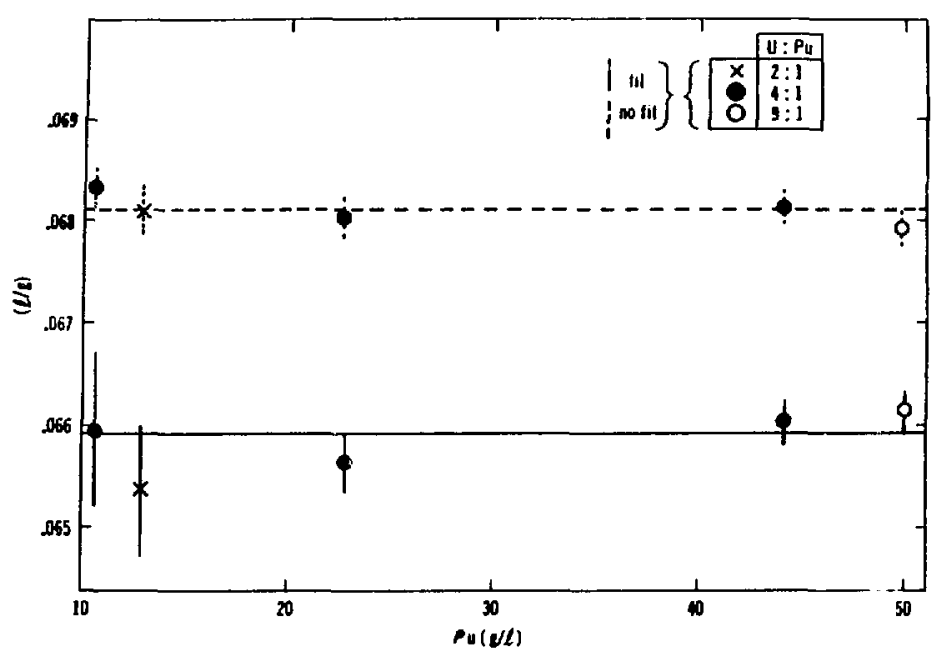

Fig. 14.

The cailbration factor for uranium in mixed (uranium plus plutonium) samples of varying uranium/plutonium ratio plotted vs uranium concentration. The fit and no-fit distinction is relevant to the technique applied in the evaluation of matrix effects. The error bars give the precision $(1 \sigma)$ in the data points.

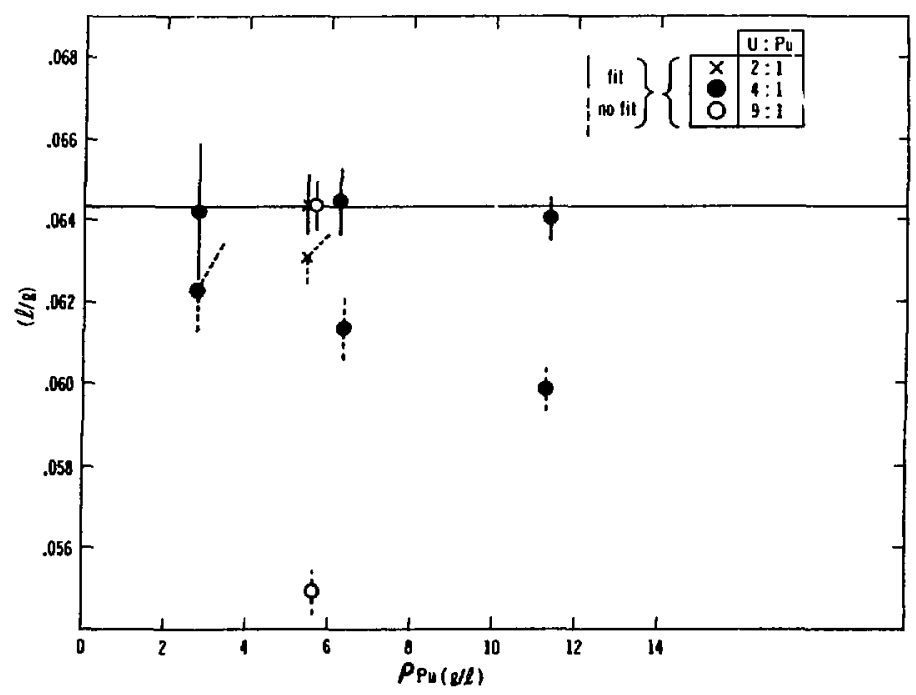

Fig. 15.

The calibration factor for plutonium in mixed (uranium plus plutonium) samples of varying uranium/plutonium ratio plotted vs plutonium concentration. The fit and no-fit distinction is relevant to the technique applied in the evaluation of matrix effects. The error bars give the precision in the data points. 


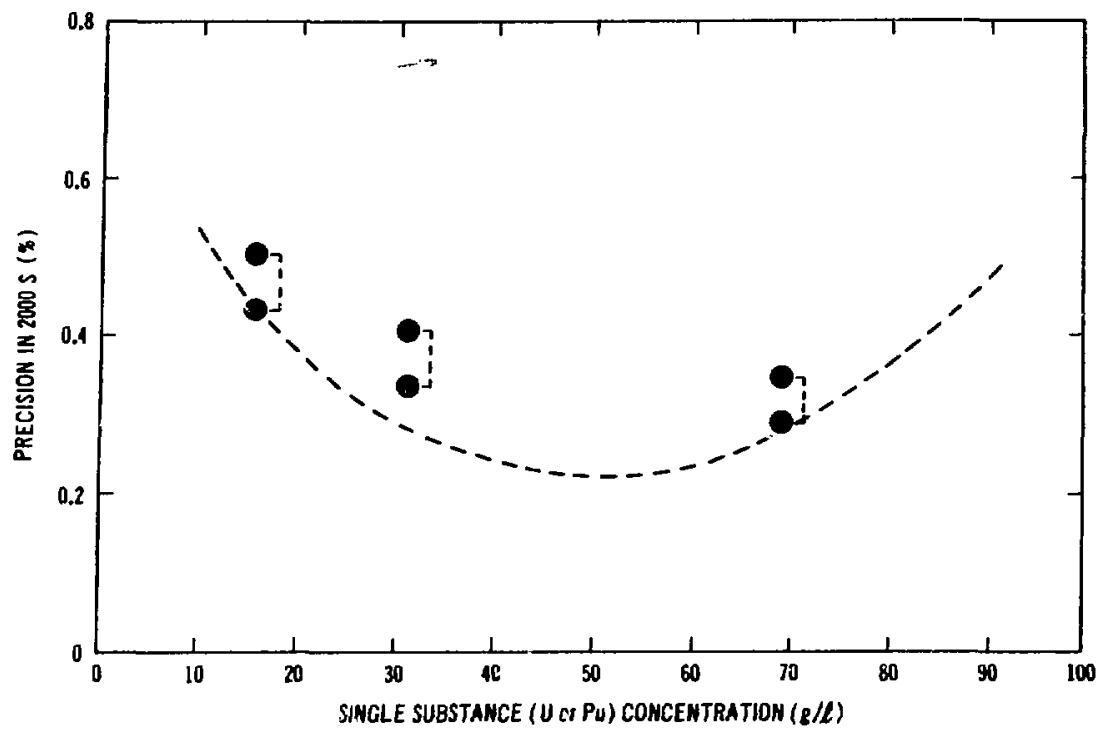

Fig. 16.

The precision for single-substance (uranium or plutonium) assays of 1000-s duration measured at Los Alamos with reference samples. Data were obtained at count rates of $15000 \mathrm{~Hz}$. The measured (upper) points were adjusted for the difference in the count rates used at SRL to give the lower points. The dashed lines illustrate the precisions measured at SRL in equivalent meg.surements.

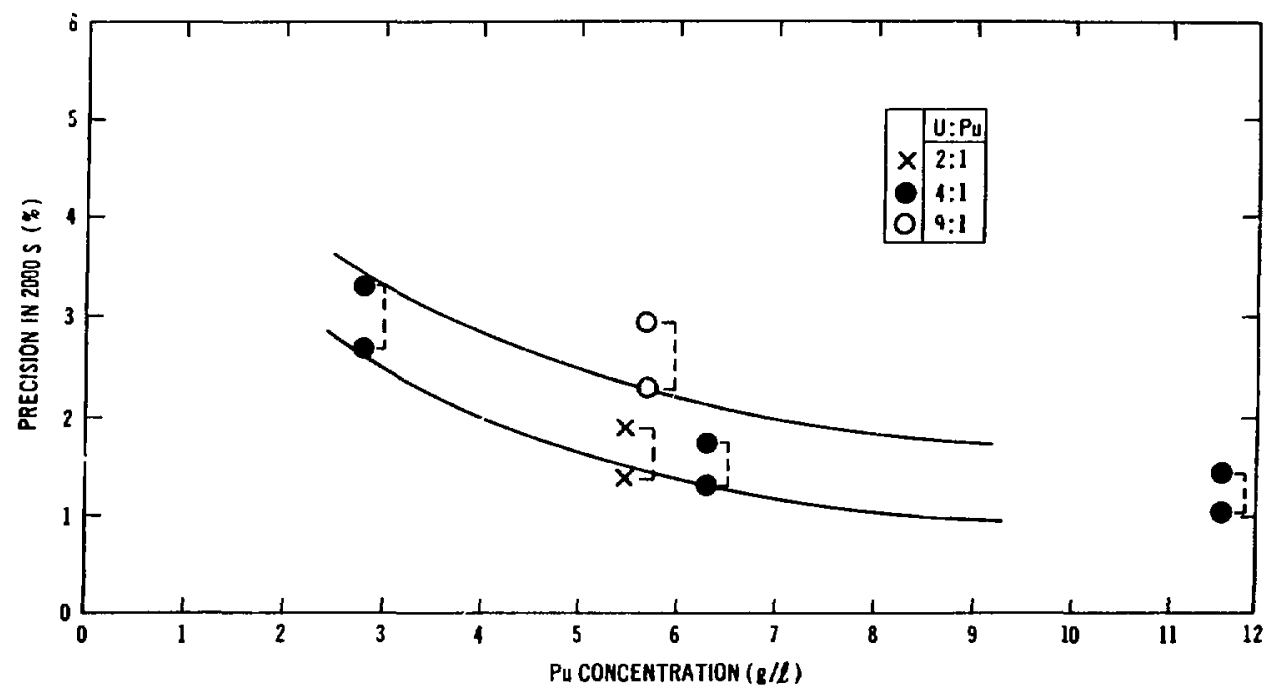

Fig. 17.

The precision for 2000-s assays of plutonium in mixed (uranium plus plutonium) samples of varying uranium/plutonium ratio plotted vs plutonium concentration. The caption for Fig. 31 describes the origin of the pairs of data points. Solid lines define the limits for similar aata obtained at SRL with uranium/phutonium ratios between 4 to 1 and 10 to 1 . 


\section{PART 2}

\section{CONTAINMENT AND SURVEILLANCE TECHNIQUES}

\section{FAST CRITICAL ASSEMBLY}

Neutron Monitoring of Plutonium Storage Vaults (J. T. Caldwell, S. W. France, R. D. Hastings, J. C. Pratt, E. R. Shunk, T. H. Kuckertz, and R. Goin)

About mid-1978, technical input to a conceptual study report entitled "Concepts for Inventory Verification in Critical Facility"22 was requested. Two separate technical proposals ${ }^{23}$ resulted. The first was aimed at rapid verification of reactor fuel drawers, and the second involved on-line monitoring of the plutonium contents in a storage vault. Both proposals subsequently were funded by Department of Energy/Office of Safeguards and Security (DOE/OSS) for technical development and evaluation. Technical developments of the first project recently have been reported. ${ }^{24}$ The present report discusses the status of development and evaluation of the second project, neutron monitoring of plutonium storage vaults.

At initiation of the project, the, zero-power plutonium reactor (ZPPR) plutonium storage vault [Argonne West, Idaho National Engineering Laboratory (INEL)] was used as the host site for required experimental measurements. We wish to acknowledge the cooperation and technical support provided by the ZPPR staff and the INEL criticality safety and vault security personnel.

Figure 18 shows the neutron monitoring system; 25 separate ${ }^{3} \mathrm{He}$ tubes are placed near the vault ceiling to detect neutrons emitted from stored plutonium. Plutonium in standard aluminum canisters is stored in concrete storage walls (see Fig. 18). Typically, each canister contains up to $3 \mathrm{~kg}$ of plutonium, and each horizontal storage location along the wall has slots for six vertical level storage places. At ZPPR, plutonium is stored on both sides of the wall, and during measurement times seven separate storage walls were in place. Figure 19 shows the ZPPR vault with dimensions and relative locations of the seven plutonium storage walls. Each cubicle ( 80 of these were used during the measurements)

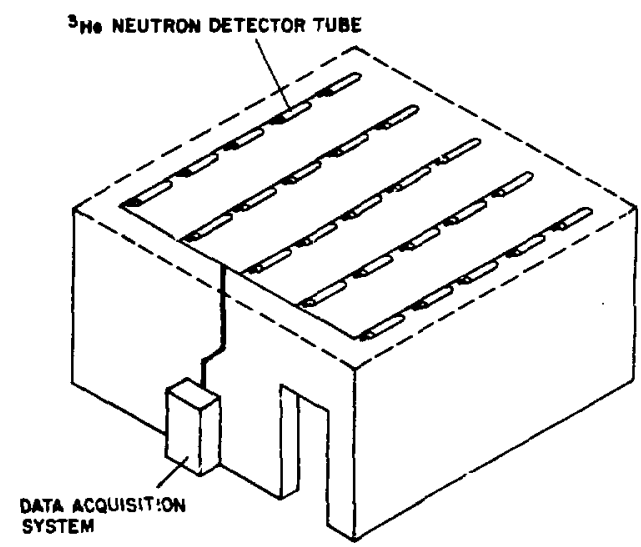

Fig. 18.

Plutonium storage vault with neutron monitors.

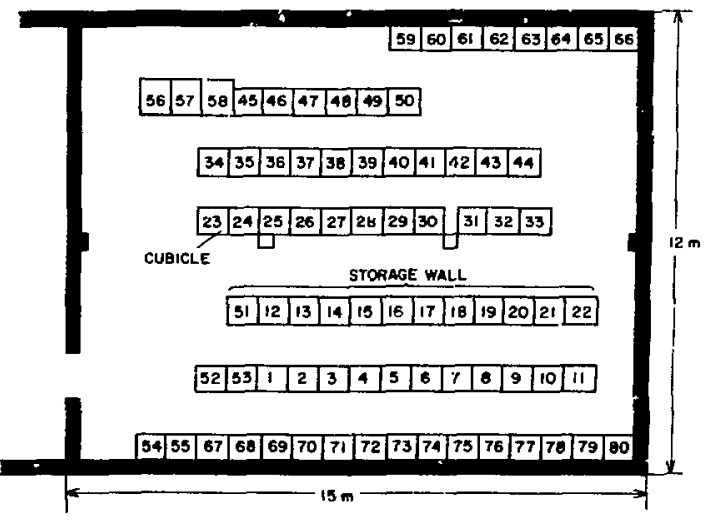

Fig. 19.

Plutonium storage vault. 
can store 24 plutonium-containing canisters. Thus, if required, the vault can be used to store as much as $\mathbf{5 7 6 0}$ $\mathrm{kg}$ of plutonium. Normally, lesser amounts are in storage at one time because many cubicles are filled only partially or are completely empty.

Initially, measurements were made using a grid of five ${ }^{3} \mathrm{He}$ proportional counters with commercially available modular individual counting electronics and scaler readouts. These instruments determined gross count rates, crude removal sensitivities, and optimum ${ }^{3} \mathrm{He}$ counter spacings required to maintain overall detection sensitivity throughout the vault. Analysis of these data led to the proposed detector array (Figs. 18 and 19), which has a grid of $25{ }^{3} \mathrm{He}$ proportional counters, each outfitted with individual counting electronics and scaler. This work completed the initial phase of the study. With the $25{ }^{3} \mathrm{He}$ counter array, $\pm 0.5 \%$ changes in the neutron count rate, or roughly the removal of $5 \mathrm{~kg}$ of plutonium from an inventory of $1000 \mathrm{~kg}$, could be reliably detected.

The project's next phase solved two technical problems: (1) the lack of inexpensive and reliable individual proportional counter counting electronics, and (2) the lack of a data acquisition system capable of handling 25 simultaneous scaler inputs and performing reasonably complicated on-line analysis.

An integrated circuit design that performed the electronic functions of preamplifier, amplifier, and discriminator, all contained within a 15.2-cm-long, $5.1-\mathrm{cm}$-diam package, was designed to mount directly to the end of a single $5.1-\mathrm{cm}$-diam ${ }^{3} \mathrm{He}$ proportional counter. Figure 20 shows one of these units, and Fig. 21 shows the unit mounted to a $5.1-\mathrm{cm}$-diam ${ }^{4} \mathrm{He}$ proportional counter.

Because the design uses common integrated circuit chips and thus has few individual electronic parts, it has a low total cost for both components and assembly. Thirty units were assembled at Los Alamos at a unit cost of about $\mathbf{\$ 3 5 0}$, which is almost an order of magnitude less than the price of standard nuclear instrument module (NIM) compatible preamplifier, amplifier, arıd discriminator units and occupies a fraction of their volume.

After a successful design was accomplished, 30 individual electronics packages (including 5 spares) were assembled at Los Alamos. Figure 22 shows the complete vault monitor set of $25{ }^{3} \mathrm{He}$ counters mated with electronic packages and with required cabling during the test and check-out phase at Los Alamos.

After carefully studying the data acquisition-storage-analysis-hard copy problem, we ascertained

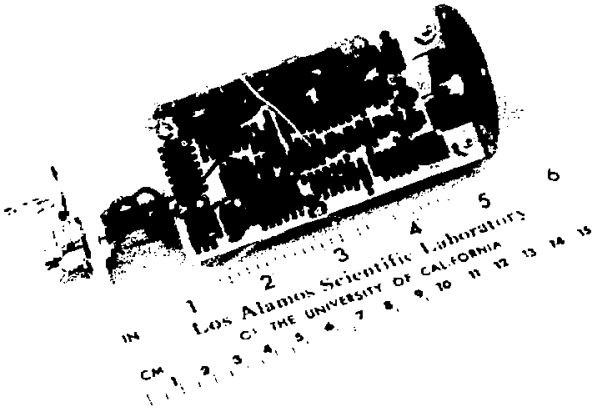

Fig. 20.

Electronics module for ${ }^{3} \mathrm{He}$ detectors.

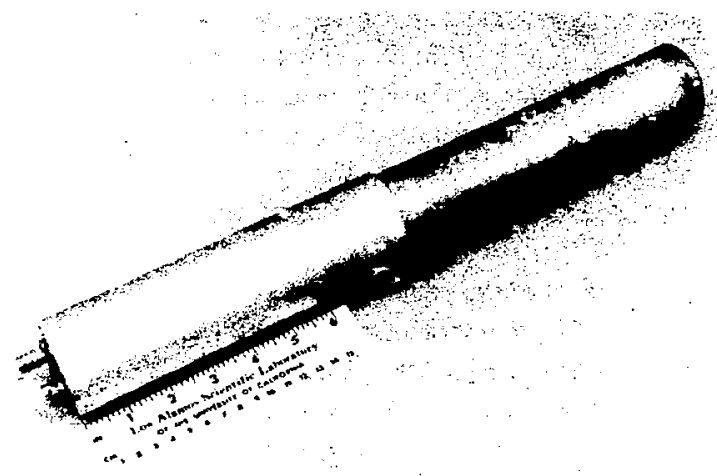

Fig, 21.

Complete ${ }^{3}$ He neutron detector assembly.

that all project requirements could be met with a commercially available data acquisition system (see Fig. 23). A unique feature of this system is its multiple scaler input module. In the space below the company name (see Fig. 23) and occupyin', a horizontal extent slightly smaller than that of the company name, all 25 scaler inputs from the detector !)ackages enter the data acquisition system. The data a:? processed simultaneously and in real time, with negligible deadtime losses fo: a total count rate up to $50 \mathrm{kHz}$.

After the complete vault monitor system was assembled at Los Alamos (Figs. 22 and 23), several weeks were spent in system check-out, including development of specific software to provide acquisition analysis, hard 


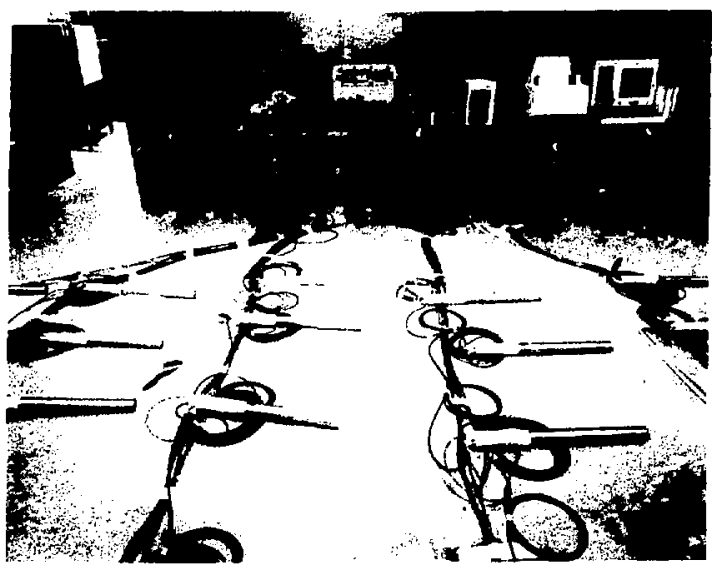

Fig. 22.

Test configuration of data gequisition system and 25 ${ }^{3} \mathrm{He}$ detectors.

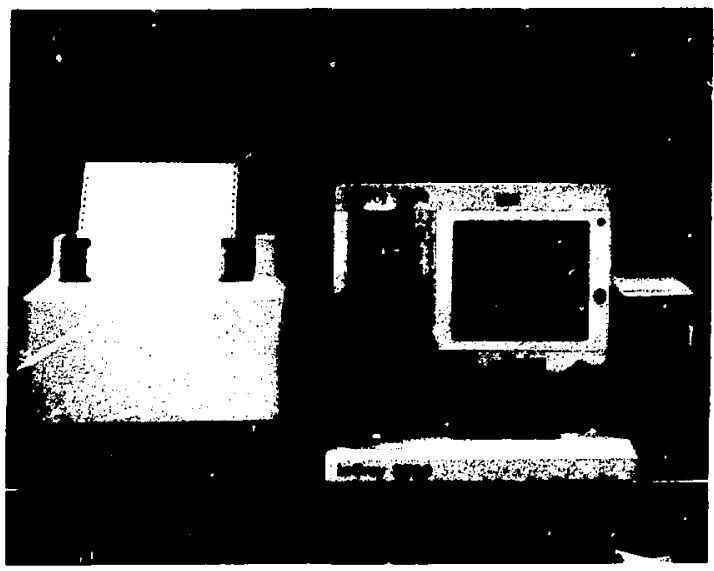

Fig. 23.

LeCroy $\mathbf{3 5 0 0}$ microcomputer data acquisition system.

copy, and disk storage of all data. One such program provides

- storage of the 25 proportional counter scaler values for a stated acquisition time;

- a least squares comparison of these 25 values to any previously recorded set of 25 values;

- calculation of the standard chi-square value for the set of 25 comparisons;

- hard copy from a paper printer (shown in Fig. 23, left side), including the printed matrix of 25 data values indexed to correspond to their geometric location (that is, a matrix minror of the detector array shown in Fig. 22); also printed out is the signed deviation of each detector scaler number calculated from its corresponding comparison record value, given in \pm siandard deviation units; and

- other hard copy, including total system count rate, elapsed time for the record, date and time, and other information.

Figure 24 shows a typical record of this type (the generating program is called VAULT). Th:s particular program is of special interest during check-out phases and for evaluating plutonium removal sensitivity.

After the check-out phase, INEL and DOE/Chicago granted permission to bring the system to the ZPPR plutonium storage vault for an extended in situ measurement and evaluation program, and in April 1980 the hardware was installed at INEL. Figure 25 shows an elevation view (both end and side) of the plutonium storage vault with some detail of the physical installation of the detector-electronics packages. The detectors were mounted in existing unistrut grooves, and all cabling was routed overhead to avoid operational impact.

Once the system was installed with data acquisition and power supply systems external to the vault, no perceptible impedance to normal vault operations occurred. However, plutonium removal sensitivity measurements did require the vault custodians to iemove stored plutonium from specific locations.

This measurement phase at ZPPR extended from April to December 1980. During this 8-month period, data were recorded almost continuously, except for brief down periods associated with power outages or power line surges that caused dead stops of the data acquisition system. After installation of a power filter system in June 1980 , the latter source of dead stops was eliminated. From Octuber to December 1980, the monitoring system was up continuously. In December 1980, all hardware was removed from the vault and returned to Los Alamos.

To serve as an effective plutonium mass sensing device, the overall neutron monitoring system stability must be excellent. As noted earlier, at the start of the program we thought a $\pm 0.5 \%$ system count rate stability over extended time periods could be achieved. This expectation was based on previous experience with reasonably large proportional counter systems, using nights and weekends for long-term stability studies. This level of stability was, in fact, achieved from the start of the ZPPR measurements. Figure 26 shows a typical 


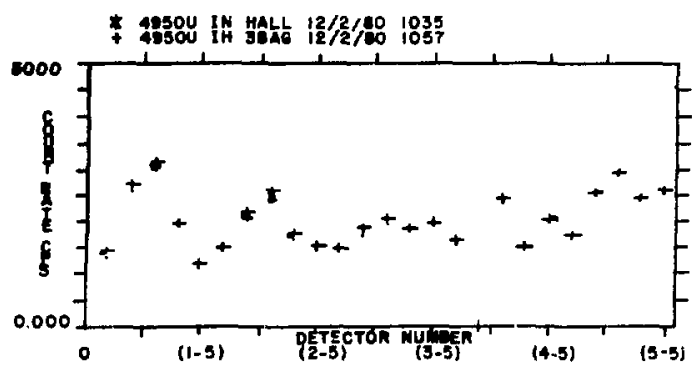

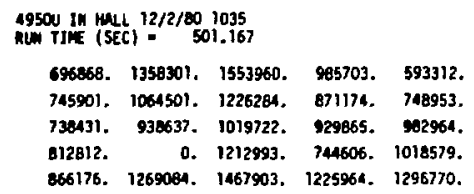

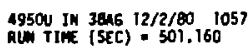

702982. 1372268. 1573999. 994584. 596737.

755796. 1090232. 1304269. 8886!3. 759392.

745256. 999046. 1034468. 936606. 957534.

617116. O. 1226514. 750622. 1023850.

869335. 1277356. 1473758. 1229924. 1301584.

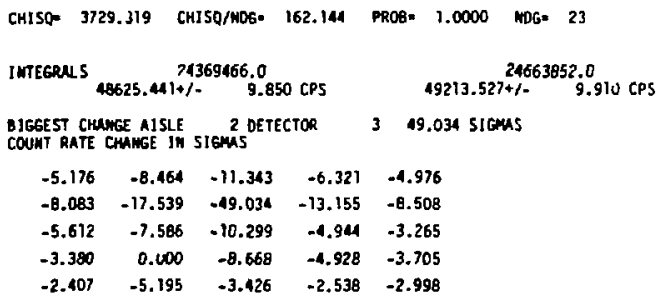

count rate record obtained during the evening and early morning hours of June $13-19,1980$. This record covers about $13 \mathrm{~h}$ and shows the summed count rate from all 25 detectors on a greatly expanded scale. The full vertical scale covers the count rate range from 51720 to 52040 cps, or a $\pm 0.3 \%$ variation from the mean count rate. The actual excursions cbserved were less than $\pm 0.3 \%$; typically, the count rate stability was $\pm 0.25 \%$ for overnight and weekend runs (that is, during periods when no power outages or surges occurred).

This stability was twice as good as initially had been hoped for and corresponds roughly to the capability of detecting $2.5 \mathrm{~kg}$ of plutonium removed from a vault inventory of $1000 \mathrm{~kg}$.

However, detailed examination of the count rate histories of individual detectors (all data from each
Fig. 24.

Typical output page from VAULT. detector were recorded on disk) revealed that most drift typified by the record of Fig. 18 was attributable to large fluctuations in just a few detectors. Subsequent tests also showed that the single high-voltage power supply (HVPS) used to provide anode high voltage to all $25{ }^{3} \mathrm{He}$ proportional counters was undergoing small but significant high-voltage output drifts, generally on a diurnal cycle and in apparent response to slight room-temperature variations.

At this point, we tried to significantly improve system stability. A highly stable HVPS (high-voltage drift specification 10 times better than the previously used HVPS) was obtained and installed at ZPPR. At the same time, all electronics units were rechecked and those needing change were either gain and threshold adjusted or replaced with available spare units. 

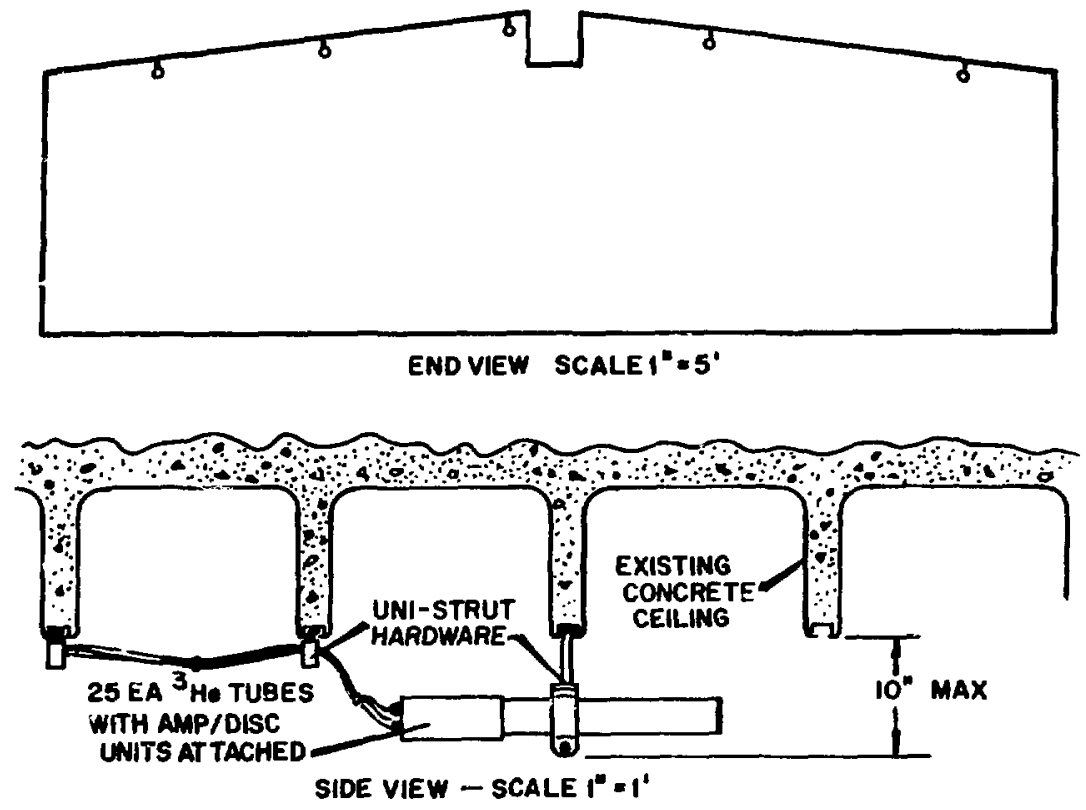

Fig. 25.

Installation detail of neutron detectors.

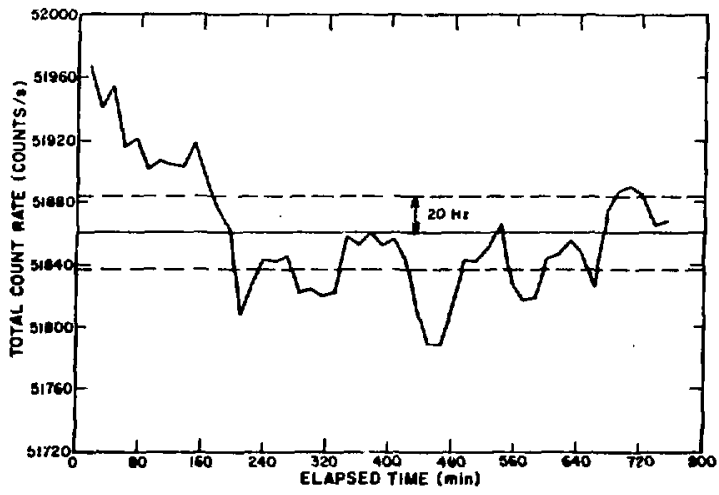

Fig. 26.

Stability experiment of June 18-19, 1980, using all detectors.

The resultant system stability is shown in Fig. 27, a typical 18-h record obtained during the evening and early morning hours of December 1-2, 1980. The full vertical scale range is 50600 to 50920 , or a gain of about $\pm 0.3 \%$ range around the average. The marked periodic fluctur+ions are apparent and curious to say the least. The overall experimental count rate stability is about $\pm 0.12 \%$, a considerable improvement, however. Examination of the individual detector records of those data indicate that almost all the observed fluctuation was associated with detector $(4,2)$. Figure 28 shows the same data as Fig. 27, with the contribution from detector $(4,2)$ arbitrarily set to zero. That is, the stability of the set of 24 detectors excluding $(4,2)$ is shown. Consequently, the fluctuation band is reduced to about $\pm 20 \mathrm{cps}$ around an average value of 49030 . This count rate stability of $\pm 0.04 \%$ is very close to the expected fluctuation pattern for purely statistical fluctuations. The low values at start and finish of both Figs. 27 and 28 are artifacts of the plotting process and should not be considered in evaluating system stability.

Figure 29 shows similar data $[(4,2)$ set to zero] for a longer continuous monitoring period-65 h recorded Juring the Thanksgiving holiday period starting November 26, 1980. The fluctuation band in Fig. 29 again covers a $\pm 0.04 \%$ range. Similar records were obtained for most extended monitoring periods following our last system improvement. However, some notable irregularities were observed during a few monitoring periods. Though not totally understood, they appear to be associated with line power fluctuations that penetrate our line power filter unit. 


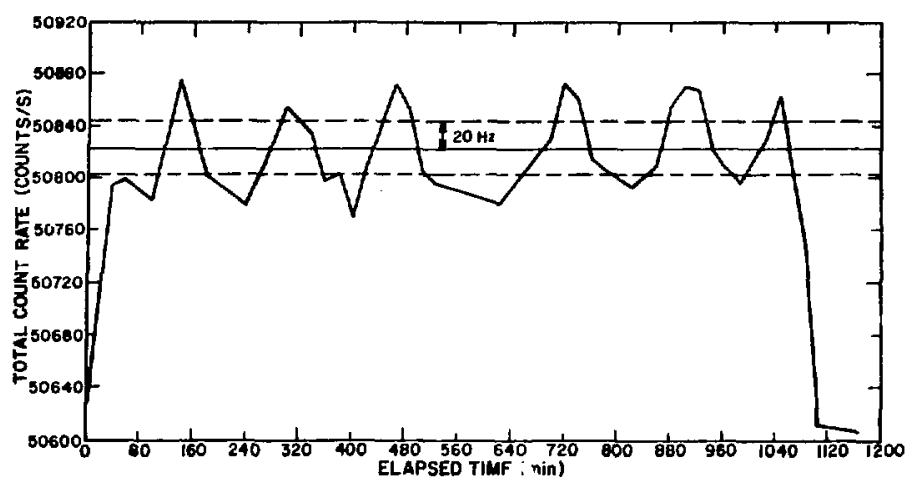

Fig. 27.

Stability experiment of December 1-2, 1980, using all detectors.

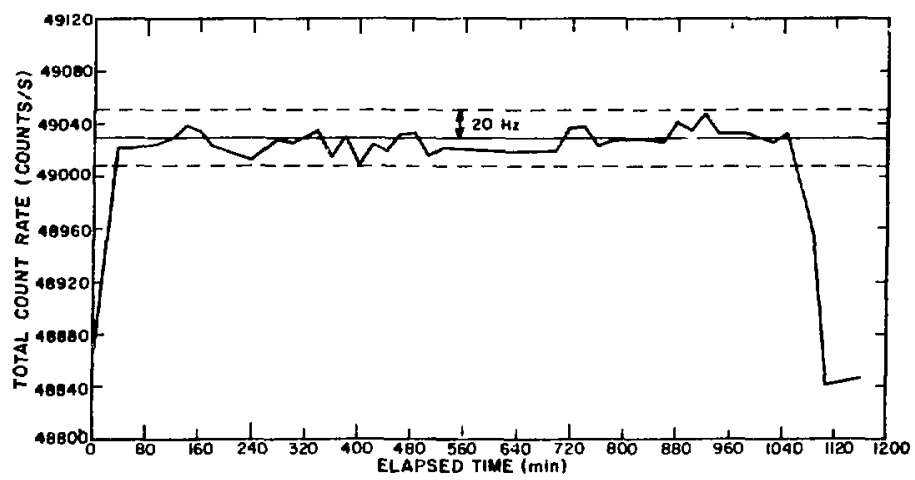

Fig. 28.

Stability experiment of December 1-2, 1980, excluding detector $(4,2)$.

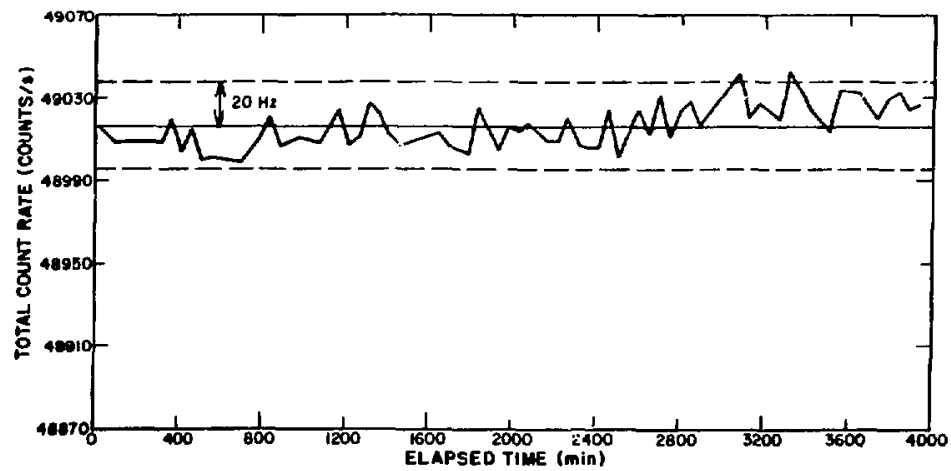

Fig. 29.

Stability experiment beginning November 26,1980 , excluding detector $(4,2)$. 
A clear implication of the system count rate stability studies, supported by the 24 detector system stability records taken during 2 months of no system maintenance, is that neutron monitoring of a plutonium storage vault can be done at the \pm 0.04 to $\pm 0.05 \%$ stability level, or 10 times better than our initial projections. Thus, detection of plutonium removals on the order of $1 \mathrm{~kg}$ from a vault total inventory of $2500 \mathrm{~kg}$ appears possible.

Many direct plutonium removal sensitivity measurements were performed during the 8-month period the detection system was installed at the ZPPR plutonium storage vault. These data have not been completely analyzed, but data analyzed to date indicate the following.

- The lowest five vertical storage locations within a given cubicle have about the same removal sensitivity. The actual removal sensitivity value is reasonably constant for all 80 cubicles in the vault, with an average value of about $20 \mathrm{cps}$ count rate change for removal of $1 \mathrm{~kg}$ of standard ZPPR fuel.

- The top vertical storage location yields almost twice this sensitivity, or about $40 \mathrm{cps}$ count rate change for removal of $1 \mathrm{~kg}$ of standard fuel.

- A plutonium removal from a top storage location is easily distinguished from a removal from the other five locations because top location removals lead to spatially peaked count rate distributions, with the nearest detectors responsible for most observed change in count rate. On the other hand, the lower locations lead to relatively flat count rate distributions with larger contributions from more spatially remote detectors.

Figure 30 shows shape fit analysis of plutonium removal data from two different storage cubicles. The quantity $\mathbf{X}^{2}$ divided by count rate change is plotted as a function of vertical storage location. All data show the effects of removing the same plutonium mass from each location, leaving all other contributors to the observed count rate constant. The plot shows decreasing ordinate values as plutonium is removed from successively lower storage locations. Only the topmost location value is greatly different. This difference is expected for spatially peaked distributions because the corresponding $\mathrm{X}^{2}$ values weight the individual detector excursions as the square of the excursion, leading to a much larger $\mathbf{X}^{2}$ for a given total count rate change if that count rate change occurs primarily in a few detectors rather than in many.

The practical import of this observation is that an unknown change in system count rate can be attributed

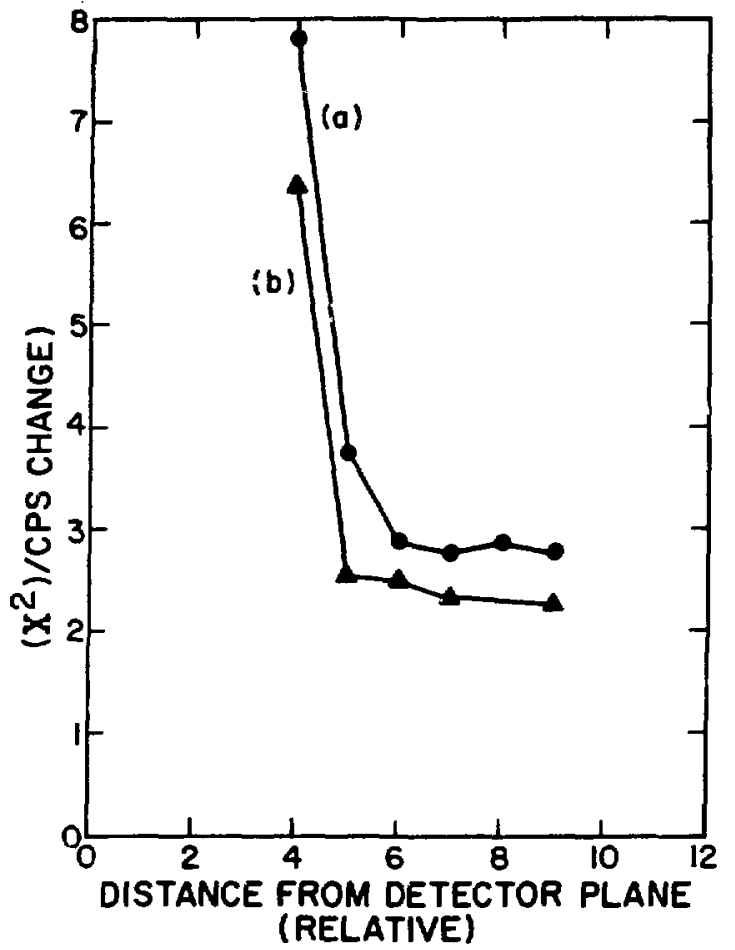

Fig. 30.

Shape fit analysis of plutonium removal; (a) indicates removal from cubicle 13 , and (b) indicates removal from cubicle 38.

to a removal from a topmost storage location or from one of the other five vertical locations based on the observed $\mathrm{X}^{2}$ divided by $\Delta$ count rate value. With this information, we may uniquely interpret a given $\Delta$ count rate in terms of a missing plutonium mass.

For example, a $\Delta$ count rate of 40 eps corresponds to a removal of $2 \mathrm{~kg}$ of plutonium if the $X^{2}$ divided by $\Delta$ count rate value is about 3 , but it corresponds to a removal of $1 \mathrm{~kg}$ of plutonium if $X$ divided by $\Delta$ count rate is $\geq 6$. This difference will be significant if a neutron monitoring system, such as a semi-quantitative real-time vault plutonium inventory device, is used. Much detailed calibration data would be required to use a neutron-based plutonium vault monitoring system in this fashion. However, based on our measurements, a $\pm 1 \mathrm{~kg}$ out of $2500 \mathrm{~kg}$ inventory could be maintained in real time with this system, if all transactions were accounted for. 
The feasibility of neutron proportional counter monitoring of a plutonium storage vault has been demonstrated successfully, as have count rate stability at the \pm 0.04 to $\pm 0.05 \%$ level for extended periods of time and a removal sensitivity of about $1 \mathrm{~kg}$ of $Z P P R$ fuel from a nominal vault loading of $2500 \mathrm{~kg}$. This sensitivity applies to removal from any storage location within the vault and is based on the use of approximately $4000-\mathrm{s}$ counting periods. The statistically expected 1-kg trip level false alarm rate for this situation is about one false alarm per $2 \mathrm{yr}$ of continuous monitoring. Experiences over an 8-month period, from neutron monitoring with actual hardware in a real plutonium storage vault, indicates that with only modestly improved hardware we can achieve this predicted false alarm level.

\section{AUTOMATED INVENTORY TEST AND EVALUATION}

Real-Time Inventory (N. Nicholson, J. D. Atencio, and T. H. Kuckertz)

1. Shelf Monitor Test and Evaluation. The three separate shelf monitor arrays, two at Pajarito Site and one at the TA-55 Plutonium Storage Vault, have been operational for approximately 15 months. Eighty monitors in the TA-55 vault are linked by telephone to the Data General NOVA 3 computer at TA-18, Pajarito Site. The other two array? at Pajarito Site also are linked to the Data General NOVA 3 by telephone. The data transmissions between these arrays and the computer have heen error free during the 15-month test and evaluation.

ГA-18 has the highest component failure rate of the thiee arrays; seven monitors have stopped transmitting data. The failure in each case was caused by a Universal Synchronous/Asynchronous Receiver/Transmitter (USART) chip. This same chip caused almost every failure during the initial burn-in period. The manufacturer has acknowledged that early batches of these chips were defective and that Los Alamos probably received one of these batches. Another cause of problems is the oscillator chip; it is fragile when subjected to a small static charge and is the most likely circuit element responsible for unstable scale operation in several monitors. Two gamma detectors [Geiger-Muller (G-M) tubes] stopped operating during this period, and one other has behaved erratically.

2. Weight Sensors. The parallel plate and spring weight sensor was chosen for the shelf monitor because of its low cost and its transparency to gamma radiation. Although this sensor has worked satisfactorily, its recognized shortcomings, such as large dimensions and the use of four coil springs, are incentives to continue searching for an alternative. Experiments were con- ducted to determine the feasibility of replacing the spring mechanisms with another type of weight sensor. We investigated two possibilities: strain gauges and piezoresistive sensors.

A strain gauge is used to accurately measure weights and pressures and usually is built into a load cell incorporated into the weight or pressure measuring apparatus. A literature search has shown that a load cell capable of making the weight measurements would cost more than \$200, an unreasonable cost for these shelf monitors.

A piezoresistive compound (Pressistor ${ }^{\mathrm{TM}}$ ) manufactured by Innovation Laboratories of College Station, Texas, appeared to offer the second alternative. A thin film of Pressistor ${ }^{\mathrm{TM}}$ compound changes its dynamic resistance with increasing pressure on the film. Two experimental arrangements were used to study the properties of this compound: a rod and plate arrangement and overlapping plates. Various weights were placed on a brass rod in contact with a Pressistor ${ }^{\mathrm{TM}}$ film. The dynamic resistance of this junction was measured as a function of the mass placed on the rod. Whenever a load was placed on the bar, a change in the resistance of the material was observed. Unfortunately, this change in resistance was not reproducible. Because the resistance of the material is exponentially related to the applied pressure, the variation in observed resistance using the same loading was as high as a factor of 10 . Several different film thicknesses and curing conditions were tried to reduce these variations, but they were unsuccessful. None of the expected piezoresistive properties were observed using this configuration. As a result of these studies, we concluded that this piezoresistive material is not a suitable substitute for the parallel plates and springs now used as weight sensors in the shelf monitor. 
3. Cadmium Telhuride Detectors. Although the G-M tubes and their associated circuitry have performed well, we wanted to eliminate the 450 -Vdc power source that must be bussed to each detector. Cadmium telluride (CdTe) crystals are available in a $2-\mathrm{mm}$ cube that can operate with a S-V bias. Sixteen CdTe detectors, complete with the circuitry required to supply a logic pulse to the microcomputer, were obtained for evaluation. These crystals are less expensive than the normal high-quality CdTe detectors used for obtaining gamma spectral information. The less expensive detectors are rejects from the high-quality detector production but still can be used to measure total gamma flux. They were expected to be good substitutes for G-M tubes from the standpoint of gamma efficiency, count rate, and expected lifetime.

The CdTe detectors were subjected to two types of testing to determine their performance characteristics. A bench test of each detector was made separately, followed by a test of the detector integrated into a functioning shelf monitor. The count rates observed with individual detectors varied greatly for the same source. In the shelf units, the gamma count rates also varied by orders of magnitude, and some detectors produced very high count rates.

is a result of these investigations, the following conclusions were reached.

- CdTe detectors will be more expensive to buy and to use than G-M tubes.

- Even though a solid-state detector is more efficient per unit volume than a G-M tube to gamma radiation, the small CdTe chips resulted in few net counts.

- CdTe detector count rates exhibited a much larger variance than those of the G-M tubes.

- CdTe detectors will operate with a bias of $5 \mathrm{~V}$. However, the high gain requirel as a consequence results in a serious noise problem.

- The additional adjustment required for each shelf monitor using CdTe is a serious drawback.

The general conclusion is that the CdTe detector is not a suitable replacement for the G-M tube used in the shelf monitor.

\section{WASTE MANAGEMENT MEASUREMENTS}

\section{A. Electron Linac Based Transuranic Waste Assay (J. T. Caldwell, W. E. Kunz, and J. C. Pratt)}

Measurements were made recently at the EG\&G Santa Barbara electron linac to evaluate use of $12-\mathrm{MeV}$ electron bremsstrahlung to assay or screen transuranic (TRU) waste imbedded in two typical but difficult matrices: concrete and bitumen (asphalt). Barrels of $208 \ell$ filled with concrete and bitumen were used for this purpose. A preliminary evaluation of these data indicates that TRU contained in concrete matrices can be assayed accurately and with better than $10-\mathrm{nCi} / \mathrm{g}$ sensitivity using 12-MeV bremsstrahlung photofission. In the worst case (TRU samples placed at the geometric center of a barrel of concrete), the detected delayed neutrons from photofission were reduced about a factor of 8 relative to the empty barrel case. The radial variation in delayed neutron yield was within a band of $\pm 25 \%$ in comparing yields from the barrel center, the mid-radial region, and the outer-radial region. With suitable barrel rotation and neutron detector optimization, routine photofission assay of TRU within concrete matrices appears feasible. In recent unoptimized measurements, the experimental 3- $\sigma$ detection limit at the center of a 208- $\ell$ barrel of cement was about $20 \mathrm{nCi} / \mathrm{g}$ for plutonium samples. $A$ more efficient neutron detection system (the differential die-away neutron detection system, for instarce, is 10 times more efficient than that used for these measurements) would easily result in $10-\mathrm{nCi} / \mathrm{g}$ sensitivity.

Unfortunately, the situation for bitumen is not so optimistic. The observed delayed neutron yield for TRU samples placed at the geometric center of a $208 \ell$ barrel of bitumen is reduced by a factor of about 1000 relative to the corresponding yield in an empty barrel. The main effect appears to be gross neutron attenuation in transport from the barrel center to the external neutron detection system. (A ${ }^{252} \mathrm{Cf}$ neutron source placed at the bitumen barrel center produced $\mathbf{4 0}$ times fewer detector counts than the same source in an empty barrel.) Thus, TRU waste assay within a bitumen matrix appears to be very difficult, and a solution is not readily apparent. 
B. Differential Die-Away Pulsed Neutron Assay System (W. E. Kunz, J. D. Atencio, J. T. Caldwell, W. Bernard, and G. C. Herrera)

Earlier reported measurements with our proof-of-principle differential die-away system ${ }^{23-27}$ have established firmly the milligram level fissile assay sensitivity of the technique. The design and construction of a fieldable version of this system recently have been completed, incorporating features developed with the proof-of-principle system.

The prototype fieldable system is constructed with basically the same graphite and polyethylene layers described in Refs. 26-28. One side of the system has been made into an easily opened door to facilitate placement of TRU waste or scrap-containing barrels. This system is designed to accommodate all barrels, boxes, etc. up to and including the standard 208- $\ell$ size. Each side (including the door) contains a main detector pod consisting of a cadmium-wrapped package of three $91-\mathrm{cm}$-long by 5-cm-diam with 3-atm-fill-pressure ${ }^{3} \mathrm{He}$ proportional counters moderated by a 1.3-cm-thick layer of polyethylene. In addition, two shorter ${ }^{3} \mathrm{He}$ counters (also polyethylene moderated and externally wrapped in cadmium) are placed at the top and bottom of each side. The latter detectors serve principally for vertical sensitivity flattening.

Figure 31 shows the observed assay sensitivity with the new system for ${ }^{233} U$ samples placed at the assay chamber center and with the neutron generator operated for 4000 pulses (less than 100-s elapsed time). As can be seen, a tinear response with ${ }^{233} \mathrm{U}$ mass is obtained. The experimental 3- $\sigma$ detection limit for these data is $1.3 \mathrm{mg}$ ${ }^{233} \mathrm{U}$. The corresponding 3- $\sigma$ detection limit for ${ }^{239} \mathrm{Pu}$ is $0.9 \mathrm{mg}$.

In Fig. 32, (a) shows the experimental response to a standard ${ }^{23} U$ sample as a function of vertical position within a standard 208- $\ell$ barrel filled with density 1.0 $\mathrm{SiO}_{2}$. These data have been normalized to a constant interrogating thermal neutron flux by dividing the observed prompt fission neutron response by the observed thermal neutron flux monitor counts. The raw response is reasonably flat, and all observed data fall within a $\pm 20 \%$ band about the average value. The vertical response data were taken at three separate radial locations as indicated in the figure caption.

In Fig. 32, (b) shows the corresponding set of data for the ratio of top detector to bottom detector counts. The very strong dependence on vertical position is obvious. With this ratio, we may correct the total detector

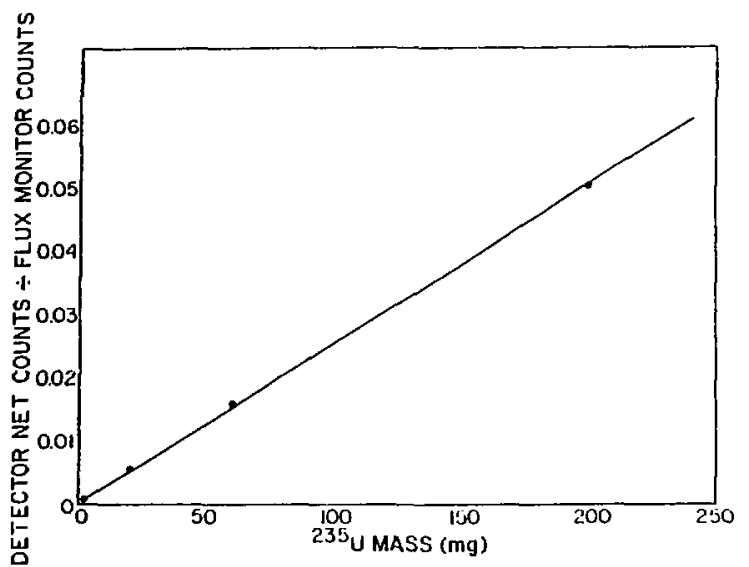

Fig. 31.

The differential die-away system linearity. The experimental 3- $\sigma$ detection limit for these data is $1.3 \mathrm{mg}$ ${ }^{235} \mathrm{U}$.

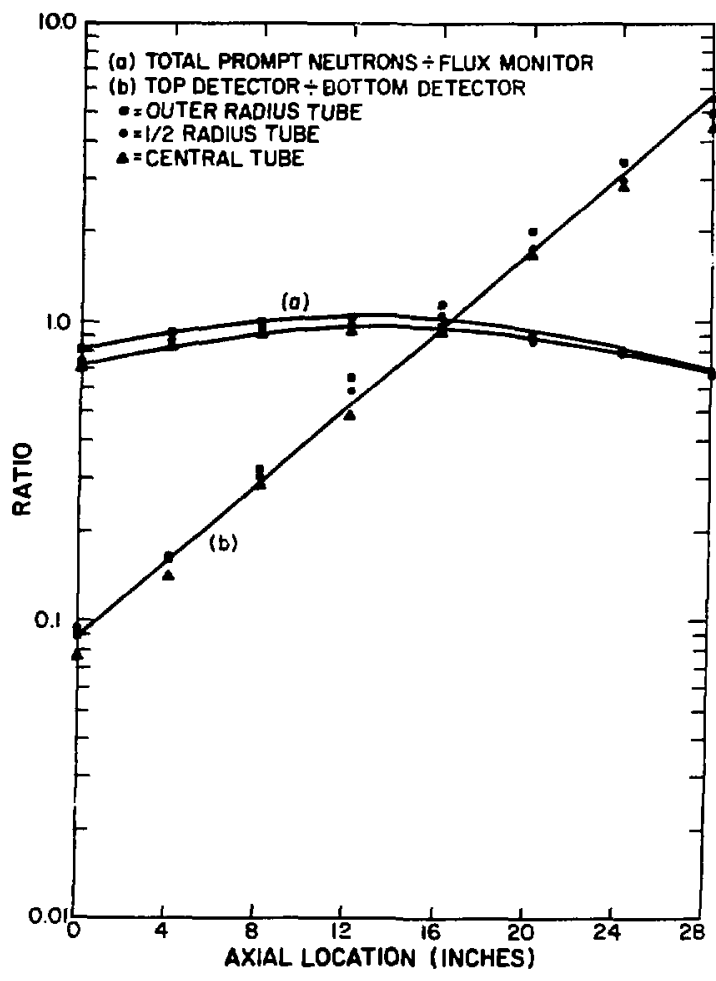

Fig. 32.

Curve (a) shows the experimental response to a standard ${ }^{235} \mathrm{U}$ sample as a function of vertical position within a standard $208-t$ barrel filled with density 1.0 $\mathrm{SiO}_{2}$. Curve (b) shows the corresponding set of data for the ratio of top detector to bottom detector counts. 
response: for the sensitivity change caused by height variation. If applied routinely to assay data, this correction should result in an overall flatness of response (includine, vertical and radial effects) of \pm 5 to $10 \%$. For these ineasurements, an internal barrel rotating mechanism was used, which will be a permanent feature of the fieldable system.

The differential die-away system, which recently was shipped to the Pantex Plant at Amarillo, Texas, completed an assay campaign on 21 barrels containing miscellaneous TRU waste from the nuclear weapon accident residue (NWAR). The contents of 10 barrels were certified as either being below the $10-\mathrm{nCi} / \mathrm{g}$ fiducial or containing only depleted uranium. This certification was possible through a combination of active and passive measurements with our detection system.

A series of prompt-to-delayed ratio measurements with our pulsed neutron system recently has been completed. (Prompt events are recorded typically 0.6 to $4.5 \mathrm{~ms}$ following a pulse, and delayed events are recorded 15 to $30 \mathrm{~ms}$ following a pulse.) A prompt-to-delayed ratio generally will be measurable if $100 \mathrm{mg}$ or more fissile material is present in a container. Fissile isotope identification is possible using prompt-to-delayed ratios; the ratio is 156 for ${ }^{235} \mathrm{U}, 385$ for ${ }^{233} \mathrm{U}$, and 472 for ${ }^{239} \mathrm{Pu}$. These measurements will facilitate assay of mixed fissile wastes.
C. NWAR Field Trip (J. T. Caldwell, H. H. Hsu, E. R. Shunk, J. M. Bieri, S. W. France, and R. D. Hastings)

The first field trip to the Pantex Plant to perform measurements on NWAR was accomplisied the week of September 29. Equipment included $11 \% \mathrm{HPGe}$, a ${ }^{3} \mathrm{He}$ slab detector, and ' $\mathrm{He}$ detectors. Four independent measurements were performed: (1) high-resolution gamma spectra, (2) absolute passive neutron output, (3) passive neutron spectra, and (4) active neutron induced fission (using americium/lithium source and ${ }^{4} \mathrm{He}$ detector). These measurements were performed on 21 barrels and 8 large plywood boxes of NWAR.

Results were good and served to screen the 29 NWAR containers by approximate contents so that more comprehensive and accurate measurements may be performed when appropriate. The 29 containers are from four separate weapons accidents. In addition, there are five barrels of undocumented, unidentified residue.

A preliminary analysis of the screening data is consistent with known (or suspected) contents where documentation exists. No unforeseen problems with performing the quantitative assay of the NWAR as stated in the original work proposal are apparent.

\section{PART 3}

\section{SAFEGUARDS SYSTEMS AND TECHNOLOGY TRANSFER}

\section{SAFEGUARDS CONCEPT DEFINITION FOR FUEL CYCLE FACILITIES}

\section{A. Enrichment Plant Safeguards (D. B. Smith and D.} Stirpe)

The results of a study of materials accounting at the Portsmouth Gas Centrifuge Enrichment Plant were published as Los Alamos National Laboratory report LA-8651-MS, "A Preliminary Report of Short-Term Materials Accounting at GCEP."2s
B. Los Alamos Plutonium Facility: Plutonium Metal-to-Oxide Conversion and Purification Process (C. C. Thomas, Jr., C. A. Ostenak, R. G. Gutmacher, H. A. Dayem, and E. A. Kern)

A draft of "Materials Measurement and Accounting in an Operating Plutonium Conversion and Purification Process, Phase I: Process Modeling and Simulation" was 
prepared and will be submitted for publication as a Los Alamos informal report. ${ }^{29}$

The process model and simulation program were modified to include controlled atmosphere rather than air oxidation of the plutonium metal buttons feeding the TA-55 fast flux test facility process line. The modification was intended to determine the effect of an alternative button burning process on total plutonium throughput. The simulation results indicated a $44 \%$ increase in throughput over the current air-oxidation process. Recommendations for future efforts at TA-55 include (1) investigating the potential effects of other process modifications, (2) modeling the existing materials measurement system, (3) examining methods for measuring in-process inventory without shutdown and cleanout, (4) evaluating alternative measurement and accounting strategies using simulated materials balance data, and (5) comparing simulated data with actual process data.

C. Implementation of Near-Real-Time Accounting at TA-55 (J. J. Malanify)

Implementation of the DYMAC system at the new Los Alamos Plutonium Processing Facility occurred in three phases over 5 yr. Phase I, which was a limited test and evaluation study conducted at the old Los Alamos plutonium facility, tested the basic principles of near-real-time accountability in a working environment. ${ }^{30}$

The success of the initial phase led to Phase II: the design, fabrication, and installation of the DYMAC system at the new plutonium facility, including routine operation and transfer of responsibility. Phase II extended from March 1977 through 1980, at which time the essentially completed and functioning DYMAC system was turned over to the facility operator. ${ }^{31}$

Phase II evaluates system performance. This system, now designated the Plutonium Facility/Los Alamos Safeguards Systems (PF/LASS), has enhanced nuclear materials accountability and process ccntrol. ${ }^{32}$ The nondestructive assay instruments and the central computer system are operating accurately and reliably. As anticipated, several uses of the system have evolved in addition to safeguards, notably scrap control and quality control. The successes of this experiment strongly suggest that implementation of DYMAC-based systems should be attempted at other facilities.
D. Advanced Materials Accounting System Demonstration at Allied-General Nuclear Services (D. D. Cobb, A. L. Baker, and H. A. Dayem)

Since April 1981, Allied-General Nuclear Services (AGNS) has conducted five miniruns with Los Alamos Safeguards Systems Group and Oak Ridge National Laboratory (ORNL). The miniruns have been week-long experiments that processed natural uranium through the plutonium purification area to simulate operating plant conditions. Some of these experiments involved clandestine diversions designed to test the diversion-detection capabilities of various safeguards approaches.

The Safeguards Systems Group developed a technique for estimating in-process inventories in pulsed columns that was tailored for use at AGNS and designed near-real-time accounting strategies for AGNS based on existing process control instrumentation. Using the in-house computerized data acquisition system at AGNS, sufficient measurements, such as densities, flows, and levels, were selected and characterized to draw materials balances about several unit-process accounting areas once every hour. The advanced data analysis codes, developed by the Safeguards Systems Group, that combine sequential testing procedures with color graphics displays of the results also were adapted, installed, and operated.

The fifth minirun experiment, held at AGNS from November 17-21, 1980, was scheduled to coincide with a DOE Contractors' Review Meeting at AGNS. After start up the process operated smoothly, and the period from Tuesday afternoon, November 18, through Friday, November 21, may provide the best set of baseline steady-state data obtained to date. A protracted-diversion test from the IBP tank covered the 24-h period from midnight Tuesday to midnight Wednesday. Also, one or more small removals from static product storage tanks occurred Friday morning.

In addition to collecting and analyzing the minirun data, a briefing to about 50 DOE representatives and other contractors described our participation in the miniruns. Friday morning the visitors toured the minirun work stations. In the control room at the Los Alamos work station the visitors were briefed on the Los Alamos National Laboratory Group Q-4 data analysis methods that use color graphics displays of up-to-date results.

During the protracted-diversion test from the 1BP tank, materials balances were analyzed from the $1 B P$ 
tank to the product sample tank, including the inventory in the pulsed columns and the product concentrator in the balance. These balances showed the diversion clearly and appeared to give good results when no diversion existed.

A new pulsed-column inventory estimator was implemented during the November run. After start up the total uranium inventory in the pulsed columns stabilized at approximately 30 to $35 \mathrm{~kg}$ (estimated) and remained essentially constant at that level throughout the run. Friday afternoon the columns were valved off for a column-dump experiment in which the columns were drained and the contents were analyzed for total uranium in the aqueous and organic phases. AGNS is preparing a memorandum describing the results of this column dump. The results will be compared with the inventory estimated during the run and with calculations using the Burkhart/Iowa State pulsed-column model.

There will be three additional miniruns in $F^{\prime \prime} 1981$. These techniques will be refined further and additional aspects of the near-real-time accounting approach will be tested.

E. Design of Integrated Materials Control and Accounting and Physical Security Safeguards (E. A. Hakkila, J. P. Shipley, K. G. Gutmacher, J. T. Markin, and W. J. Whitty)

A Los Alamos-Sandia National Laboratories (SNL) task was initiated to develop detailed integrated safeguards concepts for materials accounting, materials control, physical protection, and process operations. A series of meetings between Los Alamos and SNL personnel defined safeguards functions, objectives, and threat categories for this study; categorized facility and materials forms that are important for materials control and accounting and for physical protection systems; and established possible approaches to interfacing physical protection, materials control, materials accounting, and facility operation as a step toward designing integrated systems. A Los Alamos-SNL briefing describing this first phase of the project is being prepared for DOE/OSS.

F. Safeguards Systems Design for the Fuels and Materials Examination Facility (D. D. Cobb and R. G. Gutmacher)

Los Alamos National Laboratory has started a review of the complete safeguards system (including physical protection, materials control and accounting, process control, health and safety, and data acquisition and processing systems) for the Fuels and Materials Examination Facility (FMEF) being constructed by the Hanford Engineering Development Laboratory (HEDL) at Richland, Washington. The FMEF will contain several fabrication lines and fuel examination facilities, including the secure automated fabrication (SAF) line.

Allowable accuracy figures specified by HEDL for measurements for the MOX fuel fabrication process in the SAF line were examined. The allowable accuracies (that is, total combined error) for most of the weight measurements cannot be met if weigh hoppers and load cells are used. Accuracy figures that are reasonable under specified operating conditions were calculated and transmitted to HEDL.

A preliminary report reviewing the overall FMEF safeguards design will be provided to HEDL in June 1981. Based on that report, potential vulnerabilities will be identified and a revised work plan will be developed to study systematically the vulnerable areas. If justified, computer modeling of the FMEF accountability system will be initiated by September 1981 .

\section{SAFYGUARDS CONCEPTS FOR ALTERNATIVE FUEL CYCLE FACILITIES}

\section{A. Spent-Fuel Storage Facility Project (D. D. Cobb)}

The second annual Spent-Fuel Storage Contractors' Review Meeting was held at Augusta, Georgia, October 29-30, 1980. Dr. L. A. Heinrich, SRL, presented the safeguards concepts developed by Los Alamos and SNL for away-from-reactor (AFR) spent-fuel storage facilities. Potential applications of the Los Alamos concepts for spent-fuel verification and assay to facility requirements, such as criticality control and financial settlements, were of particular interest.

A program schedule for Los Alamos support to the AFR program was completed with the Savannah River program manager. The schedule and milestones agreed to through FY 1987 are $^{33-35}$ as follows. 
1. Complete report on optical verification (Cerenkov) technique

2. Complete preconceptual design report on verification and assay system (VAS)

3. Complete conceptual design of VAS

4. Complete GE-Morris field test

5. Begin IAEA inspector training program

6. Construct prototype assay system

7. Check and evaluate prototype at Los Alamos

8. Install and evaluate prototype at AFR

9. Build prototype for second AFR

10. Install and evaluate second prototype

11. Complete final modification for both systems

Mid FY 1982

End FY 1982

FY 1982

Mid FY 1983

End FY 1983

FY 1984-85

FY 1985

FY 1986

FY 1987

An experimental spent-fuel nondestructive measurement system was installed in the cask unloading pool at the GE-Morris spent-fuel storage facility. Seventeen spent-fuel assemblies from four different reactors were measured to determine the reproducibility, the effect of angular burnup inhomogeneities, and the effect of variations in fuel assembly geometry. Preliminary analysis of the data indicates that

- spent-fuel assemblies can be positioned for measurement with a variability of 1 to $2 \%$, and

- angular orientation of spent-fuel assemblies can have a significant effect on measurement signatures, with variations of 30 to $40 \%$ observed.

Additional measurements are planned to determine the source of variability in angular measurements and to evaluate empirical correlations between measurements and spent-fuel parameters.
B. Consolidated Fuel Reprocessing Program-Hot Experimental Facility (H. A. Daycm, C. C. Thomas, Jr., E. A. Hakkila, C. A. Ostenak, E. A. Kern, and D. P. Martinez)

The conceptual design of a materials accounting system for the Hot Experimental Facility (HEF) is under way. A model of the chemical separations process, from fuel disassembly and shearing to the uranium-plutonium nitrate product, was completed. The three major areas modeled were feed preparation, codecontamination and partition, and copurification. Some improvements were made to the MODEL code during this activity. Generalized subroutines were developed for many individual unit processes frequently encountered, thus eliminating the need to develop a separate subroutine for each unit process. In past simulations, maintaining tank volumes within desired limits has been difficult. To rectify this situation, a volume control subroutine that controls the volume through small changes in the output flow rate was added to the code.

HEF materials accounting systems performance goals and ground rules for the HEF study were developed. Four levels of performance represent a range of measurement capabilities, from those assumed attainable with existing technology to those stated as IAEA and National Regulatory Commission (NRC) guidelines. In this study, measurement errors will be partitioned to each measurement type, at each measurement point, and for each measurement strategy so that every performance goal can be met. A method for partitioning the measurement errors while minimizing risk and cost is being developed. Calculated measurement errors will be used in the measurement model to simulate operation of the measurement system as it is applied to the simulated process data. These simulations will be used to evaluate performance of the measurement system.

\section{Conceptual Design Study for the Liquid-Metal Fast Breeder Reactor (H. A. Dayem)}

A conceptual design of a safeguards system for a 100-MWe liquid-metal fast breeder reactor (LMFBR) was developed by Los Alamos and SNL. Los Alamos 
was responsible for materials accounting and inventory verification concepts, whereas SNL developed physical protection and containment/surveillance concepts.

The materials measurement and accounting system determines the location and quantity of all nuclear materials in the facility. The entire facility is treated as a single materials balance area, with transfer measurement points for receipts and shipments and inventory measurement points for fresh driver fuel storage, ex-vessel storage tank, and reactor core.

Accounting data from the materials measurement and accounting system will be available to the IAEA. Insper:tors will make additional measurements, draw matenkis balances, analyze the data for consistency, and correlate the fresh fuel data with the fabricator's data and the spent-fuel data with the reprocessor's data.

As a result of this study, the following are recommended.
- Provide independent secure storage for fresh driver assemblies in the fuel-handling cell.

- Develop and demonstrate gamma and/or neutron measurements to identify assembiy types and to determine fissile content.

- Develop and demonstrate, in liquid sodium, an item identifier for fuel assemblies and a reader that is an integral part of fuel-handling machines.

- Conduct an inventory of the ex-vessel and fresh-fuel storage areas folic ing each refueling.

- Provide areas for nondestructive assay measurements at the fuel-handling cell, the fuel transfer elevator, and the ex-vessel reactor transfer port.

- Investigate the use of reactivity and control rod position measurements to verify the reactor core inventory.

\section{INTERNATIONAL SAFEGUARDS}

A. International Safeguards for Reprocessing (E. A. Hakkila, R. G. Gutmacher, J. T. Markin, J. P. Shipley, and W. J. Whitty)

The Los Alamos Safeguards Systems Group is performing a study with SNL to integrate advanced materials accounting concepts ${ }^{36}$ with containment/surveillance features to provide an efficient international safeguards system for nuclear reprocessing facilities. The reference facility is AGNS at Barnwell, South Carolina. The section "Detailed Concepts of Integrated Safeguards for the Reference Facility" describes the plant operator's measurement and accounting system, safeguards concerns, and the inspector's verification activities for three materials balance areas of the reference plant. The materials balance areas considered were (1) fuel receiving, storage, chop, and leach; (2) the separations process area; and (3) the plutonium nitrate storage area. Although the plant operator's measurement and accounting system may differ at other reprocessing plants, discussions of the safeguards concerns and the IAEA inspector's verification activities are intended to be applicable to other reprocessing plants.

The sensitivity of the materials measurement and accounting system to diversion using the inspector's sufficient statistics is being evaluated. ${ }^{37}$ This work involves statistical and numerical analyses of operator's and inspector's safeguards data.
B. International Working Group-Reprocessing Plant Safeguards (E. A. Hakkila anì J. P. Shipley)

Meetings were attended of Subgroup 4 on Safeguards Evaluation in Karlsruhe, Fed ral Republic of Germany (FRG) and Subgroup 2 on Facility Design Considerations in Vienna. US input to both of these subgroups was prepared by the Los Alamos Safeguards Systems Group.

The overview report summarizing the 2 yr of activities of the International Working Group-Reprocessing Plant Safeguards is being prepared by an editorial committee chaired by the United Kingdom. The Los Alamos Safeguards Systems Group provided draft input to four chapters of the overview report.

\section{Jcint US-FRG Program (J. P. Shipley)}

The first meeting of the Working Group on Near-Real-Time Materials Accountin,, which is part of the joint US-FRG program in international safeguards, was convened in Karlsruhe in December 1980. The overall purpose of the working group is to provide a comprehensive, objective evaluation of the capabilities of near-real-time accounting in international safeguards and to have this evaluation done by a multinational team of experts. The first meeting of the working group was designed to define the activity in more detail, to indicate 
those areas where research and development likely will be required, and to discuss possible approaches to pursue. The first major milestone for this effort is the LAEA symposium in the fall of 1982 at which a half-day session will be devoted to this topic. This activity and its magnitude (about 20 people will participate) are evidence of the growing interest and acceptance of advanced materials accounting techniques for international safeguards.

\section{Advisory Group on Facility Design Considerations to Facilitace Safeguards (E. A. Hakkila)}

Draft material describing facility design considerations to improve materials accounting in process and item-handling facilities was prepared for the Advisory Group on Facility Design Considerations to Facilitate Safeguards.

E. Safeguards Cooperative Program with EURATOM, Ispra (A. L. Baker, H. A. Dayem, E. A. Kern, J. T. Markin, D. P. Martinez, and J. P. Shipley)

A user's manual for the MODEL computer code, which is issued in the modeling of materials processing facilities, was completed. ${ }^{38}$ The code has evolved over 4 yr of extensive modeling activities and uses a modified version of the GASP IV simulation language for event scheduling and overall integration of the process dynamics. Any processing facility where the dynamics can be simulated with algebraic and differential equations can be modeled. In developing the code, a prime consideration was ease of use; thus, the user's manual was written to make the code more readily transportable to other agencies within the safeguards community. In April 1980 code was implemented on the computers at the EURATOM Joint Research Center in Ispra, Italy.

The measurement code MESSIM, which applies measurement errors to the process variables, is being upgraded primarily in response to requirements imposed by the new version of the decision analysis code DECANAL. A number of inventory and transfer modules are being developed and tested. This modular approach will eliminate the need for FORTRAN coding changes that have been necessary in previous versions of the code. All process-dependent information will be transferred to the code by the input data file.

The modified DECANAL code was transferred to the EURATOM Joint Research Center in Ispra, Italy. Two members of the Los Alamos Safeguards Systems Group assisted Ispra personnel in installing the code and interfacing it to the Ispra data accumulation code ISADAM.

F. Assistance to Tokai-mura in Near-Real-Time Accounting (D. D. Cobb)

The Japan Atomic Energy Research Institute (JAERI) invited a Los Alamos staff member to visit the pilot-scale nuclear fuels reprocessing plant at Tokai-mura. The purpose of the visit was to review the results of the Tokai-mura Safeguards Technology Experimental Programs (TASTEX), especially Task F, on applying the principles of near-real-time materials accounting and to recommend future $2 \& D$ activities leading to implementation of the TASTEX results at the Tokaj-mura plant.

In practical terms, the TASTEX results probably will not be implemented at Tokai-mura in the immediate future. The instruments are not mutally compatible, nor are they integrated into the plant process measurement and control systems. However, the continuing development of data acquisition/monitoring techniques will benefit safeguards by providing better quality and more timely data for verification by the safeguards inspector. Thus, in the long term, TASTEX may improve safeguards in the next generation of nuclear facilities.

Of immediate benefit for improved international safeguards inspections at the existing reprocessing plant may be the a vailability of a Cerenkov spent-fuel viewing device for the fuel receiving and storage area. Identifying spent-fuel assemblies from the cask unloading operation, through storage in closed, stainless steel canisters, to the transfer of assemblies tr ihe mechanical cell is difficult. A suitably modified Cerenkov viewing device, perhaps with a Polaroid camera back, may provide an image of each assembly before placement in the storage pool and another image for comparison before transfer to the mechanical cell. 


\section{DEVELOPMENT OF SAFEGUA.RDS TECHNOLOGY}

\author{
A. In-Process Inventory in Solvent-Extraction Contac- \\ tors (D. D. Cobb and C. A. Ostenak)
}

In support of the program to determine in-process nuclear material, the Los Alamos Safeguards Systems Group has continued sponsoring the development of techniques for estimating in-process nuclear materials in solvent-extraction contactors. These techniques, based on chemical models and process measurements, will be essential for optimizing the sensitivity of near-real-time materials accounting in future fuels reprocessing plants.

During this reporting period, AGNS provided us with pulsed-column in-process inventory data from cold miniruns in their full-scale plutonium purification process and from experiments with their pilot-scale pulsed columns. ${ }^{39}$ Using the AGNS data, the contactor-inventory linear-estimator techniques are being refined and the detection sensitivity of the decision analysis techniques are being determined for the miniruns having simulated diversions. In addition, Iowa State University is using their pulsed-column computer code to compare the results from minirun column-dump experiments with the inventory estimated during the runs.

Also during this reporting period, Clemson University released the report "Improved Chemical Contactor Models Using Modern System Identification Techniques in Nuclear Accountability," the Los Alamos Safeguards Systems Group, and modified their mixer-settler computer code (PUBG) to improve agreement between the calculated and experimental acisi and nuclear materials concentration profiles for mixer-settler contactors, including those in which plutonium reduction occurs. PUBG differs from other mixer-settler computer codes in that it accounts for departures from mass transfer equilibrium and for partitioning uranium and plutonium using U(IV) reductant, and it provides for transfer of U(IV) reductant from the aqueous to the organic phase by autooxidation of U(IV) to $\mathrm{U}(\mathrm{VI})$.
B. Away-From-Reactor Spent-Fud Storage: Comparison of Measured and Predicted Spent-Fuel Date (C. C. Thomas, Jr., D. D. Cobb, and C. A. Ottenak)

The guality of operator-predicted (calculated) values of the plutonium and uranium contents of spent fuels was compared with measured values from reprocessors. The data include six reactors [three pressurized water reactors (PWR) and three boiling water reactors (BWR)], seven reactor cores, fuel burnups from 1300 to 27000 $\mathrm{MWd} / \mathrm{tU}$, three different reprocessors, and 104 reprocessing batches. The data base does not include data from large, modern nuclear power reactors because reprocessing of fuel from such reactors has not occurred.

Assuming that most observed differences between operator-declared and reprocessor's values are caused by inaccurate bumup calculations, the results of this study are as follows.

- Total uranium content of spent fuel can be predicted with a bias of $1 \%$ or less and a 1- $\sigma$ variability of 2 to $4 \%$.

- Total plutonium content can be predicted with a positive bias of 3 to $5 \%$ and a 1- $\sigma$ variability of 4 to $6 \%$.

- Fissile uranium $\left({ }^{235} U\right)$ content can be predicted with a negative bias of 3 to $4 \%$ and a $1-\sigma$ variability of 4 to $6 \%$.

- Fissile plutonium $\left({ }^{239} \mathrm{Pu}+{ }^{241} \mathrm{Pu}\right)$ can be predicted with a bias of -1 to $+6 \%$ and a $1-\sigma$ variability of 3 to $7 \%$.

- Total fissile content can be predicted to 1 to $3 \%$ (possible negative bias) with a 1- $\sigma$ variability of 3 to 6\%.

In general, the larger values of the ranges of uncertainty are associated with BWRs and the smaller values with PWRs. The quality of burnup calculations may be better for modern power plants.

Based on these results, nondestructive spent-fuel measurements having a total uncertainty of 5 to $10 \%$ (1 o) or better should be useful for quantitative verification 
of "typical" spent fuel. The quality of NDA measurements will improve as experience with specific types of reactor fuel increases and as more reprocessor's data become available. Measurement outliers of 10 to $20 \%$ might be expected for "atypical" fuel, that is, fuel with unusual irradiation history.

\section{Development of Sequential Tests of Near-Real-Time Accounting Data (D. D. Cobb, J. P. Shipley, and D. B. Smith)}

A two-step scan-research procedure using sequential tests to analyze near-real-time accounting data has been developed and has performed well on examples of simulated and real data. Detection of diversion is obtained with good power and good control of false alarms, and losses are localized in space and time.

The test procedure and test boundaries were derived under a restrictive set of assumptions concerning use of only the cusum statistic for data with constart. pair-wise correlation and uniform diversion. However, experience with various simulated materials-balance data shows that this test procedure and the associated test boundaries can, in fact, be used to analyze near-real-time accounting data obtained under many conditions.

The test procedure and test boundaries can be applied to various normaily distributed test statistics derived under different assumptions concerning the pattern of diversion. The performance of these sequential tests generally will be good as long as the pattern of diversion is not restricted to a large, single diversion, in which case a test of the materials-balance data for outliers, such as the Shewhart test, performs better.

A useful estimate of the detection sensitivity of a near-real-time system is provided by the fixed-length cusum test that terminates the sequential decision process. The fixed-length cusum test was used previously " to construct three-dimensional cusum performance surfaces, which were interpreted as bounds on the performance of near-real-time systems. This estimate of detection sensitivity, corresponding to $\beta=\alpha=0.05$, is

$N_{j_{j}}=3,3 o_{c}(N)$,

where $N \mu_{1}$ is the total diversion after $N$ balances under the alternative hypotheses.

Straightforward analysis of Eq. (1) shows that increasing the number of materials balances in a given accounting period (or the number of sub-MBAs in a single MBA) reduces the random-error variance of the net transfer if the number of transfer measurements aiso increases. The effect on inventory measurement errors and net-transfer systematic errors usually will be small. The detection sensitivity will be no worse than that of a single fixed-length cusum test. It will improve if the number of transfer measurements increases until either the materials balances are completely inventory dominated or the cusum error is totally dominated by systematic errors in the transfer measurements. Any improvement in detection sensitivity is in addition to the benefits of improved timeliness and localization that accrue by increasing the number of materials balances.

A modest increase in false-alarm probability over the theoretical value might be expected in practice for various reasons, such as

- using imperfect measurement-error models and measurement-control procedures, which also affect the performance of the fixed-length tests;

- restarting the power-one test to scan different data sets; and

- applying different tests to analyze the same data set.

However, our limited experience with real data indicates that a positive test result is alway ; traceable to a real occurrence, either a measurement problem or an identifiable loss, and not to a statistical fluctuation.

\section{Modeling and Simulation Codes (E. A. Kern and D. P. Martinez)}

Modeling of the HEF process produced a process code larger than codes used previuusly. To compensate for the larger code, the dimensions on both our generalized modeling code MODEL and our scope plotting package PLOTIT had to be increased.

The uniform random number generator in the MOP EL code was deficient for the HEF simulation, so a new random number generator was installed. ${ }^{42}$ Although the initial tests with this new generator have been encouraging, further tests are necessary to prove its worthiness.

\section{E. Computer Upgrades (R. M. Tisinger)}

The program MAPPER was installed on the Prime computer system and is operational in the black and white mode. The UT 200 emulator was updated and made compatible with the CCF Rev. level. 
F. Systems Implementation (TA-55) (M. Jain and B. H. Erkkila)

The Hewlett Packard (HP) System 45, which has been configured for the systems implementation studies, consists of an HP-9845B computer, plotter, two floppy disks, a hard disk (19.6 megabyte), a line printer. The HP data base management program QUERY/45 was implemented on the system.
The data-base management program was used extensively with a sample data base, and subprograms to link with QUERY were written for further processing of search results. A general program was written to display graphically raw accountability data as well as processed data for a real plant. With these programs, we will study processes at TA-55 by using the HP-9845 to analyze data collected by the Plutonium Facility-Los Alamos Safeguards Systems.

\section{TECHNICAL SUPPORT AND TECHNOLOGY TRANSFER}

\section{(Los Alamos Safeguards Systems Staff)}

In Tokyo, members of the JA ERI, the Power Reactor and Nuclear Fuel Development Corporation (PNC), the Mitsubishi, the IAEA, and the Japan Nuclear Fuel Services were briefed on new developments in near-real-time accounting, and in Tokai-mura members of the PNC and the JAERI were briefed on in-process inventory estimation. A summary of the short-term detection study for the Gas Centrifuge Enrichment Plant was presented for members of DOE/OSS, Union Carbide Corporation, SNL, and Brookhaven National Laboratory/Technical Support Office.

GE personnel at San Jose, California, who were briefed on the Los Alamos AFR program, agreed to support a continuing experimental measurement program at their Morris facility and the design of a prototype VAS for AFR storage facilities. In turn, GE requested that Los Alamos consider the impact of disassembly, rod removal, and storage on safeguards and materials accounting. Disassembly and reconstitution of fuel bundles are becoming routine for improved fuel use, and rod storage eventually may be the most economic method of spent-fuel storage.

On January 20, 1981, L. A. Heinrich, C. E. Jewell, and G. K. Wren from Savannah River were briefed on our spent-fuel storage project (Heinrich is the technical program manager at Savannah River for this project) and on various other ongoing $R \& D$ activities of the $L O S$ Alamos sateguards groups.

A paper entitled "Simulation and Actual Plant Operation of Uranium Purification in Testing Materials Accounting Techniques for Nuclear Safeguards" was presented at the Joint National Meeting of the Operations Research Society of America and The Institute of Management Sciences, Colorado Springs, Colorado, November 10-12, 1980.

A bibliography of Los Alamos National Laboratory safeguards activities from 1970 to 1979 was compiled. ${ }^{13}$

PART 4

\section{INTERNATIONAL SAFEGUARDS}

\section{IAEA INSPECTOR INSTRUMENTATION DEVELOPMENT}

A. High-Level Neutron Coincidence Counter Implementation: Assay of the Plutonium Content of MOX Fuel Assemblies (J. E. Foley and G. E. Bosler)

The IAEA faces the task of measuring various sizes, shapes, densities, etc. of plutonium-bearing materials throughout the world. Part of the job of implementing the high-level neutron coincidence counter (HLNCC) is developing detailed assay procedures for specific measurement problems. The problems associated with measuring a reference MOX fuel assembly (Table IX) have been investigated using neutron coincidence counting with the HLNCC. 
TABLE IX

\section{CHARACTERISTICS OF THE REFERENCE MOX FUEL ASSEMBLY}

\begin{tabular}{ll} 
Linear MOX loading & $\approx 450 \mathrm{~g} / \mathrm{cm}$ \\
Linear Pu loading & $\approx 3.5 \mathrm{~g} / \mathrm{cm}$ \\
Outer diameter of assembly & $\approx 11 \mathrm{~cm}$ \\
Number of fuel rods & 28 \\
Rod diameter & $1.6 \mathrm{~cm}$ \\
\hline
\end{tabular}

Neutron coincidence counting has been used for many years to assay the plutonium content of plutonium-bearing scrap and waste and cans (approximately $1 \mathcal{l}$ volume) of $\mathrm{PuO}_{2}$ powder. Assay of these types of low-density $\left(<3-\mathrm{g} / \mathrm{cm}^{3}\right)$ samples is well understood. However, a MOX fuel assembly is composed of many rods containing pellets of MOX that have high densities (about $10 \mathrm{~g} / \mathrm{cm}^{3}$ ). These high densities, which result in high MOX linear fuel loadings (mass of MOX per unit length), introduce new problems that must be investigated.

The major goals of the work are

- to understand the parameters (such as plutonium loading, uranium loading, etc.) that affect the assay results; and

- to develop detailed assay procedures for measuring MOX fuel assemblies.

For the measurements in these investigations, the reference MOX fuel assembly was simulated by combining both unirradiated $\mathrm{MOX}$ and unirrudiated $\mathrm{UO}_{2}$ fuel rods from a $B W R$ reactor into specific geometries.

The reference MOX assembly was not constructed exactly because the MOX fuel rods with the correct diameters or the correct plutonium/uranium loading were not available. However, the reference assembly was simulated in several ways.

One method duplicated the outside diameter, approximate plutonium loading, and appioximate uranium loading of the reference assembly. A mixture of MOX rods and $\mathrm{UO}_{2}$ rods was assembled so that (1) the ratio of MOX rods to $\mathrm{UO}_{2}$ rods gave the same average plutonium/uranium loading as the reference assembly, and (2) the total number of rods gave the same linear fuel loading ( $\mathrm{UO}_{2}+\mathrm{PuO}_{2}$ ). Because the fuel rods used to make the simulated fuel assembly were smaller in diameter than those of the reference assembly $(1.43 \mathrm{~cm}$ vs $1.60 \mathrm{~cm}$ ), more rods were put into the simulated assembly than are in the reference assembly to give the correct average linear fuel loading. Thus, if the correct average linear fuel loading was simulated, the proper geometry could not be simulated.

The assembly also was simulated by using the correct number of fuel rods and the correct rod pattern, but the proper linear furll loading was not simulated because the diameter of the rods is too small.

The fact that a MOX fuel assembly can be simulated with $\mathrm{UO}_{2}$ fuel rods and a californium neutron source, which provides the spontaneous fission neutrons, has been established experimentally. Depleted, natural, and low enriched PWR fuel rods containing only $\mathrm{UO}_{2}$ were available at Los Alamos. These rods, which have a smaller diameter than the BWR rods, were used with the californium neutron source to investigate the effects of fissile loading and fuel rod diameter on coincidence count rate.

Figure 33 shows an example of the measurement results. The HLNCC response is strongly dependent on the linear fuel loading: the higher the loading, the higher the response.

Some preliminary results of the investigation are as follows.

- The linear fuel loading, which is primarily ${ }^{238} \mathrm{U}$, greatly affects the HLNCC response.

- Because the HLNCC response depends strongly on the ${ }^{231} U$ loading in the assembly, the MOX assembly should be viewed as a uranium assembly

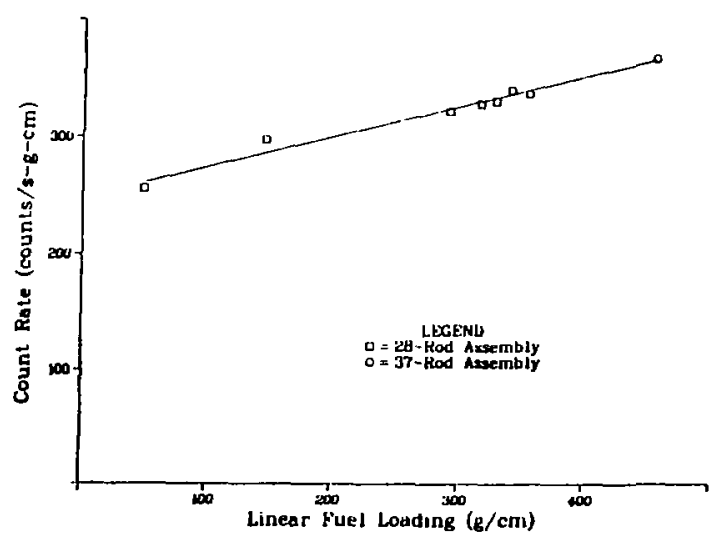

Fig. 33.

Coincidence count rate as a function of linear fuel loading ( $\left.\mathrm{UO}_{2}{ }^{\prime}+\mathrm{PuO}_{2}\right)$. 
containing a small amount of nlutonium, rather than as a plutonium assembly.

- The coincidence response of a gram of plutonium is higher in a heavily loaded assembly than in a less heavily loaded one because

- there is more fast multiplication in the heavily loaded assembly (as a result of more ${ }^{23 !} \mathrm{U}$ ), and - the neutron detection efficiency of the HLNCC is higher in the more heavily loaded assembly because of less neutron leakage from the HLNCC ends.

- Fissile loading has little effect on the coincidence count rate for low fissile loadings. Results obtained from PWR rods with enrichments of 3.19\% are the same as results obtained from lower enriched rods (a mixture of depleted and natural). Appriently little neutron multiplication occurs in the rissile material in the fuel assembly.

- The diameter of the fuel rod has little effect on the coincidence count rate. Small-diameter PWR rods gave essentially the same response as the larger diameter BWR rods, when the linear fuel loading was the same.

- Because the results in Fig. 33 are from different fuel rod patterns and from assemblies filled to varying amounts, we concluded that the coincidence count rate is insensitive to the rod pattern. This insensitivity is not true if a small number of fuel rods is in the assembly.

- A small, but not insignificant, part of the coincidence count rate comes from those portions of the fuel assembly located outside the neutron detector. During an assay, the ends of the fuel assembly should extend at least $30 \mathrm{~cm}$ beyond the ends of the detector.

The MOX fuel assembly is being studied (using Monte Carlo simulation) to understand better the observed experimental results. A draft report of this study's results has been sent to the IAEA for review and comment.

B. Neutron Coincidence Coller for the Assay of Unirradiated Fuel Assemblies (H. O. Menlove)

The coincidence collar ${ }^{44}$ was developed to verify ${ }^{235} \mathrm{U}$ loading in reactor fuel assemblies. It uses neutron interrogation with an americium/hithium neutron source, and the neutrons from the induced fission reactions are counted with ${ }^{3} \mathrm{He}$ detectors operated in the coincidence mode. This coincidence counting eliminates the un- desired neutron counts from the random americium/ithium interrogation source and room background neutrons.

The coincidence collar consists of three banks of ${ }^{3} \mathrm{He}$ tubes and an americium/lithium source imbedded in a high-density polyethylene $\mathrm{CH}_{2}$ body. The $18{ }^{3} \mathrm{He}$ neutron detector tubes (4 atm pressure) are $2.54 \mathrm{~cm}$ in diameter and $33 \mathrm{~cm}$ long. The detector system and a mockup PWR fuel assembly are shown in Fig. 34.

The electronics used with the coincidence collar are the same as those used with the HLNCC ${ }^{45}$ and contain the high-voltage and low-voltage power supplies, six amplifier-discriminator lines, a microprocessor, and the shift-register ${ }^{46}$ coincidence logic. It interfaced directly to an HP-97 programmable calculator. The microprocessor reads out the run time, total counts, reals plus accidental counts, and accidental counts to the HP-97, which then reduces the data with the software program selected by the operator.

Measurements have been performed to study the penetrability of the interrogation neutron flux and the uniformity of response in the fuel assembly. $A 15$ by 15 rod mockup PWR fuel assembly with removable rods (3.19\% enriched) was used for the tests. To measure the penetration of the interrogation neutron flux, a small ${ }^{235} \mathrm{U}$ fission chamber $(1.27 \mathrm{~cm}$ in diameter by $15.2 \mathrm{~cm}$ long) was placed in various fuel rod locations to measure

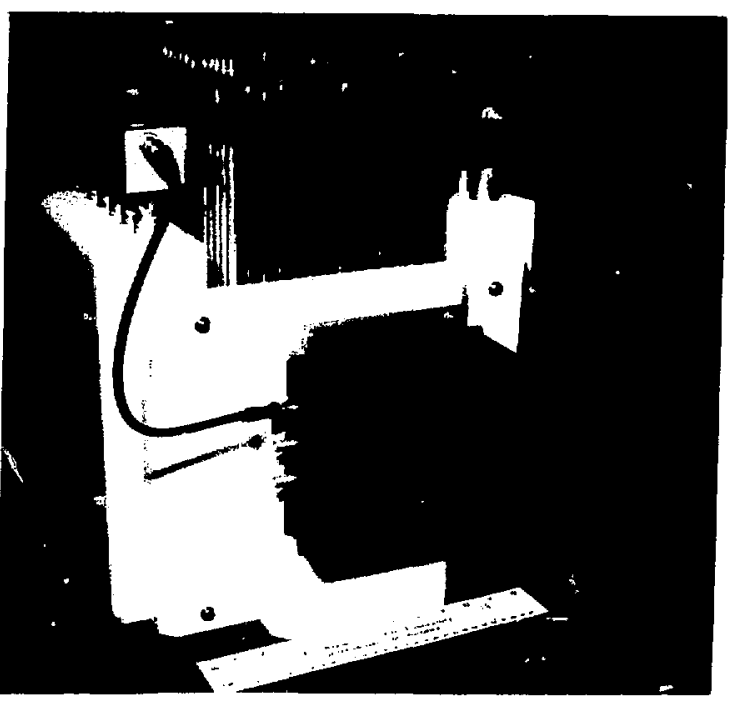

Fig. 34.

Prototype neutro.: coincidence collar positioned around the mockup PWR fuel assembly. 
directly the ${ }^{239} \mathrm{U}$ fission rate. Table $\mathrm{X}$ lists the results of these measurements where the response has been normalized to unity at the highest flux position (centered next to the americium/lithium source). The flux in the interior and back regions is roughly 10 to $15 \%$ of the front position.

Additional experiments were performed in which rods from different sections of the assembly were removed to determine the position sensitivity to rod substitution. Regions selected for the measurements are shown in Fig. 35 , which shows a cross section of the rod positions in the PWR array. For each rod configuration, several 1000-s measurements were performed and the coincidence rate was compared with the full array count rate to determine the perturbation caused by the substitution. The measured perturbation then was divided by the number of rods in the substitution region to obtain the perturbation pel rod. The fuel rods were removed one row at a time (see the darkened rods in Fig. 35) while the other rods remained in place in the assembly.

The results (see the lower section of Fig. 35) show that all rows give about the same perturbation per rod removal. The sensitivity limit is defined as the minimum number of rod substitutions that can be detected in a 1000 -s measurement time at the $95 \%(2-\sigma)$ confidence level. The detection limit for empty rod substitution has an average value of 2.8 rods and is uniform at all rod positions, including the central region.

\section{TABLE X}

\section{${ }^{235}$ U FISSION RATE FOR DIFFERENT POSITIONS IN THE 15 by 15 ROD ARRAY}

Position Normalized Fission Rate

$\begin{array}{ll}\text { Front center } & 1.00 \\ \text { Front corner } & 0.63 \\ \text { Side, midway back } & 0.20 \\ \text { Back corner } & 0.15 \\ \text { Back center } & 0.11 \\ \text { Center } & 0.12\end{array}$

By removing the americium/lithium interrogation source from the coincidence collar, passive measurements give the ${ }^{238} \mathrm{U}$ content by coincidence counting the

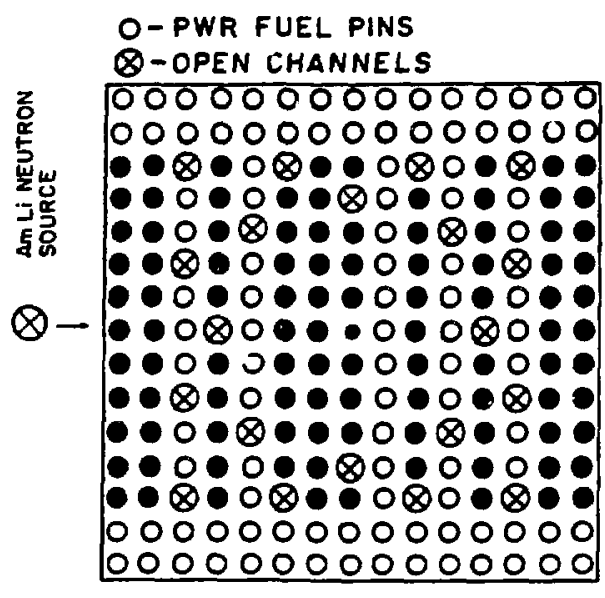

I5 $x$ IS PWR ARRAY

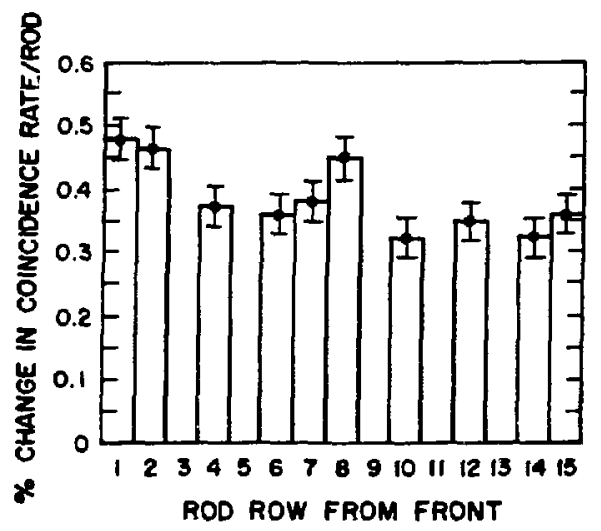

Fig. 35.

The PWR fuel assembly where the darkened rod positions represent rod removals. Removing one row at a time resulted in the coincidence rate reduction shown in the bar graph. 
${ }^{238} \mathrm{U}$ spontaneous fission neutrons. Combining the ${ }^{235} \mathrm{U}$ and ${ }^{238} U$ results gives a high level of verification for the fuel assembly.
Fabrication and initial tests of the coincidence collar have been completed, and the units will be evaluated in field tests in 1981.

\section{SPENT-FUEL VERIFICATION TECHNIQUE DEVELOPMENT}

A. Nondzstructive Measurement of Spent-Fuel Assemblies at the GE-Morris Spent-Fuel Storage Facility (J. R. Phillips, J. K. Halbig, S. F. Klosterbuer, L. A. Stovall, F. A. Duran, and O. R. Holbrooks)

The experimental measurement system for collecting base-line data on spent-fuel assemblies was installed in the unloading pool at the GE-Morris Spent-Fuel Storage Facility. The positioning mecinanism is shown in Fig. 36 with a PWR fuel assembly in place. Spent-fuel assemblies from four reactcrs (sec Table XI) were examined using fission chambers to measure neutron emission rate and ion chambers to measure gamma dose. There were two immediate and two longer range objectives of these measurements.

- Reproducibility. How precise can replicate measurements be made with the $V$-shaped positioning fixture? Also, can the errors covered by positioning and counting statistics be separated? Which of these two error sources is dominant?

- Angular Effects. Are the neutron and gamma measurements at all four corners of the spent-fuel assembly consistent?

- Fuel-Assembly Geometry. What is the effect of variations in fuel gcometry on measurements-PWR fuel assemblies with 14 by 14 and 15 by 15 arrays and BWR fuel assemblies with 7 by 7 arrays?

- Evaluation of Empirical Correlations. Does the empirical relationship between neutron emission rate and declared exposure apply to fuel assemblies from different reactors? Can the neutron emission rate be corrected for decay of the ${ }^{244} \mathrm{Cm}$ isotope?

To address the first two questions, we measured 17 spent-fuel assemblies, 16 PWR assemblies, and one BWR assembly from four power reactors. Table XI summarizes the parameters of the fuel assemblies, and T'able XII describes the specific fuel assemblies that were measured.
1. Reproducibility. The positioning mechanism consists of a V-shaped holder with two limit switches, one on

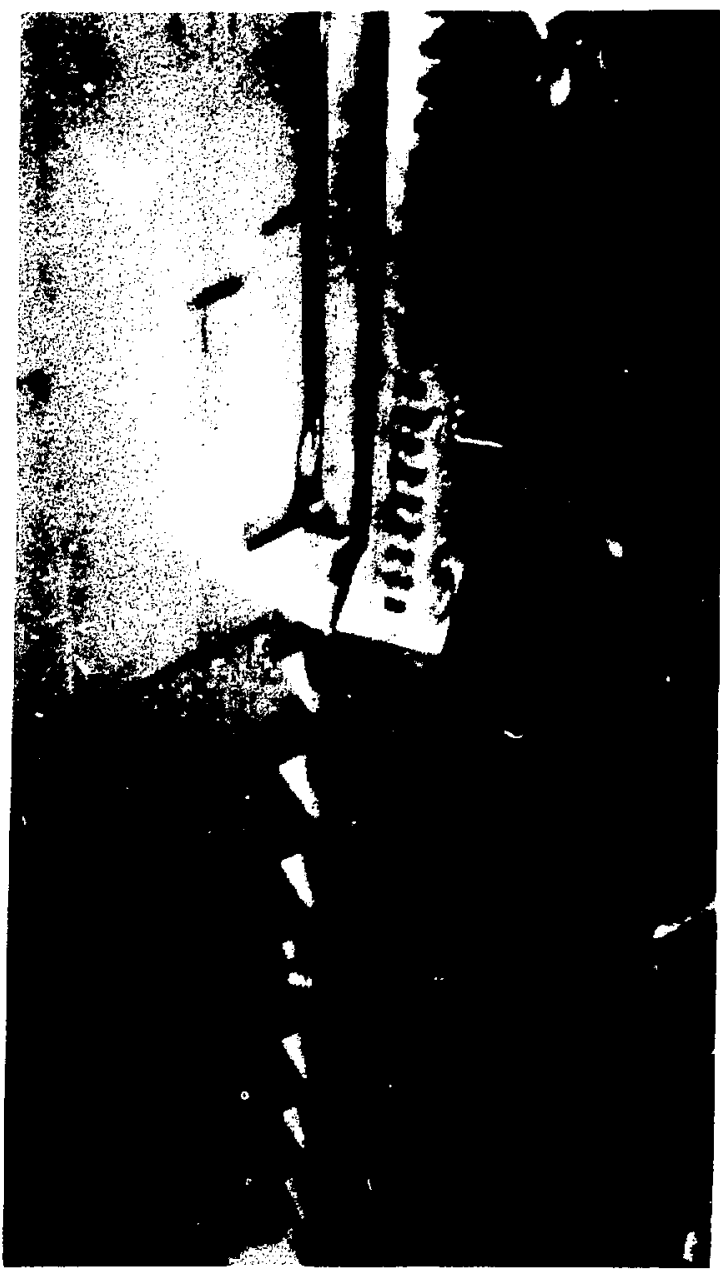

Fig. 36.

A spent-fuel measurement system with a PWR assembly. 
TABLE XI

FUEL ASSEMBLIAS EXAMINED AT GE-MORRIS FACILITY

\begin{tabular}{|c|c|c|c|c|c|c|c|c|c|c|}
\hline $\begin{array}{c}\text { Reactor } \\
\text { Designation }\end{array}$ & $\begin{array}{l}\text { Rated Output } \\
\text { (Reactor Type) }\end{array}$ & $\begin{array}{l}\text { Number of } \\
\text { Assemblies }\end{array}$ & $\begin{array}{c}\text { Fuel } \\
\text { Geometry }\end{array}$ & $\begin{array}{c}\text { Fuel } \\
\text { Diameter } \\
\text { (cm) }\end{array}$ & $\begin{array}{c}\text { Active } \\
\text { Length } \\
\text { (cm) }\end{array}$ & $\begin{array}{l}\text { Cladding } \\
\text { Material }\end{array}$ & $\begin{array}{l}\text { Fuel Rods/ } \\
\text { Assembly }\end{array}$ & $\begin{array}{c}{ }^{233} \mathrm{U} \\
\text { Enrichment } \\
(\%)\end{array}$ & $\begin{array}{c}\text { Declared } \\
\text { Exposure } \\
(G W d / t U)\end{array}$ & $\begin{array}{c}\text { U/Fud } \\
\text { Assembly } \\
\text { (kg) }\end{array}$ \\
\hline $\mathbf{A}$ & $510 \mathrm{MWe}$ (PWR) & 4 & $15 \times 15$ & 0.97 & 309.4 & $\mathbf{Z r}$ & 204 & $3.02-3.67$ & $10.8-26.0$ & 419.7 \\
\hline B & 450 MWe (PWR) & 3 & $14 \times 14$ & 0.93 & 366 & $\mathrm{Zr}$ & 179 & 3.4 & $23.6-40.7$ & 443.7 \\
\hline $\mathbf{C}$ & $715 \mathrm{MWe}$ (BWR) & 1 & $7 \times 7$ & 1.24 & 366 & $\mathbf{Z}_{\mathbf{r}}$ & 49 & 2.13 & 5.1 & 169.8 \\
\hline D & $430 \mathrm{MWe}$ (PWR) & 9 & $14 \times 14$ & 0.97 & 305 & ss & 180 & $3.4-4.0$ & $26.5-32.4$ & 318.5 \\
\hline
\end{tabular}


TABLE XII

INDIVIDUAL FUEL ASSEMBLIES

\begin{tabular}{lllc}
$\begin{array}{c}\text { Fuel } \\
\text { Assembly }\end{array}$ & $\begin{array}{c}\text { Discharge } \\
\text { Date }\end{array}$ & $\begin{array}{c}239 \\
\text { Enrichment } \\
(\%)\end{array}$ & $\begin{array}{c}\text { Declared Exposure } \\
\text { (GWd/tU) }\end{array}$ \\
\hline & & & \\
A-A019 & $4 / 17 / 70$ & 3.02 & 19.7 \\
A-C049 & $4 / 17 / 70$ & 3.67 & 10.8 \\
A-A045 & $4 / 17 / 70$ & 3.02 & 19.5 \\
A-B12 & $4 / 16 / 71$ & 3.23 & 26.0 \\
& & & \\
B-C56 & $3 / 4 / 77$ & 3.397 & 40.7 \\
B-C32 & $4 / 6 / 74$ & 3.400 & 23.6 \\
B-C52 & $3 / 4 / 77$ & 3.397 & 32.8 \\
& & & \\
C-DN201 & $4 / 72$ & 2.13 & 5.1 \\
& & & \\
D-A051 & $12 / 28 / 72$ & 3.404 & 26.7 \\
D-C004 & $6 / 21 / 73$ & 3.865 & 26.8 \\
D-D001 & $3 / 14 / 75$ & 4.005 & 31.4 \\
D-C001 & $6 / 2 / 73$ & 3.865 & 26.5 \\
D-A036 & $12 / 28 / 72$ & 3.404 & 26.5 \\
D-D020 & $3 / 14 / 75$ & 4.005 & 26.9 \\
D-A009 & $12 / 28 / 72$ & 3.404 & 26.8 \\
D-B046 & $3 / 14 / 75$ & 4.005 & 32.3 \\
D-C020 & $6 / 2 / 73$ & 3.865 & 32.4 \\
& & & \\
\hline
\end{tabular}

each side of the $V$ to indicate when the fuel assembly is in contact. Reproducibility of the gross gamma and neutron measurements was determined by measuring each of the four corners of four fuel assemblies six times. After each individual measurement, the fuel assembly was removed from the positioning mechanism and repositioned to simulate actual measurement conditions. Precision of the gross gamma measurements was $0.6 \%$. The ion chamber measures analog current. A one-unit change in the least significant digit corresponded to a $0.3 \%$ expected error. For the neutron measurements, the reproducibility was $1.5 \%$ with approximately a $0.9 \%$ error caused by counting statistics. One fuel assembly was selected and was measured on each of the 5 days of measurements. An uncertainty of 2 to $3 \%$ was obtained for the neutron measurements and $1.4 \%$ for the ion chamber measurements on this assembly. Another series of measurements was performed to quantify the repro- ducibility of measurement for various fuel-assembly designs. Two 14 by 14 PWR, one 15 by 15 PWR, and one 7 by 7 BWR fuel assemblies each were measurued a minimum of six times at each corner, and the fuel assembly was repositioned for each measurement. For the three PWR fuel assemblies, the variation of neutron measurements was $1.1 \%$ and the variation of the ion chamber measurements was $0.6 \%$. These results demonstrate that reproducible results can be obtained with a simple positioning mechanism.

2. Angular Effects. The second longer range objective involved quantifying angular burnup effects by measuring different corners of the spent-fuel assemblies. The results of the reproducibility studies were combined with additional measurements made on all 17 spent-fuel assemblies and are given in Table XIII. The neutron emission rate varied by as much as 30 to $40 \%$ across the 
TABLE XIII

\section{ANGULAR VARIATION IN NEUTRON AND GROSS GAMMA MEASUREMENTS}

\begin{tabular}{lrr} 
& \multicolumn{2}{c}{ Maximum Variation (\%) } \\
Fuel Assembly & Neutron & Gross Gamma \\
\hline & & \\
A019 & 3 & 3 \\
C049 & 40 & 49 \\
A045 & 9 & 6 \\
B12 & 6 & 5 \\
C56 & 12 & 8 \\
C32 & 42 & 37 \\
C52 & 31 & 31 \\
DN201 & 18 & 19 \\
A051 & 9 & 7 \\
C004 & 36 & 25 \\
D001 & 5 & 4 \\
C001 & 34 & 27 \\
A036 & 11 & 7 \\
D020 & 28 & 24 \\
A009 & 4 & 3 \\
B046 & 12 & 7 \\
C020 & 24 & 10 \\
\end{tabular}

corners of an assembly. A similar variability was observed in the ion chamber results. Because the measurement reproducibility (or precision) was much better than this, the angular effects are real and their source is being investigated.

Additional evaluation of the data is continuing, including investigation of the effect of the fuel geometry and evaluation of empirical correlations. The primary conclusions drawn from these experimental measurements are as follows.

- Spent-fuel assemblies can be positioned using the V-shaped positioning mechanisms to obtain reproducible results. For neutron measurements the precision is 1 to $2 \%$, and for gross gamma measurements the precision is approximately $1 \%$. A significant part of the uncertainty associated with neutron measurements concerns the counting statistics.

- Angular orientation uf spent-fuel assemblies can be significant for passive neutron and gamma-ray measurements with yariations of 30 to $40 \%$ in both measurements. Additional experimental measurements and computer simulations are planned to establish the source of this nonuniformity.

B. Calculation of Fission Product Inventories in Spent-Fuel Assemblies (J. R. Phillips, G. E. Bosler, T. R. England, R. J. LaBauve, and W. B. Wilson)

Gamma-ray signatures of irradiated BWR and PWR can be measured nondestructively to verify the operator-declared values of exposure and cooling time. ${ }^{17}$ The responses of various gamma-ray signatures and isotopic ratios as a function of irradiation exposures have been determined using the EPRI-CINDER ${ }^{\text {ss }}$ code and library. ${ }^{49}$ The build up of the isotopic ratios of ${ }^{134} \mathrm{Cs} /{ }^{137} \mathrm{Cs}$ and ${ }^{194} \mathrm{Eu} /{ }^{137} \mathrm{Cs}$ for a typical PWR fuel assembly has been discussed in a previous progress report. ${ }^{2}$ These two isotopic ratios are plotted as a function of ${ }^{239} \mathrm{Pu}$ for two exposure histories in Figs. 37 and 38. The detailed history is the actual history of a PWR fuel assembly that includes a 61-day downtime between cycles. Once the ${ }^{134} \mathrm{Cs} /{ }^{137} \mathrm{Cs}$ ratio becomes $>0.065$, the quantity of ${ }^{239} \mathrm{Pu}$ does not vary by more than $5 \%$. This range corresponds to a burnup range of 20 to $50 \mathrm{GWd} / \mathrm{tU}$. Similar results are found for the ${ }^{154} \mathrm{Eu} /{ }^{137} \mathrm{Cs}$ isotopic ratio with a threshold of approximately 0.022 .

Figures 39 and 40 show the results of plotting these two isotopic ratios as a function of the remaining fissile inventory $\left({ }^{235} \mathrm{U}+{ }^{239} \mathrm{Pu}+{ }^{241} \mathrm{Pu}\right)$ in a typical PWR fuel assembly. The functional relationship is linear in both cases. The ${ }^{134} \mathrm{Cs} /{ }^{137} \mathrm{Cs}$ ratio is affected by the 61-day downtime more than the ${ }^{154} \mathrm{Eu} /{ }^{137} \mathrm{Cs}$ ratio is because the ${ }^{134} \mathrm{Cs}$ half-life is only $2.062 \mathrm{yr}$ as compared to a $8.6-\mathrm{yr}$ half-life for ${ }^{154} \mathrm{Eu}$. These calculations show that more information than just an estimate of the declared exposure can be obtained from the isotopic ratios of ${ }^{134} \mathrm{Cs} /{ }^{137} \mathrm{Cs}$ and ${ }^{154} \mathrm{Eu} /{ }^{137} \mathrm{Cs}$. They can be correlated directly with the remaining fissile inventory of spent-fuel assemblies.

\section{Active Source Calculations (G. E. Bosler and H. O. Menlove)}

Preliminary Monte Carlo calculations have been performed for the active-neutron, spent-fuel interrogation system shown in Fig. 41 . For these calculations, a ${ }^{252} \mathrm{Cf}$ source served as the neutron source, and various neutron 


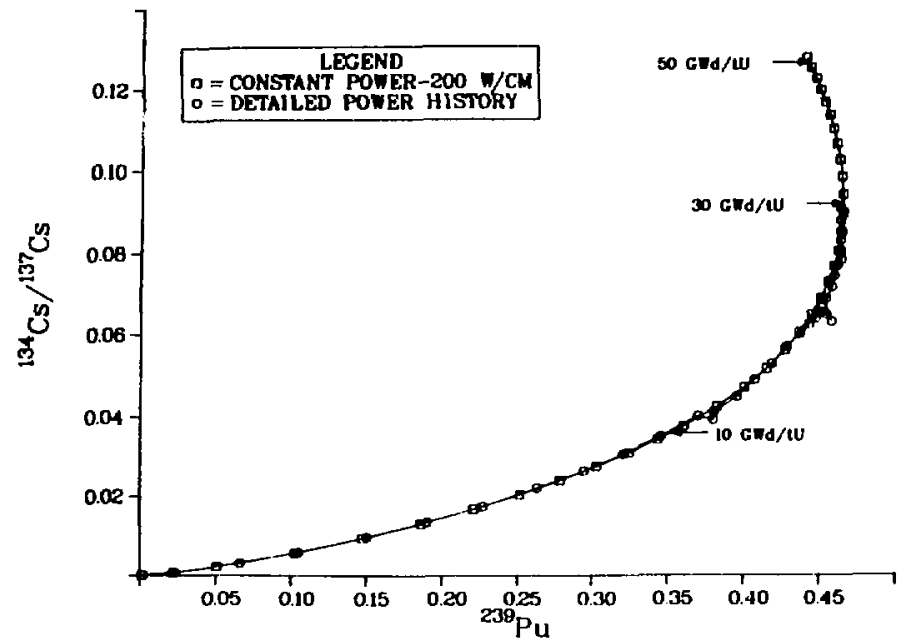

Fig. 37.

${ }^{134} \mathrm{Cs} /{ }^{137} \mathrm{Cs}$ isotopic ratio as a function of the remaining ${ }^{239} \mathrm{Pu}$ for exposures up to $50 \mathrm{GWd} / \mathrm{tU}$.

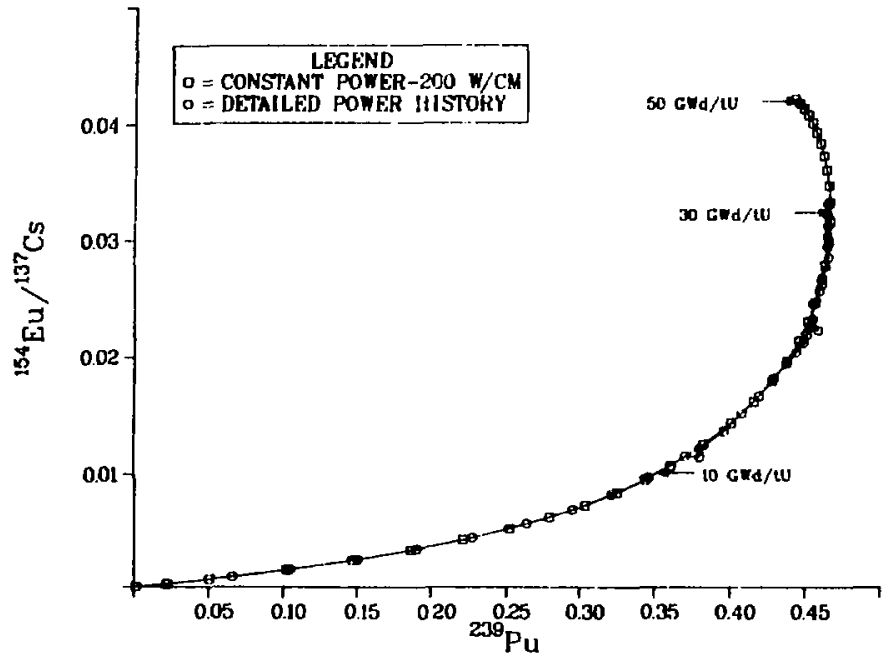

Fig. 38.

${ }^{154} \mathrm{Eu} /{ }^{137} \mathrm{Cs}$ isotopic ratio as a function of remaining ${ }^{239} \mathrm{Pu}$ for exposures up to $50 \mathrm{GWd} / \mathrm{tU}$. 


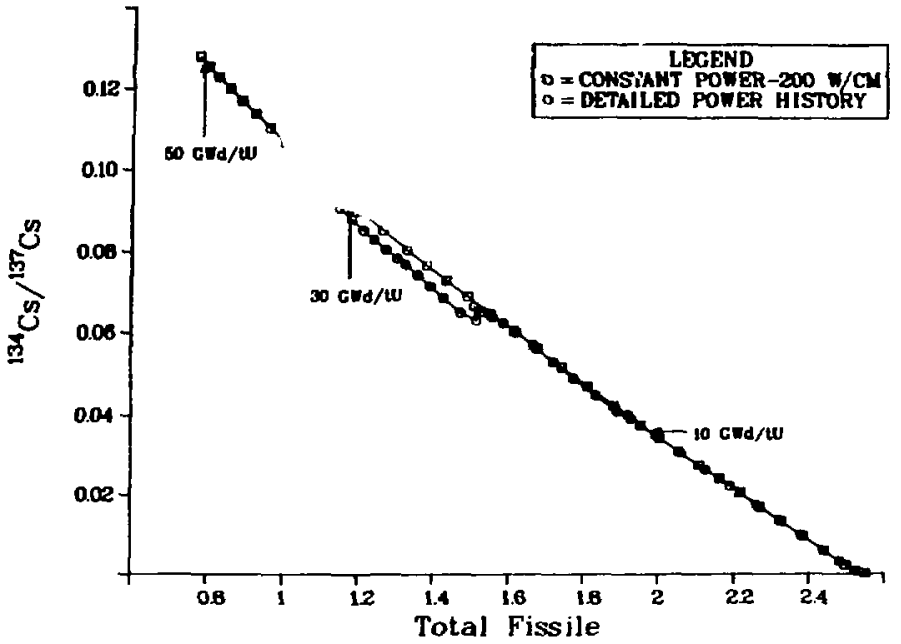

Fig. 39.

${ }^{134} \mathrm{Cs} /{ }^{137} \mathrm{Cs}$ isotopic ratio as a function of the remaining fissile inventory for exposures up to $50 \mathrm{GWd} / \mathrm{tU}$.

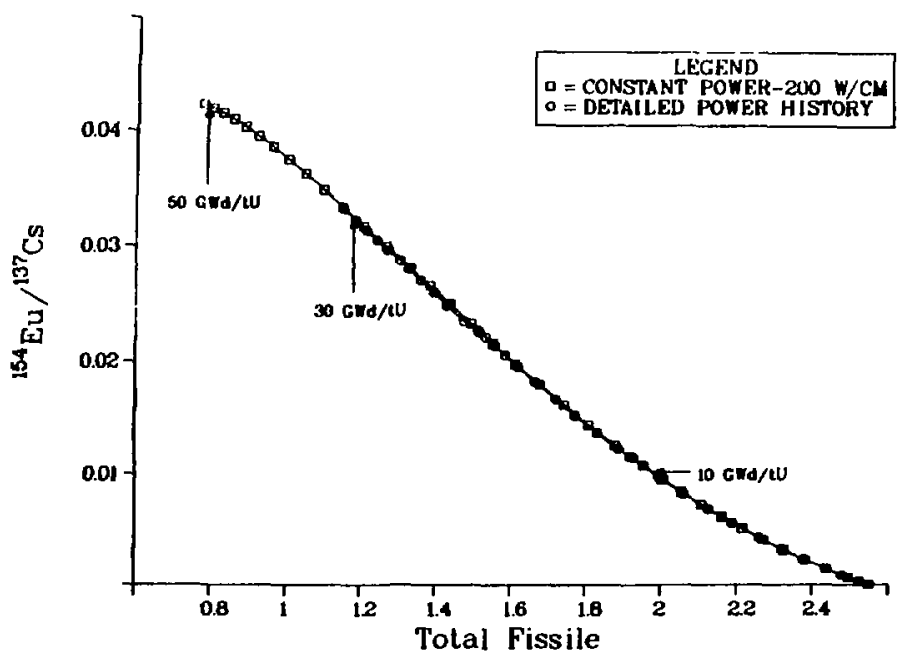

Fig. 40.

${ }^{154} \mathrm{Eu} /{ }^{37} \mathrm{Cs}$ isotopic ratio as a function of the remaining fissile inventory for exposures up to $50 \mathrm{GWd} / \mathrm{tU}$. 


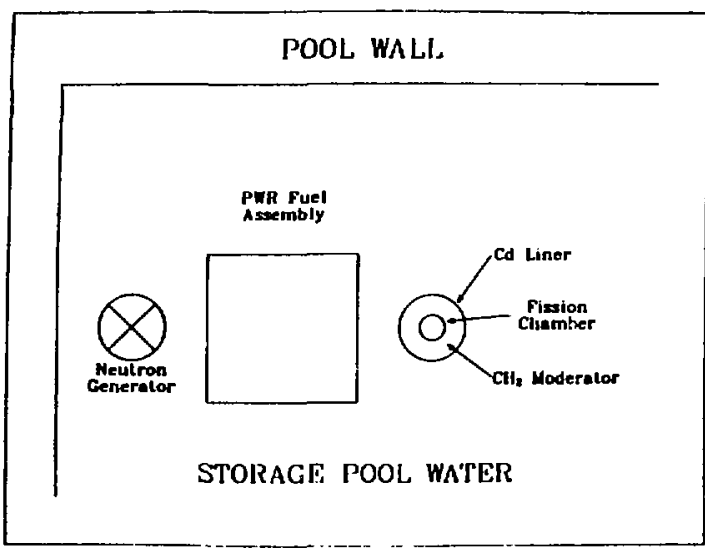

Fig. 41.

An active source interrogation system.

responses were determined for PWR fucl assemblies having exposure levels of approximately $0,10,20,30$, and $40 \mathrm{GWd} / \mathrm{tU}$. Actinide isotope compositions at these exposure levels were predicted from the H. B. Robinson-2 buildup-depletion calculational effort of Los Alamos Group T-2. Epithermal (that is, energies $>0.625$ $\mathrm{eV}$ ) and thermal (that is, energies $<0.625 \mathrm{eV}$ ) responses examined include

- number of neutrons exiting from the fuel-assembly surface opposite the californiurn source;

- number of neutrons entering the cadmium liner outside the polyethylene;

- number of neutrons entering the polyethylene;

- fission response in the fission chamber; and

- flux within the fission chamber.

For these studies, a special version* of the Los Alamos Monte Carlo code MCNP $^{30}$ was used. In this version, tally contributions caused by source neutrons and those caused by prompt fission neutrons can be separated.

To optimize the source-fuel-detector geometry, parametric studies were performed with a fresh-fuel assembly. By using the cadmium-polyethylene configuration around the fission chamber, the system detecis primarily epithermal neutrons from the fuel. The cadmium absorbs thermal neutrons exiting from the assembly, and the polyethylene moderates the epithermal neutrons passing through the cadmium liner. The op-

*This information was supplied by the G. I Eccleston, Los Alamos National Laboratory Group Q-1 and R. G. Schrandt, Los Alamos National Laboratory Group X-6. timization for detecting epithermai neutrons consists of two parts:

(1) selecting a polyethylene thickness that adequately moderates the epithermal neutrons, and

(2) maximizing the ratio of the induced fission neutron flux to the ${ }^{252} \mathrm{Cf}$ source neutron flux in the fission chamber.

For (1), the distance between the fuel assembly surface and the cadmium surrounding the detector was fixed at $1.27 \mathrm{~cm}$, and the polyethylene thickness was varied. From these studies, a polyethylene thickness of $5 \mathrm{~cm}$ was chosen for the design. Larger thicknesses yielded slightly more moderation; however, the added bulk of a detector configuration with polyethylene thicknesses $>5 \mathrm{~cm}$ more than offsets the slight moderation advantages.

For (2), the detector configuration chosen from (1) studies was used, and the source-to-fuel assembly distance was varied. The ratio of prompt fission nevtron to ${ }^{252} \mathrm{Cf}$ source neutron fluxes varied from 5 for a source position almost touching the fuel assembly to 22 for . source position $2 \mathrm{~cm}$ from the assembly. The ratio did not change greatly for positions beyond $2 \mathrm{~cm}$, but the detector response per source neutron decreased. Thus, for the design source-fuel-assembly-detector configuration, a source-to-fuel assembly distance of $2 \mathrm{~cm}$ was chosen.

Using this design configuration, a series of calculations was performed to predict the detector response for fuel assemblies having different exposures. Results of these calculations for H. B. Robinson-2 fuel are given in Table XIV and Figs. 42 through 44. Error bars on the various figures represent one standard deviation in the calculated results. In Figs. 42 through 50, the epithermal and thermal neutron currents into and out of various surfaces are shown. The epithermal neutron current from the fuel assembly is larger than the thermal current, and it is primarily from prompt fission neutrons (see Fig. 42). The thermal neutron current is composed of both source and prompt fission neutrons that have been moderated in the water. Thus, besides having a larger signal to measure, an epithermal neutron detector system provides an inherent means for measuring prompt fission neutrons while discriminating against ${ }^{252} \mathrm{Cf}$ source neutrons. We hope that correlations between prompt neutron responses and fissile content in the fuel assembly can be developed. In Figs. 43 and 44, the effect of the cadmium liner around the detector is shown. Whereas both epithermal and thermal neutrons enter the cadmium (Fig. 43), primarily vinly epithermal neutrons exit the cadmium (Fig. 44). 
TABLE XIV

EPITHERMAL AND THERMAL NEUTRON RESULTS

FOR MEASUREMENT GEOMETRY

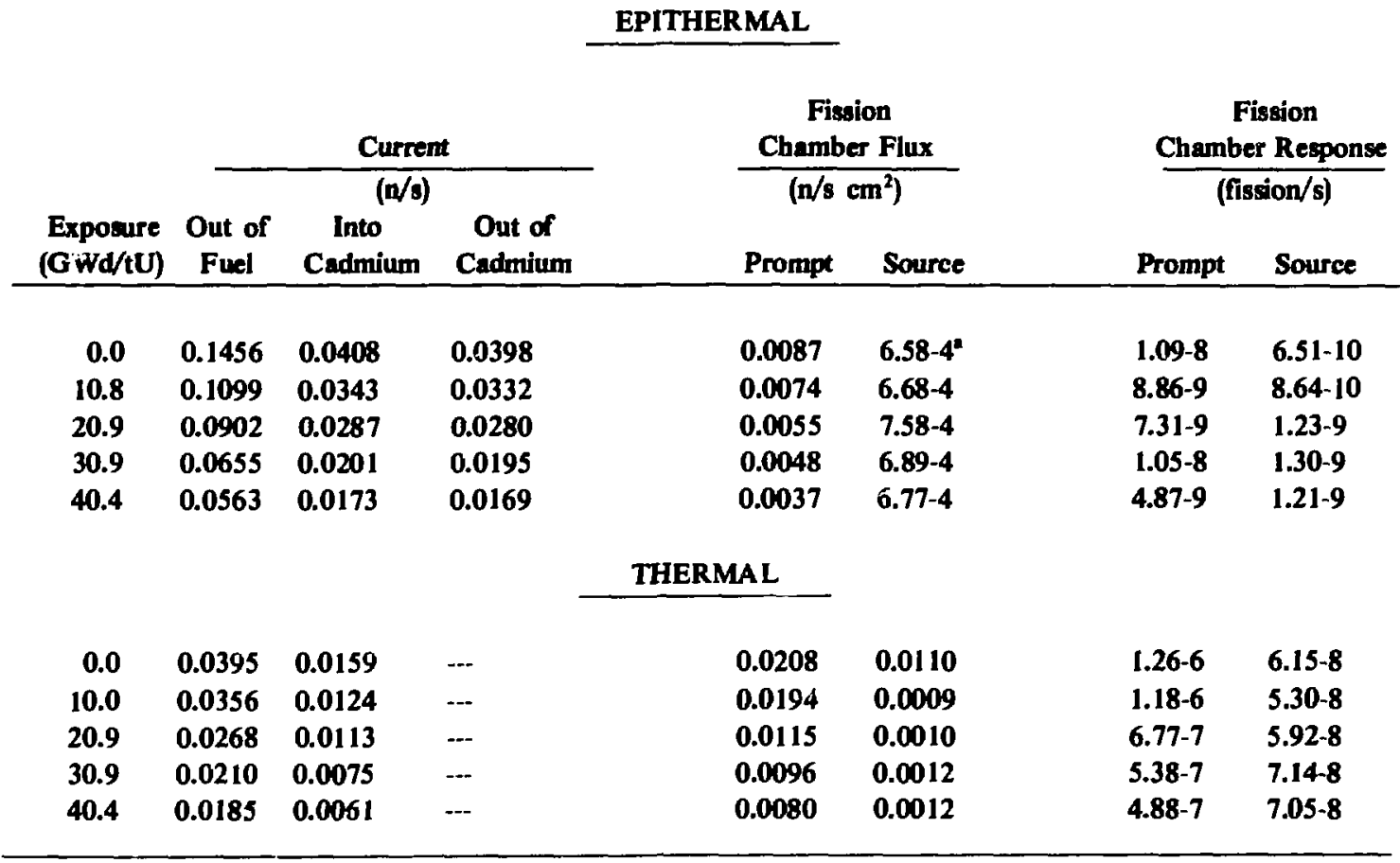

'Read as $6.58 \times 10^{-4}$.

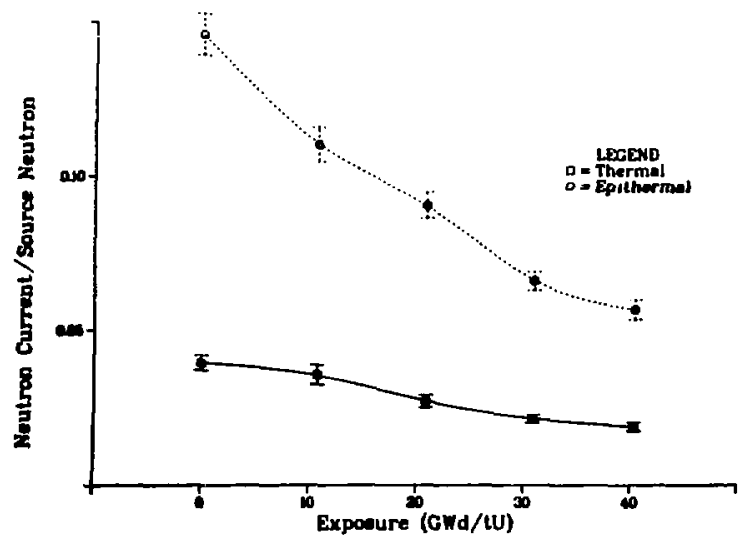

Fig. 42.

Neutron currents from the fuel-assembly surface opposite the ${ }^{292} \mathrm{Cf}$ source.

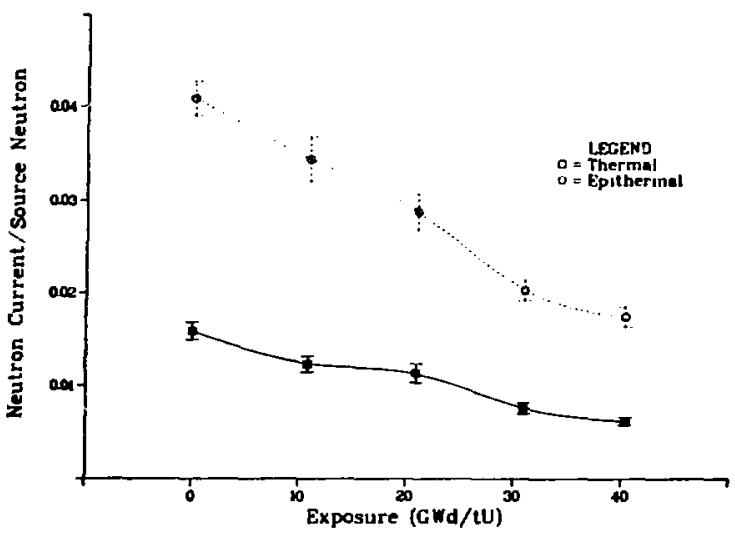

Fig. 43.

Neutron currents into the cadmium liner surrounding the detector. 


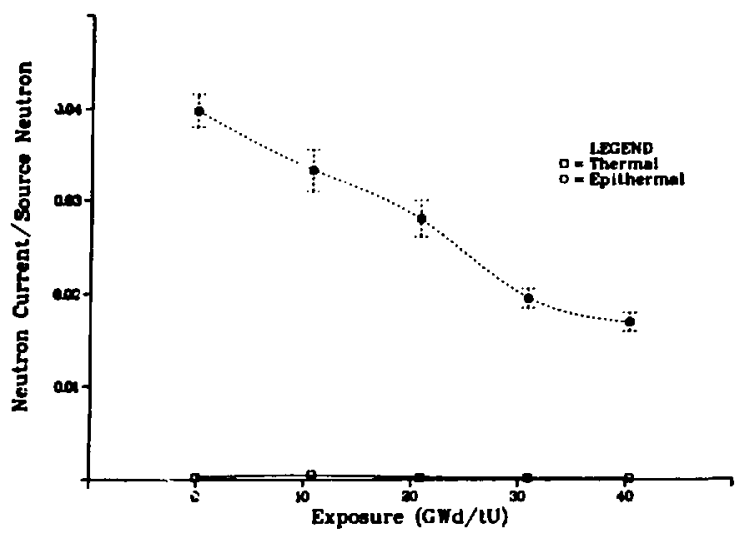

Fig. 44.

Neutron currents from the cadmium liner and into the polyethylene.

Fig. 45.

Normalized neutron currents from the fuel-assembly surface opposite the ${ }^{252} \mathrm{Cf}$ source. Epithermal and thermal currents are normalized to the respective fresh-fuel (zero exposure) values.
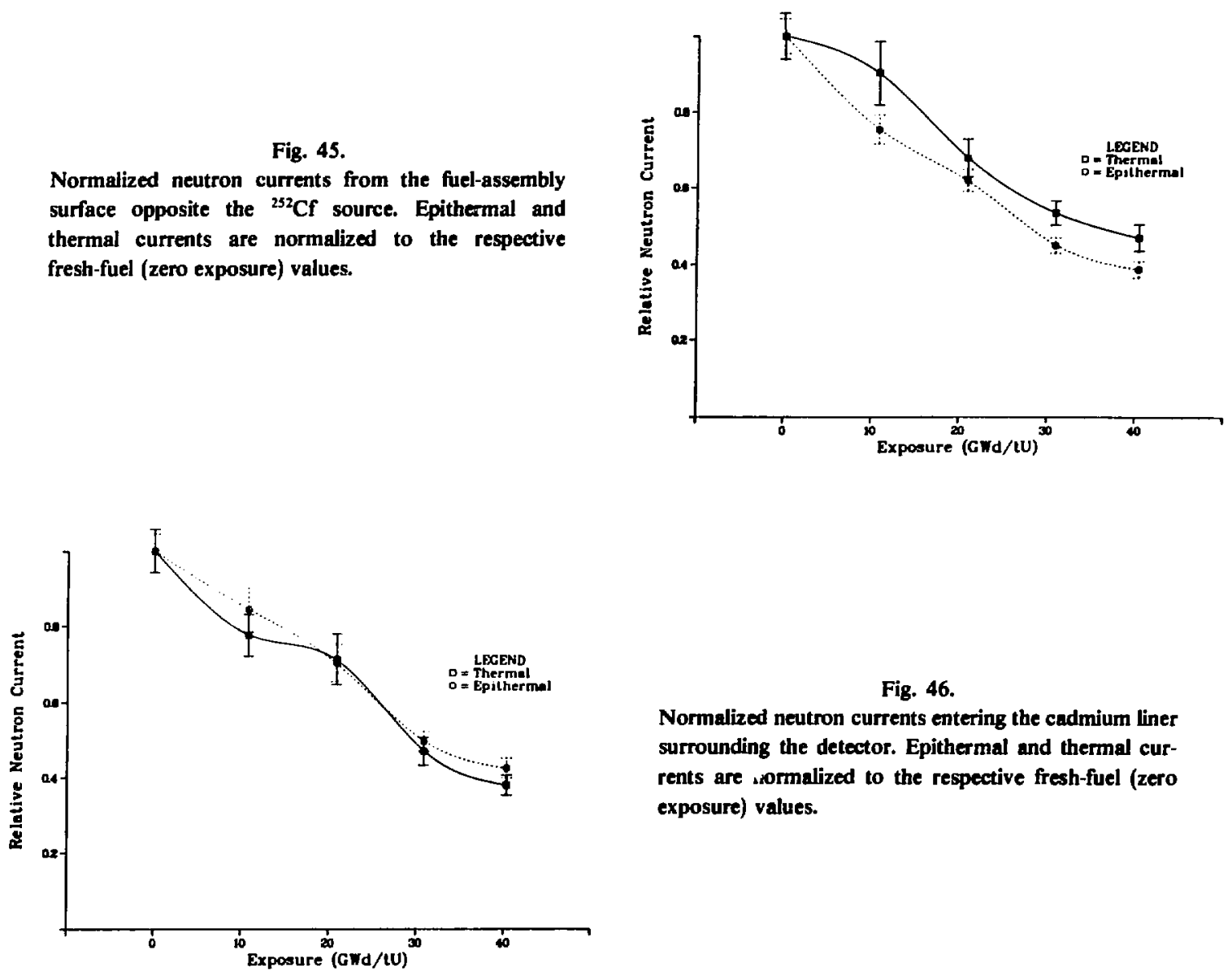

Fig. 46.

Normalized neutron currents entering the cadmium liner surrounding the detector. Epithermal and thermal currents are sormalized to the respective fresh-fuel (zero exposure) values. 


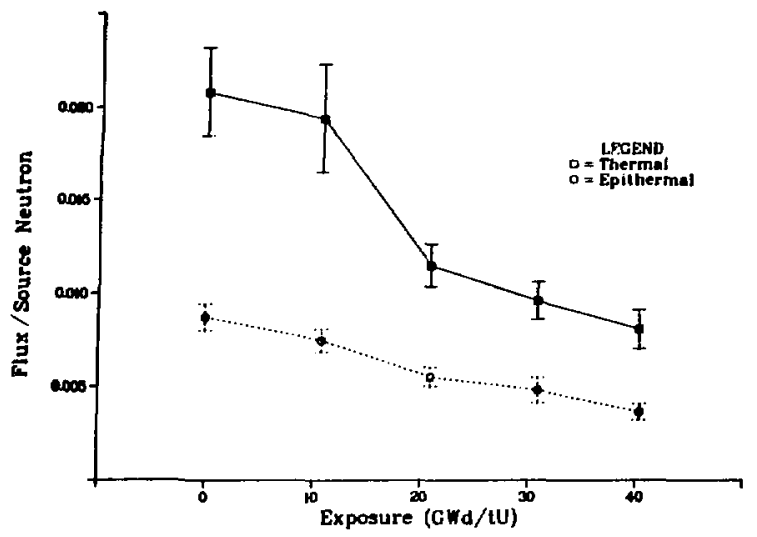

Fig. 47.

Epithermal and thermal fluxes in the fission chamber caused by prompt fission neutrons.

Fig. 48.

Epithermal and thermal fission responses in the fission chamber caused by prompt fission neutrons.

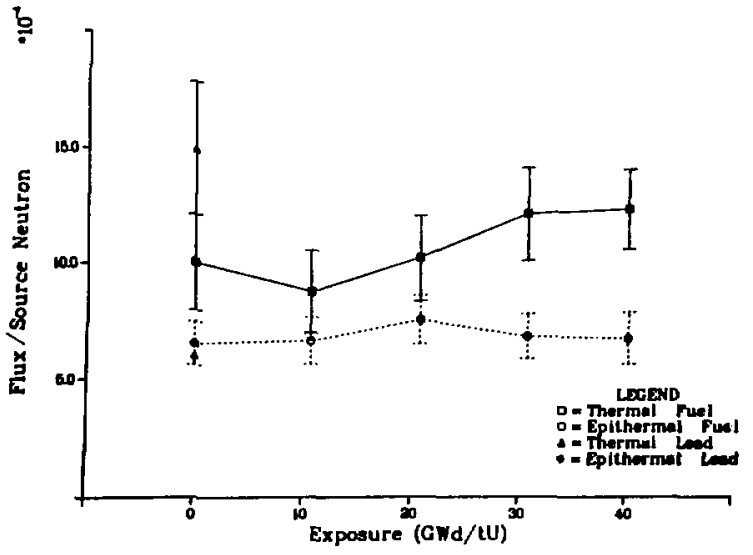

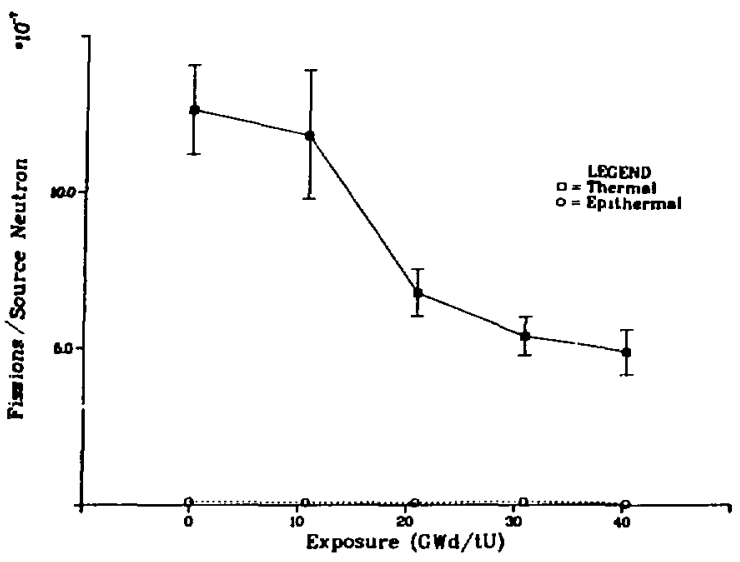

Fig. 49.

Epithermal and thermal fluxes in the fission chamber caused by ${ }^{292} \mathrm{Cf}$ source neutrons. The effect of substituting lead for the fuel pins also is shown. 


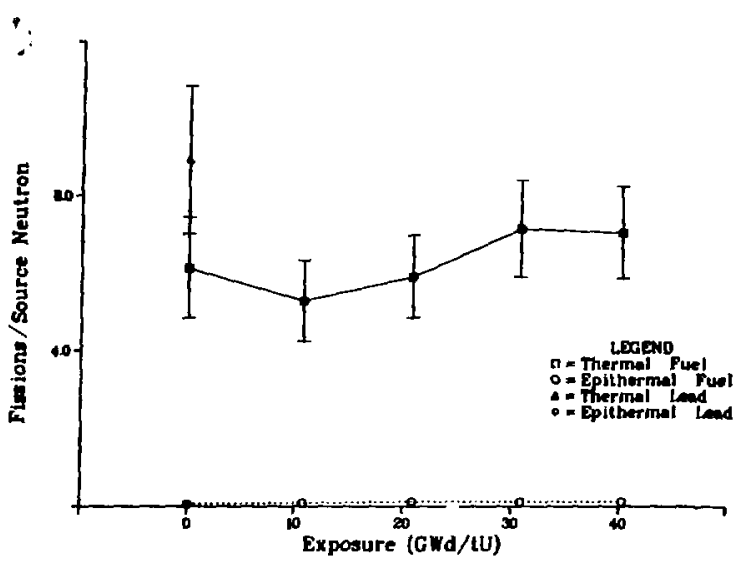

Data in Figs. 42 and 43 are renormalized and plotted in Figs. 45 and 46. In these plots, the epithermal and thermal neutron currents are normalized to the fresh-fuel values to show that the slopes as a function of exposure are similar. Because both currents display similar sensitivities to exposure levels, there is no distinct advantage in using one current over the other to correlate signal-to-exposure level. Therefore, the epithermal measurement system is still more advantageous beceuse of the discrimination against source neutrons. These arguments for an epithermal detector system still are contingent on further calculations to study the authenticity of the prompt neutron signal. If the epithermal prompt fission signal reflects only fission events near the edge of the assembly, then the signal cannot be used as proposed with any confidence. This situation is not expected to occur because of neutron multiplication.

In Figs. 47 through 50, the prompt and source neutron responses in the fission chamber are shown. Figure 47 shows the epithermal and thermal prompt neutron fluxes in the chamber. Because most thermal neutrons from the fuel assembly are captured in the cadmium surrounding the detector, epithermal and thermal fluxes in the chamber are principally a measure of moderation effects in the polyethylene. As a result, the thermal flux in the fission chamber is larger than the epithermal flux. In Fig. 48, the actual detector response for the prompt neutrons is estimated. For these plots, the macroscopic fission cross section is folded in with the fluxes, and the large thermal fission cross section for ${ }^{235} \mathrm{U}$ results in the much larger thermal contribution.
Fig. 50.

Epithermal and thermal Assion respones in the fiesion chamber caused by ${ }^{25} \mathrm{Cf}$ source neutron. The effect of substituting lead for the fuel pins also is shown.
Figures 49 and 50 show the same data as Figs. 47 and 48 for the source neutron response in the fission chamber. As expected, within the statistical errors the source contribution remains relatively constant over the exposure range investigated. Because the source contribution does remain constant, experimental techniques can be used to quantify the detector response resulting from source neutrons. One such technique would replace fuel with a nonfissioning material that has similar scattering and absorption properties. The detector response obtained from such a dummy assembly should be similar to the detector response for source neutrons. As shown in Figs. 49 and 50, a lead substitute assembly yields a response that is approximately $50 \%$ higher than the source response. Because lead has small absorption properties compared to fuel materials, a heavy material such as tungsten with larger absorption cross sections may be more suitable for dummy assembly use. Calculations on various dummy assembly materials are in progress.

These preliminary calculations demonstrate the feasibility of using active source interrogation techniques for determining spent-f, ol parameters. The prompt neutron response decreases as the exposure level increases. Because this decrease depends primarily on the fuel's fissile content, correlating epithermal neutron respoilse with fissile content or similar quantities may be possible. All active systems must have source strengths large enough to override the inherent spent-fuel neutron background. These background neutrons come from spontaneous fission and $(\alpha, n)$ events, usually in the higher 
actinides. Such background levels increase with exposure, so the active source strength must be large enough to overcome neutron levels in assemblies with high exposures. Additional calculations to examine the active system potential and to establish correlations are planned. As much as possible, correlations established by calculation will be verified experimentally.

D. Active Neutron System for Spent-Fuel Measurements at AFR Storage Facilities: Comparison of Design Calculations and Experiments (G. W. Eccleston)

Developing active and passive neutron assay techniques for light-water-reactor spent fuels is in progress. This measurement program will enable AFR facilities to verify and assay spent-fuel assemblies when received.

Designing a spent-fuel assay system for neutron measurements depends on understanding the neutronics of background neutrons (primarily spontaneous fission from ${ }^{242} \mathrm{Cm}$ and ${ }^{244} \mathrm{Cm}$ ) and neutrons from fission produced by an external neutron-interrogation source. Measurements that enable the study of neutronics are difficult to obtain in a laboratory where the actual spent-fuel assemblies cannot be handled. Computer calculations using Monte Carlo and discrete ordinates codes enable parametric data to be obtained to supplement laboratory measurements. Experiments are possible on unirradiated fuel assemblies that represent various stages of burnup. These assemblies are constructed with appropriate combinations of cold fuel rods containing plutonium or uranium. Calculations that simulate the experimental geometries are compared with the measured data to check the validity of the computer models. In addition, the calculations, once validated, give information on the suitability of the experimental mockup assemblies for providing AFR design data that correspond to actual spent-fuel assemblies.

Neutron measurements on spent-fuel assemblies require counters capable of operating in large neutron vields $\left(10^{10} \mathrm{n} / \mathrm{s}\right)$ while subject to intense gamma dose rates $(50000 \mathrm{R} / \mathrm{h})$. Several neutron detectors can meet these requirements; among them fission chambers offer some distinct advantages. Fission chambers require little or no gamma-ray shielding and can detect individual neutrons in an incident gamma-ray flux of $10^{6} \mathrm{R} / \mathrm{h}$. They have low detection efficiency, enabling neutron counting to be performed with minimal deadtime effects when exposed to large neutron fields. Research and development experiments pertaining to the AFR assay system now are using fission chambers for both passive and active neutron measurements.

The fission chambers, supplied by Reuter-Stokes (model number RS-PG-0805), may be ordered in varying dimensions. Uranium coatings on the tube wall have thicknesses up to $2 \mathrm{mg} / \mathrm{cm}^{2}$. The detectors now in use contain $143 \mathrm{mg}$ of $\mathrm{UO}_{2}$ enriched to $93.2 \mathrm{wt} \%$ corresponding to a $1 \mathrm{mg} / \mathrm{cm}^{2}$ wall coating.

Initial code validation work compared with the calculated response of a fission chamber with experimental measurements. The experiments consisted of placing a ${ }^{252} \mathrm{Cf}$ source and a fission chamber at the midplane of a $60-\mathrm{cm}$-diam by $120-\mathrm{cm}$-high aluminum barrel filled with water. Fission chamber count rates were obtained for a series of source-detector separations. The ${ }^{252} \mathrm{Cf}$ source produced a $4.51 \times 10^{5} \mathrm{n} / \mathrm{s}( \pm 1.22 \%$ on $12 / 1 / 80)$ at the time of the experiment. The Monte Carlo code tallies events/source neutron, so the measured count rates were converted to counts/source neutron for direct comparison with calculations.

Monte Carlo simulations were performed using a geometry model that described the experimental source-detector configuration. ${ }^{2}$ The fission chamber was simplified in the calculations by modeling the $\mathrm{UO}_{2}$ wall coating as a fictitious gas uniformly distributed throughout the detector. Based on the loading in the Reuter-Stokes counter, the $\mathrm{UO}_{2}$ gas density in the fission chamber was computed to be $2.22 \times 10^{-3} \mathrm{gm} / \mathrm{cc}$, corresponding to $5.0 \times 10^{18} \mathrm{UO}_{2}$ molecules/cc or $1.5 \times$ $10^{19}$ atoms/cc.

Calculations were performed for different detector-source separations corresponding to the experimental measurements. The neutron source in the computer runs was modeled as a point, isotropic neutron emitter with a fission-energy-spectrum distribution. Continuous energy cross sections supplied with the Monte Carlo code were used for all materials. Interactions of neutrons with water were treated using a free-gas thermal treatment with the $S(\alpha, \beta)$ model. This model improves the free-gas calculation by representing thermal neutron scattering by molecules and crystalline solids. Fission events in the detector were determined as fissions/source neutron. The calculational data are plotted as the upper curve of Fig. 51.

The experimental and calculational data of Fig. 51, listed in Table XV, are independeni and no normalization factor has been applied between the experimental and calculational data. Compared to the calculations, the experimental measurements (counts/neutron) are systematically smaller by 7 to $50 \%$. 


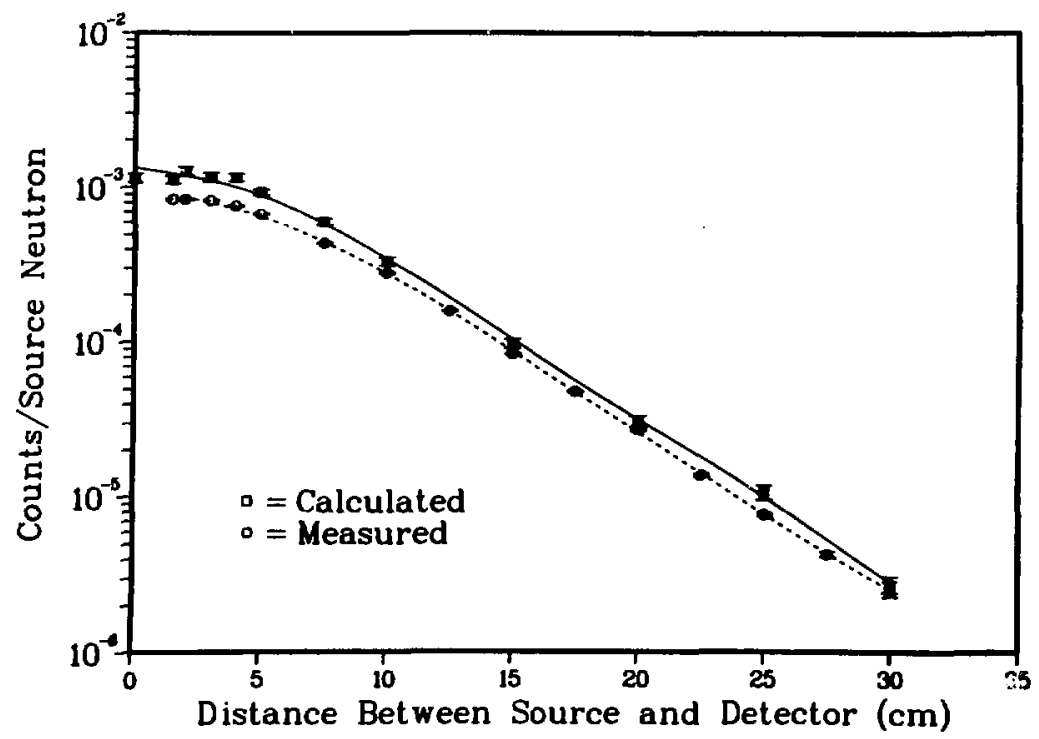

Fig. 51.

Counts/source neutron vs separations in water between ${ }^{292} \mathrm{Cf}$ source and fission chamber.

The code calculates fissions/source neutron and not counts. The measured count rate for a fission chamber with a $1-\mathrm{mg} / \mathrm{cm}^{2} \mathrm{UO}_{2}$ coating may require a correction of up to $25 \%$ to obtain the fission rate. ${ }^{50}$ This increase is required because not all fission events in the detector produce a detected pulse. This occurs when the wall coating in the detector is sufficiently thick that some fraction of the heavy mass fragments produced in fission loses enough energy escaping the $\mathrm{UO}_{2}$ to be below the alpha threshold, thus preventing the register of a fission count.

The percentage difference between the calculational and experimental data increases as the distance between the source and detector decreases. The thermal and epithermal neutron flux in water from a fission spectrum as a function of distance from the source is shown in Fig. 52. The energy spectrum from a fission source in water reaching a detector is essentially all epithermal $(>0.25$ $\mathrm{eV}$ ) for distances of $5 \mathrm{~cm}$ or less between the source and detector. Resonance self-shielding effects that depend on neutron energy and approximations in rnodeling the detector as filled with a fictitious $\mathrm{UO}_{2}$ gas may account in part for the increasing difference observed between experiment and calculation for small source-detector separations.

Active neutron measurements on spent-fuel assemblies. may measure total or epithermal counts. Epithermal events are obtained by wrapping the counters in cadmium. Generally, to increase detection efficiency for epithermal events, the counters are encased in a polyethylene sleeve wrapped in cadmium. Calculations of epithermal and total detector response can be obtained from one calculation by using an energy-bin tally with an energy bin below the cadmium cutoff.

To determine the effective cadmium cutoff energy, a series of calculations with different energy bins was completed and compared to measurements. The experimental data consisted of counts collected from a fission chamber with and without a cadmium cover. The response of a fission chamber with and without a cadmium wrap to monoenergetic neutrons was calculated with the following equations.

$$
\begin{aligned}
& R_{D}(E)=1-e^{-\Sigma_{f}(E) x}, \\
& R_{C}(E)=R_{D}(E) e^{-\Sigma_{a}(E) y},
\end{aligned}
$$

where

$R_{D}(E)=$ fission chamber response to neutrons of energy E;

$\Sigma_{f}(E)=$ macroscopic fission cross section $\left(\mathrm{cm}^{-1}\right)$ of ${ }^{235} \mathrm{U}$ at energy $E$; 
COMPARISON BETWEEN EXPERIMENTAL AND CALCULATIONAL RESPONSES TO $A{ }^{252} \mathrm{CF}$ SOURCE FOR A FISSION CHAMBER IN WATER

\begin{tabular}{cccc}
$\begin{array}{c}\text { Source-Detector } \\
\begin{array}{c}\text { Separation } \\
(\mathrm{cm})\end{array}\end{array}$ & $\begin{array}{c}\text { Experiment } \\
\text { (counts/ } \\
\text { source neutron) }\end{array}$ & $\begin{array}{c}\text { Calculation } \\
\text { (fissions/ } \\
\text { source neutron) }\end{array}$ & $\begin{array}{c}\text { Difference } \\
\text { (\%) }\end{array}$ \\
\hline 0 & - & $1.142-3 \pm 7.526-5$ & - \\
1.5 & $8.34-4 \pm 2.43-5$ & $1.112-3 \pm 6.272-5$ & 33.3 \\
2.0 & $8.37-4 \pm 1.05-5$ & $1.261-3 \pm 7.780-5$ & 50.7 \\
3.0 & $8.23-4 \pm 1.03-5$ & $1.158-3 \pm 7.133-5$ & 40.7 \\
4.0 & $7.61-4 \pm 9.58-6$ & $1.147-3 \pm 6.148-5$ & 50.7 \\
5.0 & $6.77-4 \pm 8.77-6$ & $9.268-4 \pm 3.679-5$ & 36.9 \\
7.5 & $4.40-4 \pm 6.10-6$ & $6.020-4 \pm 2.703-5$ & 36.8 \\
10.0 & $2.79-4 \pm 4.53-6$ & $3.322-4 \pm 2.100-5$ & 19.1 \\
12.5 & $1.57-4 \pm 2.27-6$ & - & - \\
15.0 & $8.41-5 \pm 1.41-6$ & $9.738-5 \pm 6.583-6$ & 15.8 \\
17.5 & $4.86-5 \pm 8.52-7$ & - & - \\
20.0 & $2.73-5 \pm 6.77-7$ & $3.098-5 \pm 2.500-6$ & 13.4 \\
22.5 & $1.37-5 \pm 3.47-7$ & - & - \\
25.0 & $7.72-6 \pm 1.91-7$ & $1.062-5 \pm 1.076-6$ & 37.6 \\
27.5 & $4.35-6 \pm 1.05-7$ & - & - \\
30.0 & $2.62-6 \pm 1.19-7$ & $2.735-6 \pm 3.320-7$ & 7.2 \\
\hline
\end{tabular}

$1.142-3=1.142 \times 10^{-3}$

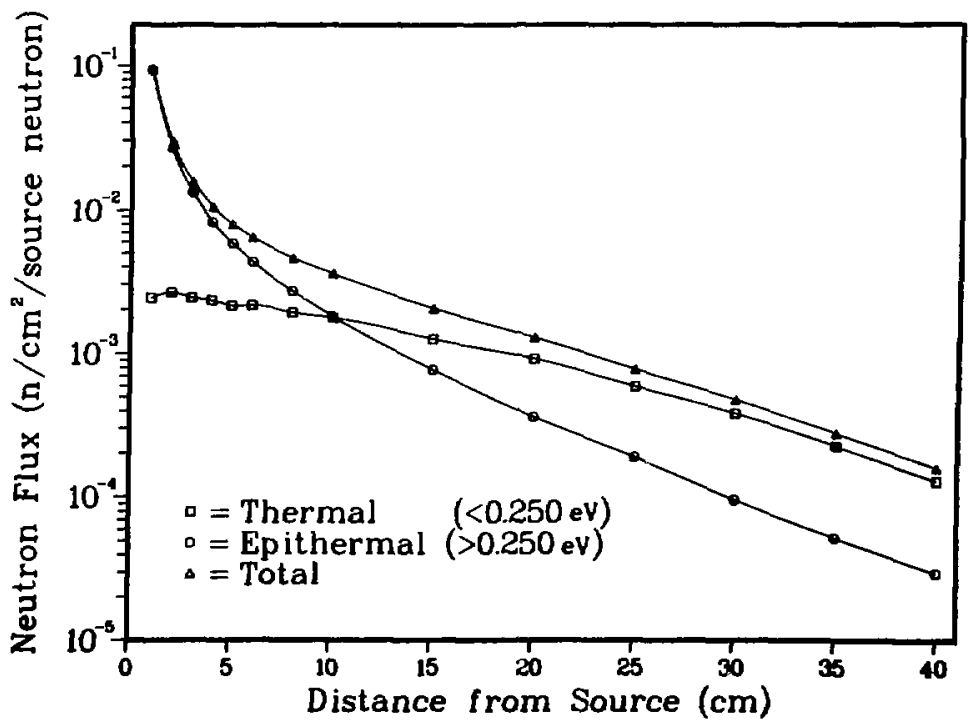

Fig. 52.

Flux in water vs distance from a point fiasion source. 
$\mathbf{x}=$ average distance $(\mathrm{cm})$ through the detector;
$\boldsymbol{R}_{\mathrm{c}}(\mathrm{E})=$ fission chamber response for a cad- mium-wrapped detector to neutrons of energy $E$;

$\Sigma_{a}(E)=$ macroscopic absorption cross section $\left(\mathrm{cm}^{-1}\right)$ of cadmium for neutrons of energy $E$; and

$\mathbf{y}=$ cadmium thickness (cm).

The data used to determine $R_{D}(E)$ in Eq. (2) and $R_{c}(E)$ in Eq. (3) are given in Table XVI, and plots of the fission-chamber response with and without the cadmium liner are shown in Fig. 53. The cross sections were obtained from the Monte Carlo library.

The response functions in Fig. 53 show that cadmium effectively prevents low-energy neutrons from reaching the fission chamber. Note that the ratio of responses (bare detector to cadmium-wrapped) listed in Table XVI becomes large for neutron energies $<0.40 \mathrm{eV}$ and that the effective cutoff energy depends on the energy spectrum of neutrons that intercept the cadmium.

Determining the cadmium cutoff energy of a fission source for a fission chamber in water was accomplished using both experimental and calculational data. Experimental data consisted of measuring counts from a bare and a cadmium-wrapped fission chamber immersed in water for various californium source-detector separations. The ratio of cadmium-to-bare detector counts is plotted in Fig. 54. Calculated fission events in the detector were tallied in an energy-bin structure for a series of computations matching the measurements. The ratio $\left(R_{e p /} / R_{t o t}\right)$ of the number of events with energy above a specified cutoff to the total number of events in the detector for a series of source-detector separations is plotted in Fig. 55. Increasing the separation between source and detector provides more thermalization of neutrons and produces a lower ratio of epithermal-to-total counts. As the energy-bin limit is decreased from $0.6 \mathrm{eV}$ toward $0.1 \mathrm{eV}$, the ratio of tallied counts above the energy-bin limit to total counts increases slowly until about $0.3 \mathrm{eV}$.

The cadmium cutoff energy was determined using Figs. 54 and 55. The data in Fig. 54 are replotted in Fig. 55 as the large asterisks. Each curve corresponds to a different source-detector separation. The cadmium cutoff energy changes with source-detector separation because the neutron spectrum reaching the cadmium and the detector changes with the separation. Typically, the detector will be separated from an actual spent-fuel assembly by about $5 \mathrm{~cm}$ or greater. Therefore, the cutoff energy should be between 0.2 and $0.3 \mathrm{eV}$, or an average value of about $0.25 \mathrm{eV}$. The response of a cadmium-wrapped fission chamber will be between 2 to $1 \%$ of the bare detector response to a fission spectrum for a separation of 5 to $15 \mathrm{~cm}$ between the source and detector.

\section{Summary}

Fission chamber response to $\mathrm{a}^{232} \mathrm{Cf}$ source in a water environment has been studied both experimentally and with Monte Carlo calculations. The fission chamber was modeled as a cylinder filled with $\mathrm{UO}_{2}$ gas. The calculated detector responses agree with the measurements. The effect of cadmium was studied and determined to have an effective energy cutoff of $0.25 \mathrm{eV}$. This cutoff energy varies with separation between the source and detector. Initial code validation work: has been completed, ensuring that a fission spectrum source and a fission chamber can be adequately modeled in a water environment.

E. Prompt and Delayed Neutron Yields as a Function of Exposure (G. W. Eccleston and S. T. Hsue)

1. LWR Spent-Fuel Assay Systems. A generic assay system for direct nondestructive measurements of the residual fissile content of spent LWR fuel assemblies is being developed and will operate underwater in the cooling pond of AFR storage facilities. Data from measurements performed on individual fuel assemblies will be used to determine the total effective fissile content and the fissile quantities of uranium and plutonium in the measured assembly.

Direct measurements of the fissile contents of irradiated fuel assemblies require active neutron interrogation techniques. The intense neutron background from high-burnup assemblies, mainly caused by ${ }^{242} \mathrm{Cm}$ and ${ }^{244} \mathrm{Cm}$, will require reasonably strong sources for the active assay measurement to override the background.

Passive neutrons from spontaneous fission and $(a, n)$ reactions in the fuel will be measured to provide background levels before performing the active interrogation measurement. The passive signal from the curium isotopes will provide correlations of burnup and plutonium content. The goal of the active measurement is to determine directly the effective fissile content. 
TABLE XVI

\section{CROSS SECTIONS AND DETECTOR RESPONSE FOR A BARE AND A CADMIUM-WRAPPED FISSION CHAMBER AS A FUNCTION OF NEUTRON ENERGY}

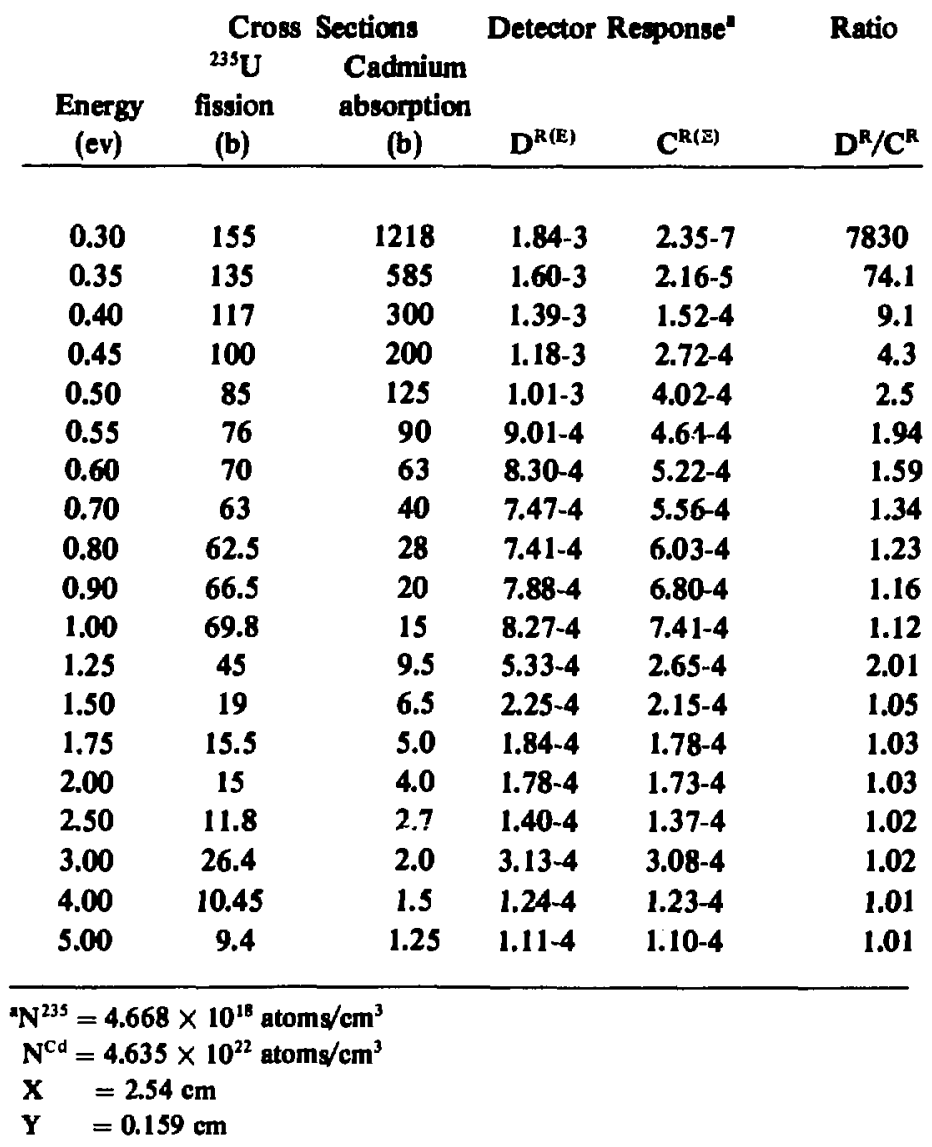

2. Spent-Fuel Composition. Prompt and delayed neutron emissions for active measurements on fuel assemblies depend on the quantities of the fissile isotopes ${ }^{233} \mathrm{U},{ }^{239} \mathrm{Pu}$, and ${ }^{241} \mathrm{Pu}$. To calculate the prompt and delayed emission sensitivities with respect to burnup, representative spent-fuel compositions as a function of burnup are required.

Atom densities for uranium and plutonium isotopes have been obtained from CINDER calculations for the
H. B. Robinson PWR fuel. ${ }^{51.52}$ The calculated atom densities compare closely with data obtained from destructive analysis of this fuel that had been irradiated up to $30000 \mathrm{MWd} / \mathrm{tU}$. A plot of the calculated atom densities vs burnup is shown in Fig. 56 with an irradiation up to $50000 \mathrm{MWd} / \mathrm{tU}$. The atom densities for each isotope at $5000-\mathrm{MWd} / \mathrm{tU}$ steps, as provided by the CINDER code, are shown in Table XVII. 


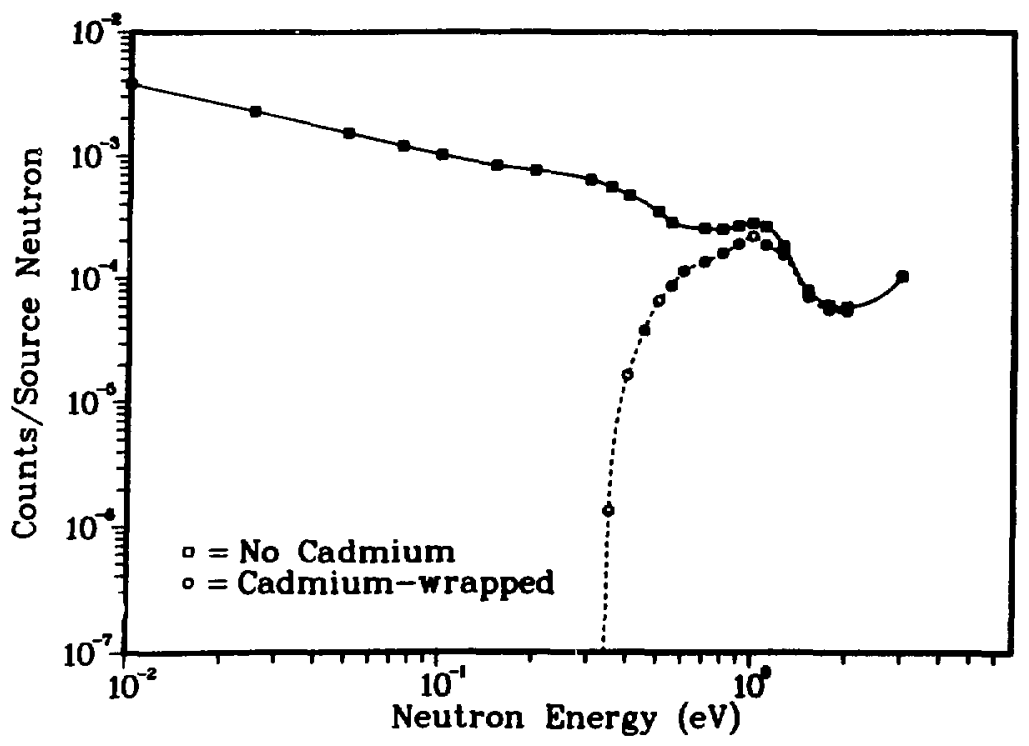

Fig. 53.

Fission chamber response with and without a cadmium wrap.

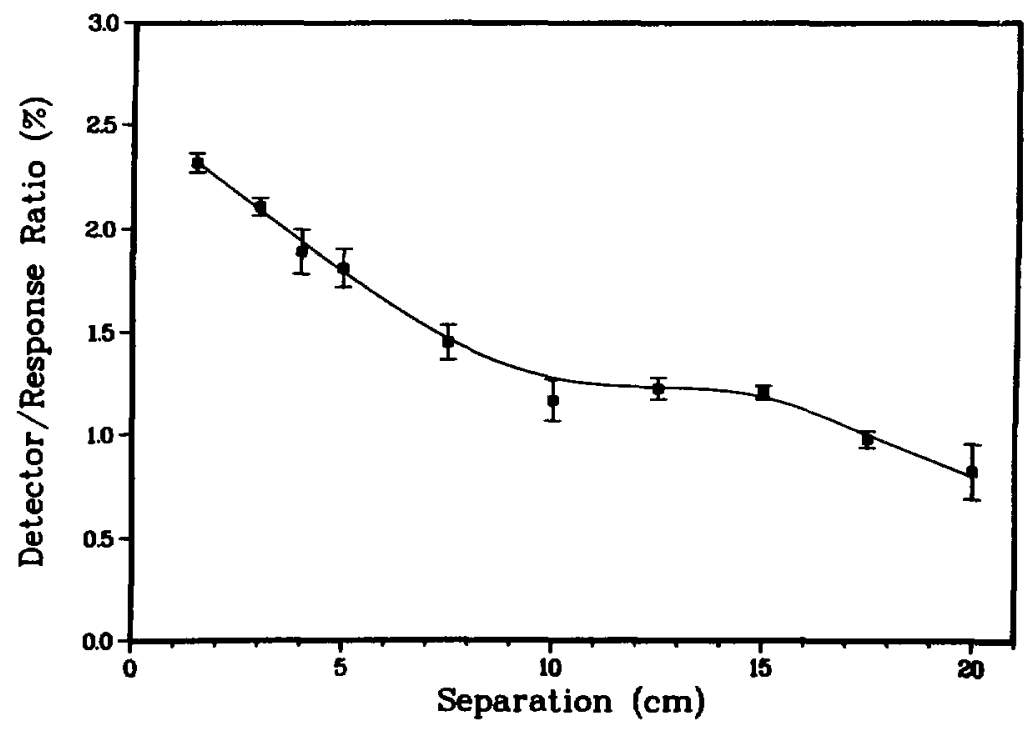

Fig. 54.

Fission chamber and ${ }^{252} \mathrm{Cf}$ source in water cadmium/no cadmium detector response. 


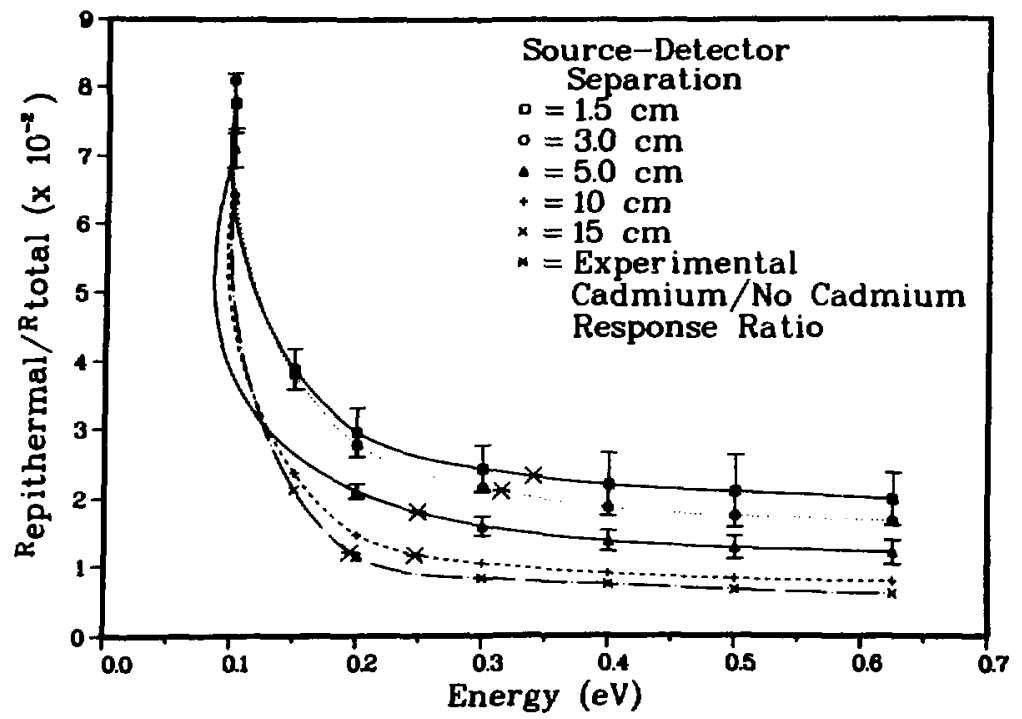

Fig. 55.

Calculational and experimental data.

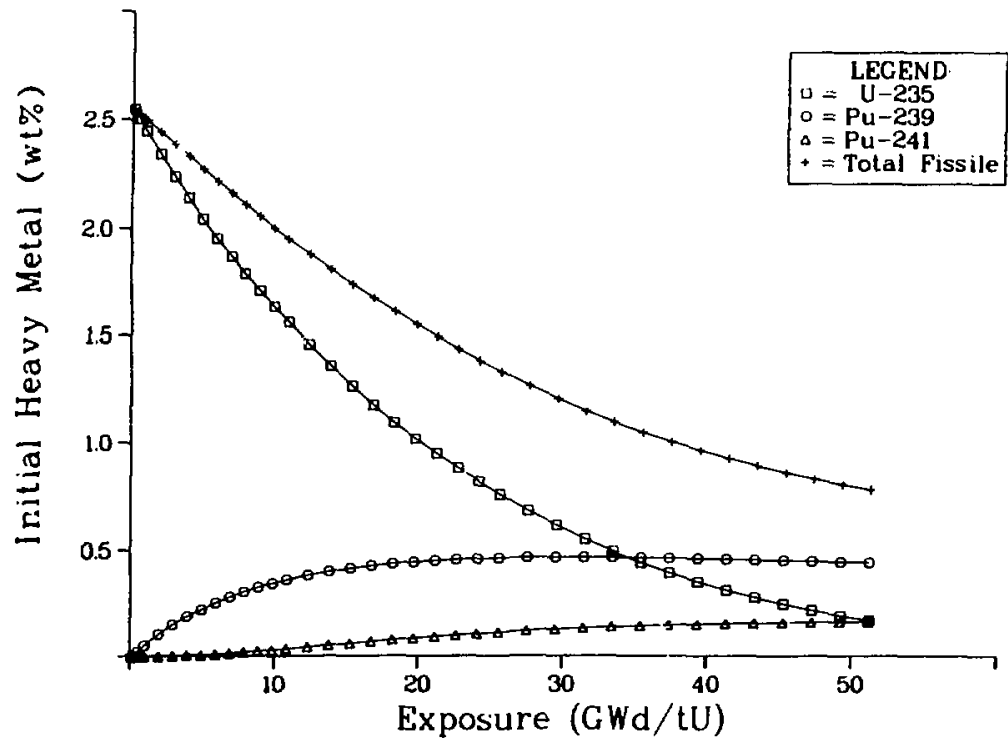

Fig. 56.

Spent-fuel composition as a function of burnup for H. B. Robinson PWR fuel. 
TABLE XVII

CINDER CALCULATED FISSILE MATERIAL DENSITIES AS A FUNCTION OF BURNUP
TABLE XVIII

THERMAL NEUTRON PARAMETERS FOR THE FISSILE ISOTOPES ${ }^{235} \mathrm{U},{ }^{239} \mathrm{Pu}, \mathrm{AND}{ }^{241} \mathrm{Pu}$

\begin{tabular}{cccc} 
Isotope & $\begin{array}{c}\sigma_{\mathrm{f}} \\
\text { (b) }\end{array}$ & $\begin{array}{c}\overline{\mathrm{v}} \\
\text { (n/fission) }\end{array}$ & $\begin{array}{c}\beta \\
\text { (delayed } \mathrm{n} / \text { fission) }\end{array}$ \\
\hline${ }^{239} \mathrm{U}$ & 577.1 & 2.43 & 0.0158 \\
${ }^{239} \mathrm{Pu}$ & 740.6 & 2.87 & 0.0061 \\
${ }^{241} \mathrm{Pu}$ & 950.0 & 3.14 & 0.0156 \\
\hline
\end{tabular}

The coefficients for low-energy fission (0.005 to 0.14 eV) were computed by Gozani using a self-shielded group cross-section set. ${ }^{93,94}$ These coefficients and the coefficients corresponding to thermal fission are listed in Table XIX. The group cross-section set provides a more accurate value for the relative fission rate of the various fissile isotopes. The results indicate that the coefficients for ${ }^{239} \mathrm{Pu}$ and ${ }^{241} \mathrm{Pu}$ are underestimated by $12 \%$ and $8 \%$, respectively, when only the thermal cross-section values are used.

The prompt neutron yield, corresponding to the data of Table XVII and to the group set coefficients $(a=1.7$, $b=2.3$ ) of Table XIX, is plotted as a function of burnup in Fig. 57. The yield $(Y)$ decreases from a maximum of $5.67 \times 10^{-4}$ atoms $/ \mathrm{b}-\mathrm{cm}$, corresponding to a PWR

TABLE XIX low-energy neutron irradiation and calculates the neutron production resulting from fission of the fissile isotopes. The yield of prompt neutrons from a thermal irradiation flux of strength $\phi\left(\mathrm{n} / \mathrm{cm}^{2}-\mathrm{s}\right)$ is described by

$Y=\left(\bar{v} \sigma_{f} N\right)_{235^{\phi}}+\left(\bar{v} \sigma_{f} N\right)_{239^{\phi}}+\left(\bar{v} \sigma_{f} N\right)_{241^{\phi}}$.

The response equation $\mathrm{Y}$ can be rewritten as

$\mathrm{YaN}_{235}+\mathrm{aN}_{239}+\mathrm{bN}_{241}$,

where $Y$ represents an effective neutron yield caused by fission of the fissile isotopes. The nuclear data corresponding to thermal energies for the fissile isotopes in Table XVII are listed in Table XVIII.

\section{PROMPT NEUTRON YIELD COEFFICIENTS FOR LOW-ENERGY FISSION} Coefficients

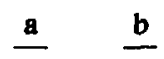

$\begin{array}{lcc}\text { Thermal }(0.025 \mathrm{eV}) & 1.52 & 2.13 \\ \text { Group set }(0.005-0.14 \mathrm{eV}) & 1.7 & 2.3\end{array}$




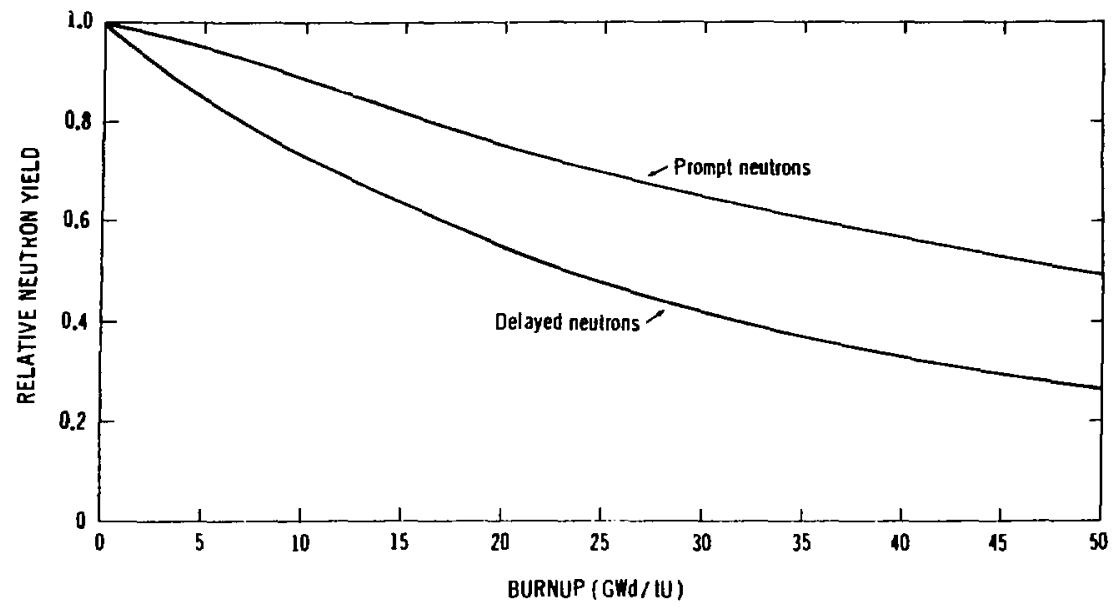

Fig. 57.

Relative yield of prompt and delayed neutrons from a PWR fuel assembly as a function of burnup.

assembly with no burnup, to $3.67 \times 10^{-4}$ at a burnup of $30000 \mathrm{MWd} / \mathrm{tU}$. This represents a $35 \%$ decrease in the prompt yield.

The fraction of the prompt yield produced by each of the fissile isotopes as a function of burnup is listed in Table XX. A fresh assembly with no burnup produces all its fissile yield from ${ }^{235} \mathrm{U}$. Increasing burnup produces higher relative quantities of the ${ }^{239} \mathrm{Pu}$ and ${ }^{211} \mathrm{Pu}$ isotopes. At $30000 \mathrm{MWd} / \mathrm{tU}, 47.2 \%$ and $16.8 \%$ of the prompt yield are produced from ${ }^{239} \mathrm{Pu}$ and ${ }^{241} \mathrm{Pu}$, respectively, whereas the ${ }^{23 s} \mathrm{U}$ produces only $36 \%$ of the yield.

TABLE XX

FRACTION OF THE PROMPT NEUTRON RESPONSE PRODUCED FROM EACH FISSILE ISOTOPE

\begin{tabular}{ccccc}
$\begin{array}{c}\text { Burnup } \\
\text { (GWd/tU) }\end{array}$ & $\begin{array}{c}\text { Effective } \\
\text { Fissile Density } \\
\text { (atoms/b-cm) }\end{array}$ & ${ }^{235} \mathrm{U}$ & ${ }^{239} \mathrm{Pu}$ & ${ }^{241} \mathrm{Pu}$ \\
\hline & & & & \\
0 & $5.67-4$ & 1.0 & 0 & 0 \\
5 & $5.37-4$ & 0.844 & 0.151 & 0.005 \\
10 & $5.02-4$ & 0.723 & 0.252 & 0.025 \\
15 & $4.64-4$ & 0.610 & 0.339 & 0.059 \\
20 & $4.28-4$ & 0.517 & 0.388 & 0.096 \\
25 & $3.95-4$ & 0.433 & 0.434 & 0.133 \\
30 & $3.67-4$ & 0.360 & 0.472 & 0.168 \\
35 & $3.41-4$ & 0.296 & 0.504 & 0.200 \\
40 & $3.15-4$. & 0.229 & 0.537 & 0.234 \\
45 & $2.97-4$ & 0.181 & 0.560 & 0.259 \\
50 & $2.70-4$ & 0.128 & 0.585 & 0.287 \\
& & & & \\
\hline
\end{tabular}


b. Delayed Yield. The delayed neutron yield, as a function of burnup, for the low-energy group structure $(0.005 \mathrm{eV}$ to $0.14 \mathrm{eV})$, was determined by Gozani ${ }^{33,54}$ to be

$$
Y_{d}{ }^{\alpha N_{235}}+0.6 N_{239}+1.65 N_{241}
$$

The delayed neutron yield for the atom densities of Table XVII is listed in Table XXI, with the fraction of the signal produced from each fissile isotope. The relative delayed yield is plotted in Fig. 57 for comparison with the relative prompt yield as a function of burnup. The delayed yielci is a stronger function of burnup than is the prompt yield. However, the much lower yield of delayed neutrons (compared to prompt neutrons) and the high background would make a delayed neutron measurement more difficult.

The effective delayed neutron fraction $\left(\beta_{e}\right)$ as a function of burnup decreases because the plutonium isotopes increase and the ${ }^{235} \mathrm{U}$ decreases. The value of $\beta_{\mathrm{c}}$ was calculated for thermal fission parameters using the relation

$B_{e}=\frac{\left(B \bar{v} \sigma_{f} N\right)_{235}+\left(B \overline{v \sigma} \sigma_{f} N\right)_{239}+\left(B \overline{v \sigma}_{f} N\right)_{241}}{\left(\overline{v \sigma} \sigma_{f} N\right)_{235}+\left(\overline{v \sigma_{f}} N\right)_{239}+\left(\overline{v \sigma}_{f} N\right)_{241}}$
In Fig. 58, the lower curve corresponds to the value of $\beta_{\mathrm{e}}$ when the contribution from the ${ }^{241} \mathrm{Pu}$ isotope is ignored, whereas the upper curve includes the contribution of ${ }^{241} \mathrm{Pu}$. At high burnup values, the ${ }^{241} \mathrm{Pu}$ isotope contributes significantly to the delayed neutron fraction.

3. Prompt Neutron Yield as a Function of Interrogation Neutron Energy. The effective prompt neutron emission decreases by $35 \%$ over a $30000-\mathrm{MWd} / \mathrm{tU}$ burnup. Increasing this change by selecting the neutron interrogation energy may be possible. The prompt neutron emission is dominated by fissions from ${ }^{235} \mathrm{U}$ and ${ }^{239} \mathrm{Pu}$ for burnup values $<30000 \mathrm{MWd} / \mathrm{tU}$. The coefficient of $\mathrm{N}_{239}$ in Eq. (5) is the ratio of $\sigma_{f} v$ for fission of ${ }^{239} \mathrm{Pu}$ to that of ${ }^{235} \mathrm{U}$ (see Fig. 59). The signal variation of prompt neutron emission with burnup depends strongly on this coefficient. Our analysis shows that as the coefficient approaches 2.5 , the prompt emission remains roug'ly constant as a function of burnup.

To maximize the change in the prompt neutron emission as a function of burnup, the neutron interrogation enersy should be selected so that the coefficient of ${ }^{235} \mathrm{U}$ is different from 2.5. Figure 59 indisates that an average interrogation energy at the assembly between 1 $\mathrm{keV}$ and $90 \mathrm{keV}$ would be optimum. This energy could

TABLE XX]

FRACTION OF THE DELAYED NEUTRON RESPONSE PRODUCED FROM EACH FISSILE ISOTOPE

\begin{tabular}{ccccc}
$\begin{array}{c}\text { Burnup } \\
(\mathrm{GWd} / \mathrm{t} \text { ) }\end{array}$ & $\begin{array}{c}\text { Delayed } \\
\text { Response }\end{array}$ & ${ }^{235} \mathrm{U}$ & ${ }^{239} \mathrm{Pu}$ & ${ }^{241} \mathrm{Pu}$ \\
\hline & & & & \\
0 & $5.67-4$ & 1.0 & 0 & 0 \\
5 & $4.84-4$ & 0.937 & 0.059 & 0.004 \\
10 & $4.17-4$ & 0.871 & 0.107 & 0.022 \\
15 & $3.57-4$ & 0.793 & 0.152 & 0.055 \\
20 & $3.09-4$ & 0.715 & 0.190 & 0.095 \\
25 & $2.69-4$ & 0.635 & 0.225 & 0.140 \\
30 & $2.37-4$ & 0.556 & 0.258 & 0.186 \\
35 & $2.11-4$ & 0.480 & 0.288 & 0.233 \\
40 & $1.85-4$ & 0.390 & 0.323 & 0.287 \\
45 & $1.67-4$ & 0.321 & 0.350 & 0.329 \\
50 & $1.46-4$ & 0.237 & 0.382 & 0.381 \\
& & & & \\
\hline
\end{tabular}




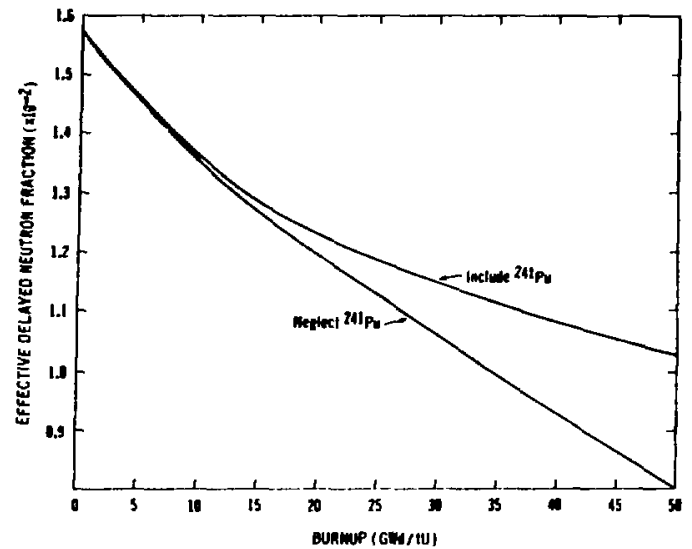

Fig. 58.

Effective delayed neutron fraction for thermal fission of a PWR fuel assembly as a function of burnup.

be achieved using an antimony/beryllium interrogation system with the spent fuel in air. However, the interrogation source is thermalized for spent fuel in water. The prompt emissions for the air and water cases are shown in Fig. 60.

In summary, the prompt neutron yield using thermal neutron interrogation decreases by $35 \%$ over a $30000-\mathrm{MWd} / \mathrm{tU}$ burnup. The decrease can be enhanced

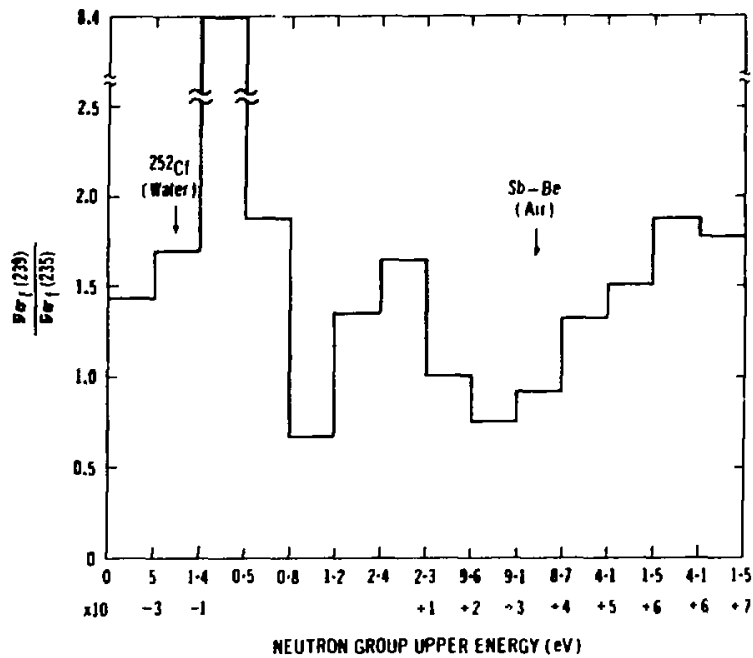

Fig. 59.

The ratio of $5 \sigma_{f}$ between ${ }^{239} \mathrm{Pu}$ and ${ }^{233} \mathrm{U}$ as a function of interrogation energy.

either by measuring the delayed neutrons (60\% decrease over a $30000-\mathrm{MWd} / \mathrm{tU}$ burnup) or by measuring in air using higher interrogation energy (60\% decrease over the same burnup range). For spent LWR fuel in water, either enhancement technique will be difficult and costly to achieve.

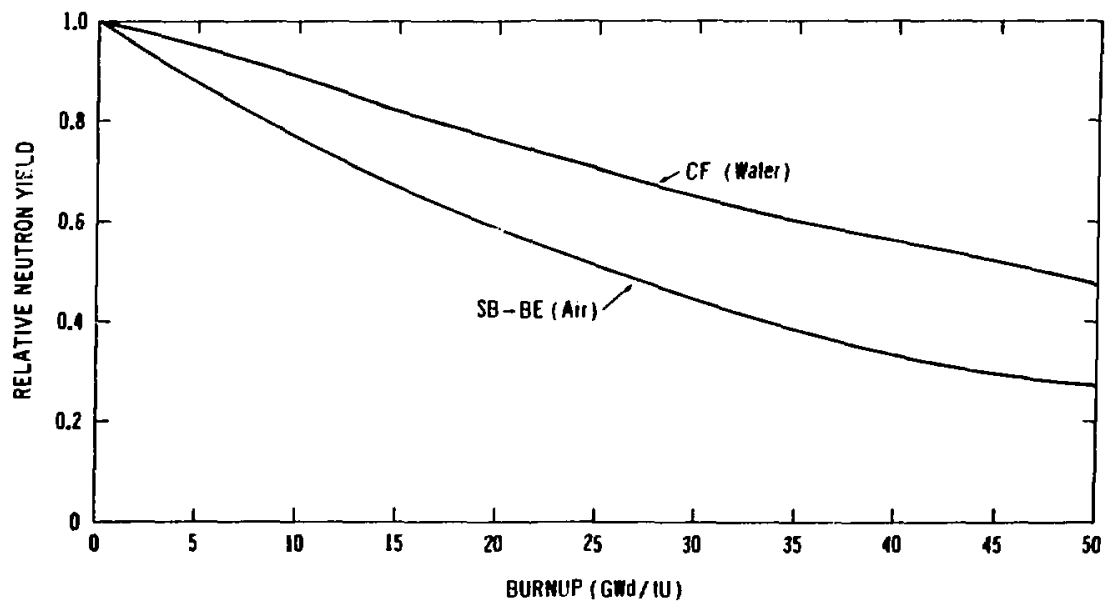

Fig. 60.

Relative prompt neutron signal as a function of burnup for two interrogation energies. 
F. Cerenkov Spent-Fuel Instrumentation Upgrade (N. Nicholson, E. J. Dowdy, D. R. Millegan, S. W. France, and D. M. Holt)

A list of suggestions and improvements from the IAEA for the improved Cerenkov viewing device (ICVD) was the result of comments from inspectors who have used the CVD in the field and from a meeting with IAEA development personnel in Vienna. Preliminary design analysis indicated the impossibility of incorporating all the desired features of the proposed ICVD and still remaining within the weight, budget, and time constraints of the program. The desired features have been listed with a priority assigned to each feature and its impact on weight, cost of development, and time of development. Alternate designs to the original proposed to the IAEA have been considered to evaluate the most effective approach. To reduce ICVD development costs, as many commercially available components as feasible will be used.

Calculations have been made that characterize the intensity of the Cerenkov glow from representative measurements made at the Morris (GE) Facility. These intensity calculations indicated that a very sensitive light detector is required to measure the weakest assemblies encountered at Morris. This requirement narrows selection of a light detector to a photomultiplier of 6 to 10 stages and a stable power supply of $1000 \mathrm{Vdc}$. The photomultiplier will measure directly the Cerenkov glow and should provide an abso'ute intensity measurement.

An ICVD design that incorporates commercially available components and appears to satisfy all design and cost requirements has tentatively been chosen, but several details must be worked out before final selection. An effort is being made to design a small package to add to the front end of existing CVDs and to provide quantitative Cerenkov intensity measurements. A prototype of this design will be constructed to prove its feasibility.

\section{G. Field Test of the Cerenkov Technique for Spent Fued} (N. Nicholson, E. J. Dowdy, J. W. Hudson, D. R. Millegan, and S. W. France)

During the week of July 21,1980 , a field test of the Cerenkov technique was conducted at the WAK facility in Karlsrihe, Germany. Two Javelin Model 222 CVD: were brought from Vienna by IAEA personnel. The objectives of the field test were to
- determine the usefulness of the CVD in identifying irradiated fuel;

- determine the effectiveness of the CVD in inventory verification of spent-fuel ponds;

- evaluate the effectiveness of the CVD under various light level conditions;

- obtain facility operator comments regarding the requirements for extinguishing lights and operating the bridge during inspections; and

- provide a basis for preparing detaileo procedures for inspectors.

Eight spent-fuel assemblies were proposed for examination with the CVDs. Exposure ranged from 18000 to $31000 \mathrm{MWd} / \mathrm{tU}$, and the cooling times ranged from 4 to $9 \mathrm{yr}$.

Because of similar burnup and cooling times for many of the assemblies proposed, only five assemblies were examined. In addition, an assembly in a covered container, a covered container with a loose fuel pin, and a WAK fuel assembly were examined. A set of light conditions was selected to evaluate the usefulness of the CVD under low-level lighting conditions.

The following observations were noted.

- With lights off, the Cerenkov glow from all irradiated fuel assemblies, even those with covers, was visible with the unaided eye. The CVD provided a much more precise view of the uncovered assemblies where the patterns of light emitted were clearly discernible.

- Examination of one assembly quickly disclosed an unfamiliar pattern of spots. We determined that in addition to the 16 bright spots associated with the control rod channels, 6 additional bright spots were attributed to missing pins. The facility operator confirmed that 6 pins were missing, a fact not revealed to the IAEA participants before this test.

- The Cerenkov glow caused by the assembly in the covered container could be seen on all four sides of the container. The top of the assembly could not be seen because of the cover.

- The glow from the loose pin in the covered container was very difficult to see with the unaided eye but was readily apparent with the CVD. The glow was limited to the corner of the container where the fuel pin was located. This observation indicated the potential value of the CVD in cases of a covered fuel assembly with a significant number of pins missing from a sector of the array. This should be apparent by a lack of Cerenkov glow from the corresponding side of the container. 
- The WAK fuel assembly had a special mechanical fixture over the top of the assembly that precluded detailed observation of the normal light pattern.

- One PWR assembly had a large number of pins missing from the central portion of the assembly in tne pattern of a Swiss cross. This pattern was readily observable with the unaided eye.

Various lighting conditions were produced and the operation of the CVD was evaluated.

- Only the most dimly lit condition, that is, a fluorescent light fixture halfway up a wall facing away from the storage pool in an adjacent area, provided a light arrangement that did not produce an excessive amount of reflection from the water or light into the pool. This light level was adequate for operations and safety in the nool area and had no serious effect on CVD operation. The Cerenkov light also was visible with the unaided eye under this condition.

- Flashlights also could be directed on nearby walls away from the pool with all the facility lights off, providing adequate light for operations and producing no serious effect on CVD operation.
The CVD provided qualitative information regarding relative brightness of the Cerenkov glow emitted from the assemblies and distinguished assemblies with similar burnup that have significantly different cooling times from assemblies with similar cooling times but significantly different burnup values. Variations in cooling time or burnup of $50 \%$ can b : detected.

As a result of this ficl, test, extinguishing all lighting may not be acceptable 0 the facility operator. Agreement and cooperation of the facility operator and national regulatory authorities are likely to be prerequisites, particularly when determining acceptable light levels. However, if the CVD can be shown to be less intrusive than other techniques for spent-iuel verification, use of the Cerenkov technique as an inspection tool appears likely.

Photographing the Cerenkov glow from spent-fuel assemblies also may have to be negotiated. The WAK security authorities would not permit use of the $35-\mathrm{mm}$ camera with the CVD, and similar objections can be expected at other facilities.

\section{INTERNATIONAL TRAINING AND TECHNOLOGY TRANSFER}

Safeguards Technology Training Program (H. A. Smith and N. Ensslin)

Two courses in the DOE Safeguards Training Program at Los Alamos were offered during this reporting period. From October 6-10, 32 representatives of the domestic and international safeguards communities attended "Fundamentals of Nondestructive Assay of Fissionable Materials Using Portable Instrumentation." Laboratory exercises on gamma-ray detection principles and assay techiques using the SAM and NaI(TI) detectors covered the enrichment principle and the quantitative assay of plutonium-bearing incinerator ash. Neutron-based laboratory exercises were expanded to include not only the passive assay of plutonium with the HLNCC, but also the active assay of uranium with the AWCC. Lectures entitled "In-Plant Experience with Gamma-Ray-Based Holdup Measurements" and "An Intelligent, Uiltraportable Multichannel Analyzer" also were presented.
The course "Gamma-Ray Spectroscopy for Nuclear Material Accountability" was given to 24 domestic and foreign students on December 8-12. Laboratory exercises were carried out in the areas of quantitative uranium and plutonium assays, plutonium isotopic analysis, and measurement of uranium enrichment using high-resolution, gamma-ray spectroscopy equipment. In addition, a laboratory in $\mathbf{K}$-absorption-edge densitometry was conducted with the in-house prototype of the instrument that is under test and evaluation in Japan. A supplementary $\mathbf{K}$-edge densitometry laboratory also was conducted using a greatly simplified measurement apparatus and featuring the latest type of cadmium/tellurium gamma-ray detector. Two lectures were presented: "The High-Resolution, Gamma-Ray Assay of Spent Nuclear Fuel" and "In-Plant Experience with a Uranium Solution Assay Instrument." 
PART 5

\title{
ANALYTICAL CHEMISTRY METHODS FOR FISSIONABLE MATERIALS SAFEGUARDS
}

\section{CHEMICAL AND ISOTOPIC ANALYSIS}

\author{
(G. R. Waterbury and Stafi)
}

Safeguarding uranium, plutonium, and thorium requires measuring the amounts and isotopic distributions of these elements to provide inventory control throughout the nuclear fuel cycle. Rapid chemical assay and isotopic methods that provide accurate and precise measurements are needed for a variety of nuclear materials, including pure products, reactor fuels with complex chemical compositions, and many scrap and waste materials.

Overall program objectives include

- developing fast dissolution techniques and analytical methods for determining plutonium and uranium with emphasis on scrap-type and difficult-to-dissolve materials,

- designing and constructing automated apparatus for determining plutonium and uranium,

- nreparing well-characterized, plutonium-containing ieference materials for the Safeguards Analytical Laboratory Evaluation (SALE) program for distribution by the National Bureau of Standards (NBS) and the NBL and for calibration of nondestructive analysis equipment at Los Alamos,

- participating in an inter-DOE laboratory program for measuring half-lives of the longer lived plutonium isotopes,

- evaluating mass spectrometric techniques for IAEA verification of plutoniur. and uranium contents of reprocessing plant dissolver solutions, and

- characterizing chemically special lots of nuclear materials as required by DOE.

\section{A. Development of Assay Methods}

1. Microgram-Sensitive Spectrophotometric Determination of Uranium (¿. F. Marsh, P. Kiefer, D. J. Hoard, and J. E. Rein). In developing a more selective method than that ${ }^{35}$ now used in the Los Alamos automated spectrophotometer, ${ }^{56}$ the extraction of the
U(VI)-2-(5-bromo-2-pridylazo)-5-diethylaminophenol complex into a $15 \%$ aliquot $/ 85 \%$ oxylene phase ${ }^{37}$ was investigated first. Although modifications were developed that give increased sample-acidity tolerance, decreased number of reagent additions, and greater than 99\% extraction of 0.5 to $20 \mu \mathrm{g}$ of uranium, the method's selectivity generally was inferior to the selectivity of the method in use and was more subject to error from minor operational and reagent composition variations.

A new reagent, 2, 2'-[2,6-pyridinediylbis (methylidynenitrilo) diphenol], described as giving a selective spot test with uranium, ${ }^{38}$ is being investigated as the basis for a selective and sensitive spectrophotometric method. Because the reagent is not available commercially, we synthesized it and verified its composition by mass spectrometry. Combinations of many buffers and organic solvents are being tested to establish conditions for extracting the U(VI) complex. So far, those combinations producing highest absorbances of the extrasted complex have lowest stability.

2. Microgram-Sensitive Spectrophotometric Determination of Plutonium (N. M. Saponara, S. F. Marsh, and J. E. Rein). This method is being developed for use with the Los Alamos automated spectrophotometer or a similar instrument in which all operations from addition of reagents through the absorbance measurement are done in a single tube. A highly sensitive method was developed in which 1 - to $20-\mu \mathrm{g}$ amounts of plutonium, as the Pu(IV)-chlorophosphonazo III (CPA) complex, are extracted into n-pentanol from $1.5 \mathrm{M} \mathrm{HCl}$. Because selectivity was not high, a prior separation of plutonium was needed for application to various nuclear materials. Conditions were established for a quantitative, anion exchange separation in $12 \mathrm{M} \mathrm{HCl}$ to provide a plutonium fraction free of uranium, thorium, and most metallic elements present in nuclear materials. Absorbance of the extracted Pu(VI)-CPA complex after this ion-exchange separation was biased low because of a 
component, believed to be an organic degradation product of the resin, that elutes from the ion-exchange column. Various organic decomposition treatments are being tested to eliminate this component.

\section{Controlled-Potential Coulometric Determination of} Plutonium (D. D. Jackson, R. M. Hollen, and J. E. Rein). The method ${ }^{39}$ developed for the Los Alamos automated, controlled-potential coulometric analyzer involves three sequential electrolyses in a $5.5 \mathrm{M} \mathrm{HC1}$ to $0.015 \mathrm{M}$ sulfamic acid electrolyte. At $0.25 \mathrm{~V}$ (relative to the saturated calomel electrode); plutonium and iron reduce to $\mathrm{Pu}$ (III) and $\mathrm{Fe}$ (II). At $0.57 \mathrm{~V}, \mathrm{Fe}$ (II) and many other metal ions oxidize. At $0.68 \mathrm{~V}$, after adding phosphate to lower the Pu(III)-Pu(IV) couple, Pu(III) oxidizes to $\mathrm{Pu}(\mathrm{IV})$ as the measurement step. Elimination of the $0.25-\mathrm{V}$ electrolysis is being investigated, which, if successful, will provide for faster analysis time, smaller blank corrections with consequent improvement in reliability, and a lesser number (and lower cost) of instrument components.

This change appears to have no adverse effects. Both $\mathrm{Pu}(\mathrm{VI})$ and $\mathrm{Pu}(\mathrm{IV})$ reduce rapidly to $\mathrm{Pu}(\mathrm{III})$ at $0.57 \mathrm{~V}$, and iron oxidizes quantitatively to $\mathrm{Fe}$ (III) and does not interfere at an equal mole ratio relative to plutonium. To ensure no subtle changes in tolerances of impurities, especially those undergoing irreversible oxidation-reduction reactions, tolerances are being established using the automated analyzer.

4. Separation of Trace Metal Impurities from Uranium, Plutonium, and Americium (S. F. Marsh). For the difficult quantitative measurement of trace metallic elements in nuclear materials, a prior separation of the actinides is being evaluated with the highly selective dihexyl-N, N-diethylcarbamylmethylenephosphonate extractant ${ }^{60}$ for the actinides and lanthanides. The purified compound, sorbed on an inert support of purous polymer beads on a 6 - by $100-\mathrm{mm}$ chromatography column, extracts $>99.99 \%$ of $15 \mathrm{mg}$ of uranium, plutonium, or americium from $5.5 \mathrm{M} \mathrm{HNO}_{3}$. Aluminum, beryllium, chromium, calcium, iron, potassium, magnesium, manganese, nickel, and lead elute completely to permit their analysis by various techniques, including multielemental emission spectrography. The distributions of other elements will be determined as a low-priority effort.

\section{B. Development of Automated Analyzers}

1. Controlled-Potential Coulometers (R. M. Hollen and D. D. Jackson). Various electronic components have been received for incorporation in an advanced instrument. Included is a less expensive programmable calculator to control all mechanical and electrical operations and process all measurement data. Preliminary experience with this calculator indicates that it will determine plutonium, especially if the two-step electrolysis discussed in Part 5, Sec. I.A.3 is adopted. Interfacing design of the various components is under way.

Orders for commercial components and drawings of mechanical components for shop construction have been prepared for an automated control-potential coulometer to be constructed for the SRP. Construction will take 1 yr after receipt of the funding allocation from DOE/OSS.

2. Microcomplexometric Titration (R. M. Hollen and D. D. Jackson). Design of the first automated instrument to use the selective uranium method ${ }^{61}$ has been started. Experiments have been planned to evaluate several basic modes of operation, including measurement of the titration end point.

C. Evaluation of the Chemistry Preceding the Mass-Spectrometric Ion-Exchange Bead Technique (S. F. Marsh, R. M. Abernathey, and J. E. Rein)

Evaluation will be complete with publication of a paper. ${ }^{\delta 2}$ Of the 10 chemical treatments evaluated for the attainment of isotopic equilibration of plutonium before its sorption on resin beads, the one consistently reliable treatment is reduction to $\mathrm{Pu}$ (III) with heated ferrous sulfamate, followed by oxidation to Pu(IV) with heated sodium nitrite.

\section{Reference Materials (G. R. Waterbury and Staff)}

1. Materials for NBS. A sixth lot of highly pure, highly enriched ${ }^{239} \mathrm{Pu}$ metal was characterized extensively for purity and isotopic composition. Several hundred 0.5 -g weighed portions in individually sealed glass ampoules containing dry argon at reduced pressure were 
packaged. After storage for 3 months, each portion will be inspected to detect any oxide coating, and 500 of the satisfactory ampoules will be shipped to NBS with detailed characterization data to incorporate in the NBS-prepared certificate.

A recent mass spectrometric, isotopic distr bution measurement by NBS of the to-be-issued ${ }^{244} \mathrm{Pu}$; sandard reference material completes its characterization. The assay measurements by NBL, Los Alamos, and NBS agree closely as do the mass spectrometric isotopic distribution measurements by Los Alamos and NBS. The material will be shipped to NBS when data treatment by NBS statisticians is complete.

2. Materials for NBL SALE Program. Assay reanalyses of three batches of $1250^{\circ} \mathrm{C}$-calcined plutonium oxide by two different controlled-potential-coulometric methods were completed satisfactorily and packaged for use as SALE materials. One batch also has been packaged as a secondary reference material for NBL distribution. Most of the materials have been shipped to NBL, including portions for NBL characterizations, and a report detailing our characterization data has been sent to NBL.

\section{E. Plutonium Isotope Half-Life Measurements}

The goal of a DOE-sponsored interlaboratory program, guided by the Half-Life Evaluation Committee with representatives from Argonne National Laboratory, Los Alamos, Lawrence Livermore National Laboratory, Mound Facility, NBS, and Rocky Flats Plant, is to establish accurate plutonium-isotope half-life values. The ${ }^{239} \mathrm{Pu}$ half-life measurements of $24119 \mathrm{yr}$ was published in $1978^{63}$ and the Los Alamos ${ }^{241} \mathrm{Pu}$ half-life measurement of $14.38 \mathrm{yr}$ was published recently. ${ }^{64}$ Measure- ments of the ${ }^{210} \mathrm{Pu}$ half-life by Livermore, Los Alamos, Mound, and NBS are nearing completion. Our progress is reported below.

1. Preparation and Characterization of the ${ }^{240} \mathrm{Pu}$ Material (G. R. Waterbury and Staff). All laboratories used a single batch of ${ }^{210} \mathrm{Pu}$ oxide. A paper describing the Los Alamos preparation and the interlaboratory characterizations has been submitzed to the International Journal of Applied Radiation and Isotopes as part of a series of papers on the half-life measurement to be published concurrently.

2. Mass Spectrometric Half-Life Determination (S. F. Marsh, R. M. Abernathey, R. J. Beckman, and J. E. Rein). This determination was based on measurement of grown-in ${ }^{236} \mathrm{U}$ daughter from three weighed portions of the ${ }^{240} \mathrm{PuO}_{2}$ at four time periods from 11 to 13 months using isotope-dilution mass spectrometry with ${ }^{233} U$ as the added internal standard. The experimental design provided 48 measurements. An analysis of variance, which takes into account all sources of error and their correlations, gives a half-life value of $6574 \mathrm{yr}$ and $95 \%$ confidence limits of 6560 to $6588 \mathrm{yr}$.

3. Alpha-Particle Counting Half-Life Determination (G. M. Matlack and F. Steinkruger). Twenty-four weighed aliquots from each of three dissolved portions of weighed ${ }^{210} \mathrm{PuO}_{2}$ were delivered onto quartz plates, evaporated, and alpha counted using a specially constructed low-geometry counter. Each of the 72 plates was counted for about $5 \mathrm{~h}$ to an accumulated count of $10^{6}$. An analysis of variance, which takes into account all error sourcer and their correlations, is under way to give a best estimate of the ${ }^{240} \mathrm{Pu}$ half-life and an associated uncertainty. The tentative half-life value is in the range 6575 to $6580 \mathrm{yr}$.

\title{
II. SUPPORT TO NONDESTRUCTIVE ASSAY
}

\author{
(T. R. Hahn, T. K. Marshall, and J. W. Dahlby)
}

Reference materials were prepared, packaged, and delivered, as specified, for calibration and testing of various nondestructive assay instruments. The reference materials included the following.
- Ten americium-plutonium reference solutions were prepared with different americium, plutonium, and acid concentrations.

- Six plutonium reference solutions were treated to reduce their volumes to $5 \mathrm{~m} \ell$. 
- Three reference solutions in $8 \mathrm{M} \mathrm{HNO}_{3}$ were prepared to contain accurately known quantities of uranium.

- Six plutonium reference solutions were prepared from plutonium metal containing $6 \%$ of the ${ }^{240} \mathrm{Pu}$ isotope. The americium contents were measured, and americium was added to one solution.

- Three $\mathrm{U}_{3} \mathrm{O}_{8}$-kaolin references were prepared and sealed into special polyethylene containers.

PART 6

COMPUTER AND OPERATIONAL SECURITY

\title{
I. DOE COMPUTER SECURTYY TECHNICAL CENTER
}

\author{
(E. A. Springer)
}

Development of the Computer Security Technicieal Center to support DOE computer facilities has begun. Technical support is being provided to DOE/OSS as requested, and computer security $R \& D$ projects in the Department of Defense (DoD) and other agencies are being monitored. Integrated computer security system s are being specified, computer security R\&D is being conducted, and computer security education is being provided. The computer security R\&D program seeks to develop computer security measures to preclude compromise of classified information.

\section{A. DOE Computer Security Technical Center Develop- ment}

A computer security $R \& D$ long range plan and a computer sf:curity management $i$ lan have been prepared. Updating the management plan is necessary to adjust to budgetary and management direction from DOE/OSS. Meetings have been held with the DoD Computer Security Management, and Los Alamos will work closely with them to avoid duplication of effort.

Los Alamos is providing technical support to the OSS in the computer security area. NSA has been designated by the DoD as the Center for Computer Security for evaluation of operating systems and development of other computer security techniques. Los Alamos will be working closely with NSA as they develop their program for DoD.

\section{B. Computer Network Key Notarization System}

The Motorola Data Security Modules have been received for the INTEL 8080 and PDP 11 computer systems. These modules will be implemented in an INTEL chassis as well as integrated into the bus structure of the PDP 11 computer system. The basic software and firmware packages for these modules, which were received from the NBS, will be modified to adapt to DOE requirements.

\section{Standards Development for the Key Notarization System}

Los Alamos is working with NBS to make the key notarization system (KNS) a standard or guideline. There are many applications for KNS in DOE, and NBS can help us further develop the system. The KNS will provide the needed security not provided by the present commercial operating systems. The security function for the computer system will be performed in an isolated module, the KNS. This module will provide for authentication of users, file encryption, communications security, and digital signatures. 


\section{Kernelized Secure Operating System Testing and Implementation}

The kernelized secure operating system (KSOS) project is being transferred from Ford Aerospace to LOGICON, a Navy support contractor. The KSOS effort at Ford has not successfully established a usable secure operating system to handle multi-level security. Los Alamos will work with LOGICON to determine the feasibility of using parts of the software version of KSOS for some DOE applications. The UNIX emulator and KSOS kernel software are the main packages for the system. The UNIX emulater needs more work, but the kernel is well defined. The main area of concern is the degradation of 4 to 5 times in throughput that results from adding the kernel and emulator to the PDP 11/70 computer system.

The Honeywell Secure Communications Processor (SCOMP) Level 6 system is being examined closely because Honeywell has implemented the security in hardware that should be much faster. This system probably will degrade the system by a factor of only 2 or less.

\title{
II. OPERATIONAL SECURITY
}

\author{
(E. A. Springer)
}

The Operational Security (OPSEC) program, which is new in DOE, identifies areas of security weaknesses in DOE and provides a tool for management to allocate security funding. The effort at Los Alamos identifies, collects, and evaluates open source weapons life-cycle data to determine vulnerabilities. A candidate weapon system (M500) was chosen and the collection process was begun by a person totally unfamiliar with this system. We are doing some ana'ysis and collection to make the best use of time on the project. We believe that collection without analysis will waste a lot of valuable time in obtaining the pertinent required information.

\section{PART 7}

\section{NUCLEAR REGULATORY COMMISSION ACTIVITIES}

Materials Holdup Study (N. Ensslin, C. C. Thomas, T. Marks, and H. A. Smith)

The Los Alamos Safeguards Assay Group (Q-1) and the Los Alamos Safeguards Systems Group (Q-4) are jointly studying nuclear material holdup in high-enriched uranium processing equipment. This study w:ll assist the new Nuclear Regulatory Commission (NRC) materials control and accounting upgrade rule by providing statistical prediction methods for estimating equipment holdup. During the initial phase of this project, a review and categorization of holdup problems was carried out. Facilities at General Atomic (San Diego) and the Los Alamos Physical Chemistry and Metallurgy Group (CMB-8) were toured. Future efforts will consist of both analysis of existing data and collection of new data where necessary. Holdup measurements of the above two facilities are planined during the next reporting period so that the relative importance of different items of process equipment for holdup can be determined. For the current project year, ducts, filters, calciners, and scrap incinerators have been selected for detailed study and measurement.

\section{Review of NDA Regulatory Guides (H. A. Smith)}

The NRC asked the Safeguards Assay Group to review the eight regulatory guides that deal with nondestructive assay of special nuclear material. This review task supports the NRC upgrade rule, and work was initiated on this project during this reporting period. The regulatory guides assigned for review are listed in Table XXII. All eight guides have been classified as to the amount of revision necessary for each one, and detailed reviews of four guides have begun. Completion of all eight guides is scheduled for the end of FY 1981. 


\section{NRC DIVISION 5 \\ REGULATORY GUIDES FOR REVIEW}

\begin{tabular}{cl} 
Guide No. & \multicolumn{1}{c}{ Title } \\
\hline 5.9 & $\begin{array}{l}\text { Specifications for Ge(Li) Spectroscopy Systems for } \\
\text { Material Protection Measurements. }\end{array}$ \\
5.11 & $\begin{array}{l}\text { Nondestructive Assay or Special Nuclear } \\
\text { Material Contained in Scrap and Waste. } \\
\text { Nondestructive Uranium-235 Enrichment Assay by } \\
\text { Gamma-Ray Spectroscopy. }\end{array}$ \\
5.21 & $\begin{array}{l}\text { In Situ Assay of Plutonium Residual Holdup. } \\
\text { Nondestructive Assay for Piutonium in Scrap Material } \\
\text { by Spontaneous Fission Detection. }\end{array}$ \\
5.23 & $\begin{array}{l}\text { In Situ Assay of Enriched Uranium Residual Holdup. } \\
\text { Nondestructive Assay of High-Enrichment Uranium Fuel } \\
5.37\end{array}$ \\
5.38 & $\begin{array}{l}\text { Plates by Gamma-Ray Spectrometry. } \\
\text { Qualification, Calibration, and Error Estimation } \\
\text { Methods for Nondestructive Assay. }\end{array}$ \\
\hline
\end{tabular}

\section{REFERENCES}

1. H. A. Smith, Jr., T. Marks, L. Cowder, C. Shonrock, S. Johnson, R. Slice, J. Sprinkle, K. MacMurdo, R. Pollard, and L. Baker, "Development of In-Line Plutonium Solution NDA Instrumentation at the Savannah River Plant," in "Proceedings of the Second Annual Symposium on Safeguards and Nuclear Material Management," Edinburgh, Scotl: ad, March 26-28, 1980 (European Safeguards Research and Development Assciciation, Brussels, 1980), p. 123.

2. G. R. Keepin, Ed., "Nuclear Safeguards Research and Devalopment Program Status Report, July-September 1980," Los Alamos National Laboratory report LA-8590-PR (March 1981).

3. T. R. Canada, D. G. Langner, and J. W. Tape, "Nuclear Safeguards Applications of Energy-Dispersive Absorption-Edge Densitometry," in Nuclear Safeguards Analysis, E. A. Hakkila, Ed. (ACS Symposium Series No. 79, 1978) p. 96.
4. D. F. Bowersox, R. B. Walton, N. Ensslin, C. A. Spirio, J. W. Tape, L. G. Speir, and W. J. Maraman, "In-Line Evaluations of Non-Destructive Assay Instruments for Plutonium-Uranium Analysis," Trans. Am. Nucl. Soc. 30, 271 (1978).

5. D. F. Bowersox, D. D. Cobb, H. A. Dayem, N. Ensslin, J. P. Shipley, D. B. Smith, L. G. Speir, C. A. Spirio, J. W. Tape, and R. B. Walton, "Coconversion of Uranium-Plutonium Nitrate Solutions to Oxide, July 1-September 30, 1978," Los Alamos Scientific Laboratory report LA-7530-PR, Vol. I (November 1978).

6. D. F. Bowersox, R. Dooley, N. Ensslin, L. G. Speir, C. A. Spirio, J. W. Tape, G. Walton, and R. B. Walton, "Coconversion of Uranium-Plutonium Nitrate Solution to Oxide, October 1-December 31, 1978," Los Alamos Scientific Laboratory report LA-7530-PR, Vol. II (February 1979).

7. D. F. Bowersox, R. Dooley, N. Ensslin, L. G. Speir, C. A. Spirio, J. W. Tape, G. Walton, and R. B. 
Walton, "Evaluation of In-Line Nondestructive Assay Systems, January 1-March 31, 1979," Los Alamos Scientific Laboratory report LA-7859-PR (May 1979).

8. D. F. Bowersox, N. Ensslin, S. T. Hsue, S. S. Johnson, L. G. Speir, C. A. Spirio, J. W. Tape, G. Walton, and R. B. Walton, "Evaluation of In-Line Nondestructive Assay Systems, July 1-September 30, 1979," Los Alamos Scientific Laboratory report LA-8202-PR (January 1980).

9. D. F. Bowersox, N. Ensslin, S. T. Hsue, S. S. Johnson, L. G. Speir, C. A. Spirio, J. W. Tape, G. Walton, and R. B. Walton, "Evaluation of In-Line Nondestructive Assay Systems, October 1-December 31, 1979," Los Alamos Scientific Laboratory report LA-8274-PR (March 1980).

10. D. F. Bowersox, N. Ensslin, S. T. Hsue, S. S. Johnson, J. L. Parker, and T. E. Sampson, "Evaluation of In-Line Nondestructive Assay Systems, January 1-March 31, 1980," Los Alamos Scientific Laboratory report LA-8411-PR (June 1980).

11. D. F. Bowersox, N. Ensslin, S. T. Hsue, S. S. Johnson, J. L. Parker, and T. E. Sampson, "Evaluation of In-Line Nondestructive Assay Systems, April 1-June 30, 1980," Los Alamos Scientific Laboratory report LA-8545-PR (September 1980).

12. D. F. Bowersox, "Standard Operating Procedure for Measuring Pu Solubility by Gamma Counting," Los Alamos Scientific Laboratory memorandum CMB-11-RDB-007 (November 1980).

13. D. F. Bowersox, "Proposed Experiments with a Solutions Neutron Counter, Rm. 209, PF-4," Los Alamos Scientific Laboratory memorandum CMB-11-RDB-81-009 (December 1980).

14. S. T. Hsue, T. E. Sampson, J. L. Parker, S. S. Johnson, and D. F. Bowersox, "Plutonium Isotopic Composition by Gamma-Ray Spectroscopy," Los Alamos Scientific Laboratory report LA-8603-MS (November 1980).

15. S. D. Gardner, Ed., "Nuclear Safeguards Research and Development Program Status Report,
July-September 1979," Los Alamos Scientific Laboratory report LA-8125-PR (January 1980), p. 6.

16. R. B. Strittmatter and J. W. Tape, "A Gas-Phase UF $_{6}$ Enrichment Monitor for Enrichment Plant Safeguards," in "Proceedings of the Second Annual Symposium on Safeguards and Nuclear Material Management," Edinburgh, Scotland, March 26-28, 1980 (European Safeguards Research and Development Association, Brussels, 1980) pp. 127-129.

17. R. B. Strittmatter, J. N. Leavitt, and R. W. Slice, "Conceptual Design for the Field Test and Evaluation of the Gas-Phase UF 6 Enrichment Meter," Los Alamos Scientific Laboratory report LA-8657-MS (December 1980).

18. G. R. Keepin, Ed., "Nuclear Safeguards Research and Development Program Status Report, January-March 1980," Los Alamos Scientific Laboratory report LA-8373-PR (September 1980), pp. 22-26.

19. "Nuclear Safeguards Research and Development Program Status Report, January-April, 1978," Los Alamos Scientific Laboratory report LA-7439-PR (December 1978), pp. 31-38.

20. G. R. Keepin, Ed., "Nuclear Safeguards Research and Development Program Status Report, January-March 1980," Los Alamos Scientific Laboratory report LA-8373-PR (September 1980).

21. P. A. Russo, T. R. Canada, D. G. Langner, J. W. Tape, S. T. Hsue, L. R. Cowder, W. C. Mosley, L. W. Reynolds, and M. C. Thompson, "An X-Ray $L_{\text {III }}$-Edge Densitometer for Assay of Mixed SNM Solutions," in "Proceedings of the First Annual Symposium on Safeguards and Nuclear Material Management," Brussels, Belgium, April 25-27, 1979 (European Safeguards Research and Development Association, Brussails, 1979), pp. 235-240.

22. D. D. Cobb, J. L. Sapir, E. A. Kern, and R. J. Dietz, "Concepts for Inventory Verification in Critical Facilities," Los Alamos Scientific Laboratory report LA-7315 (December 1978). 
23. J. T. Caldwell, P. E. Fehlau, S. W. France, and A. A. Robba, "Appendix A, New Approaches to Rapid Nondestructive Verification of Plutonium Fuels, Part II," in Los Alamos Scientific Laboratory report LA-7315 (December 1978), pp. A-13 to A-16.

24. J. C. Pratt, J. T. Caldwell, S. W. France, R. D. Hastings, H. H. Hsu, and E. R. Shunk, "Rapid Fuel Drawer Scanner for Fast Critical Assembly Safeguards," 21 st Annual Meeting of the Inst. of Nucl. Mater. Manage., Palm Beach, Florida, June 30-July 2, 1980.

25. W. E. Kunz, J. D. Atencio, and J. T. Caldwell, "Pulsed-Neutron Classified Waste Monitor," in Los Alamos Scientific Laboratory report LA-8241-PR (May 1980), pp. 12-15.

26. W. E. Kunz, J. D. Atencio, and J. T. Caldwell, "Pulsed-Neutron Classified Waste Monitor," in Los Alamos Scientific Laboratory report LA-8373-PR (September 1980), pp. 28-29.

27. W. E. Kunz, J. D. Atencio, and J. T. Caldwell, "Proceedings of the 21 st Annual Meeting of the Inst. of Nucl. Mater. Manage., Palm Beach, Florida, June 30-July 2, 1980.

28. D. B. Smith and D. Stirpe, "A Preliminary Report of Short-Term Materials Accounting at GCEP," Los Alamos Scientific Laboratory report LA-8651-MS (December 1980).

29. C. C. Thomas, Jr., C. A. Ostenak, R. G. Gutmacher, H. A. Dayem, and E. A. Kern, "Materials Measurement and Accounting in an Operating Plutonium Conversion and Purification Process, Phase I: Process Modeling and Simulation," Los Alamos National Laboratory report (to be issued).

30. R. H. Augustson, "DYMAC Demonstration Program: Phase I Experience," Los Alamos Scientific Laboratory report LA-7126-MS (January 1978).

31. J. J. Malanify and D. C. Amsden, Compilers, "Implementation of the DYMAC System at the New Los Alamos Plutonium Processing Facility (Phase II Report)," Los Alamos National Labotatory report (to be issued).
32. J. J. Malanify and R. C. Bearse, Compilers, "DYMAC Demonstration Program," Los Alamos National Laboratory report (to be issued).

33. D. D. Cobb, "Savannah River Spent Fuel Storage Technical Program Plan, FY81 and 82," Los Alamos Scientific Laboratory memorandum Q-4/80-434 (September 1980).

34. R. J. Dietz to A. L. Jennings, Jr./ALO, "Work Package Authorization System for the LASL Spent Fuel Storage Project," Los Alamos Scientific Laboratory memorandum DAD/SS-81-68 (November 17, 1980).

35. L. A. Heinrich, "The AFR Safeguards Program," Savannah River Laboratory report DPST-80-684 (November 24, 1980).

36. E. A. Hakkila, D. D. Cobb, H. A. Dayem, R. J. Dietz, E. A. Kern, J. T. Markin, J. P. Shipley, J. W. Barnes, and L. A. Scheinman, "Materials Management in an Internationally Safeguarded Fuels Reprocessing Plant, Vols. I and II," Los Alamos Scientific Laboratory report LA-8042 (April 1980).

37. J. P. Shipley, "Notes for the Seminar on Data Generation and Evaluation for Safeguards," Los Alamos Scientific Laboratory Seminar, Los Alamos, New Mexico, July 7-9, 1980 (to be issued).

38. E. A. Kern and D. P. Martinez, "User's Manual for a Process Model Code," Los Alamos National Laboratory report (to be issued).

39. A. F. Cermak, "Pilot-Scale Pulsed Columns Profile and Holdup Studies," Allied-General Nuclear Services report AGNS-35900-3.1-111 (November 1980).

40. A. L. Beyerlein, J. J. Komo, J. K. Bryan, and J. F. Geldard, "Improved Chemical Contactor Models Using Modern System Identification Techniques in Nuclear Accountability," Clemson University Report.

41. D. D. Cobb and J. P. Shipley, "Performance Analysis of Nuclear Materials Accounting Systems," Nucl. Mater. Manage. VIII(2), 81-92 (Summer 1979). 
42. G. E. Forsythe, M. A. Malcom, and C. B. Moler, "Random Number Generation and Monte $\mathrm{C} z$-'o Methods," in Computer Methods for Mathematical Computations (Prentice-Hall, Inc., Englewood Cliffs, NJ, 1977), Chap. 10.

43. S. L. Klein, Compiler, "Safeguards in the Seventies-A Bibliography of LASL Safeguards R\&D Publications, 1970-1979," Los Alamos National Laboratory report LA-8663-MS (January 1981).

44. H. O. Menlove, "Neutron Coincidence Collar for LWR Fuel Assemblies," Nuclear Safeguards Research and Development Program Status report (October-December 1979).

45. M. S. Krick and H. O. Menlove, "The High-Level Neutron Coincidence Counter (HLNCC): Users' Manual," Los Alamos Scientific Laboratory report LA-7779-M, ISPO-53 (June 1979).

46. J. E. Swansen, P. R. Collinsworth, and M. S. Krick, "Shift-Register Coincidence Electronics System for Thermal Neutron Counters," to be published in Nuclear Instruments and Methods (LA-UR-79-3456).

47. J. R. Phillips, J. K. Halbig, D. M. Lee, S. E. Beach, T. R. Bement, E. Dermendjiev, C. R. Hatcher, K. Kaieda, and E. G. Medina, "Application of Nondestructive Gamma-Ray and Neutron Techniques for the Safeguarding of Irradiated Fuel Materials," Los Alamos Scientific Laboratory report LA-8212, ISPO-77 (May 1980).

48. T. R. England, W. B. Wilson, and M. G. Stamatelatos, "Fission Product Data for Thermal Reactors, Part 2: Users' Manual for EPRI-CINDER Code and Data," Electric Power Research Institute report EPRI NP-356, Part 2 (December 1976). Also published as Los Alamos Scientific Laboratory report LA-6746-MS (December 1976).

49. T. R. England, W. B. Wilson, and M. G. Stamatelatos, "Fission Product Data for Thermal Reactors, Part 1: A Data Set for EPRI-CINDER Using ENDF/B-IV," Electric Power Research Institute repori EPRI NP-356, Part 1 (December
1976). Also published as Los Alamos Scientific Laboratory report LA-6745-MS (December 1976).

50. Los Alamos National Laboratory Group X-6, "MCNP-A General Monte Carlo Code for Neutron and Photon Transport," Los Alamos Scientific Laboratory report LA-7396-M, Rev. (November 1979).

51. G. E. Bosler, J. R. Phillips, T. R. England, R. J. LaBauve, and W. B. Wilson, "Production of Transuranic Isotopes in Simulated PWR Fuel and Their Influence on Inherent Neutron Emission." Los Alamos National Laboratory report (to be issued).

52. D. D. Cobb, Compiler, "Spent-Fuel Storage Facility Project, June 1-September 30, 1979," Los Alamos Scientific Laboratory report LA-8237-PR (June 1980).

53. 'Г. Gozani, "Active Direct Measurement of Residual Fissile Content in Spent Fuel Assemblies," Electric Power Research Institute report EPRI 278-1 (July 1975).

54. T. Gozani, "Nondestructive Assay of Spent Fuel for Determination of Residual Fissile Content," Proc. 17th Annual Meeting of the Inst. of Nucl. Mater. Manage., Seattle, Washington, June 22-24, 1976, pp. 514-524.

55. S. F. Marsh, "Extraction-Spectrophotometric Determination of Microgram Quantities of Uranium with Benzoyltrifluoroacetone," Anal. Chim. Acta $105,439-443$ (1979).

56. D. D. Jackson, D. J. Hodgkins, R. M. Hollen, and J. E. Rein, "Automated Spectrophotometer for Plutonium and Uranium Determination," Los Alamos Scientific Laboratory report LA-6091 (February 1976).

57. W. 1. Winters, "Spectrophotometric Determination of Uranium in Nuclear Waste," Atlantic Richfield Hanford report ARH-SA-250 (June 1975).

58. S. K. Thabet, S. M. Adrouni, and H. A. Tayim, ' 2,2 '- $[2,6$-pyridinediylbis (methylidynenitrilo)diphenol]: A Highly Selective Reagent 
for the Detection of U(VI), Sb(III), and Bi(III)," Anal. Chem. 47, 1870-1871 (1975).

59. D. D. Jackson, R. M. Hollen, F. R. Roensch, and J. E. Rein, "Controlled-Potential Coulometric Determination of Plutonium with a Hydrochloric Acid-Sulfamic Acid Electrolyte and Phosphate Complexing," Anal. Chim. Acta 117, 207-215 (1980).

60. L. D. McIsaac, J. D. Baker, J. F. Krupa, R. E. LaPointe, D. H. Meikrantz. and N. C. Schroeder, "Study of Bidentate Compounds for Separation of Actinides from Commercial LWR Reprocessing Wastes," Idaho National Engineering Laboratory report ICP-1180 (May 1979).

61. S. F. Marsh, M. R. Betts, and J. E. Rein, "Determination of Submicromolar Amounts of Uranium (VI) by Complexometin ic Titration with Pyridine-2,
6-Dicarboxylic Acid," Anal. Chim. Acta 119, 401-404 (1980).

62. S. F. Marsh, R. M. Abernathey, and J. E. Rein, "Evaluation of Treatments to Attain Isotopic Equilibration of Plutonium Preceding the Resin Bead Technique for Mass Spectrometric Assay Analysis of Spent Reactor Fuel," Anal. Lett. 13 (A18) (1980).

63. L. L. Lucas and W. B. Mann, Eds., "The Half-Life of Plutonium-239," Int. J. Appl. Radiat. Isot. 29, No. 8, 479-524 (A.ugust 1978).

64. S. F. Marsh, R. M. Abernathey, R. J. Beckman, and J. E. Rein, "Plutonium-241 Half-Life Determined by Mass Spectrometric Measurement of Decreasing Pu-241/Pu-242 Ratios," Int. J. Appl. Radiat. Isot. 31, 629-631 (1980). 